\title{
A Decade of Monitoring on Pool 26 of the Upper Mississippi River System:
}

\author{
Water Quality and Fish Data from the
}

Upper Mississippi River Restoration Environmental

Management Program

\author{
John H. Chick \\ Lori A. Soeken-Gittinger \\ Eric N. Ratcliff \\ Eric J. Gittinger \\ Benjamin J. Lubinski \\ Rob Maher
}

Illinois Natural History Survey Bulletin

Volume 39, Article 6

September 2013 
Prairie Research Institute

William Shilts, Executive Director

Illinois Natural History Survey

Brian D. Anderson, Director

Forbes Natural History Building

1816 South Oak Street

Champaign, Illinois 61820

217-333-6880

Citation:

Chick, J.H., L.A. Soeken-Gittinger, E.N. Ratcliff, E.J. Gittinger, B.J. Lubinski, and R. Maher. 2013. A decade of monitoring on Pool 26 of the Upper Mississippi River system: water quality and fish data from the Upper Mississippi River Restoration Environmental Management Program. Illinois Natural History Survey Bulletin 39(6):323-420.

For permissions: contact the Prairie Research Institute.

Editor: Charles Warwick

US ISSN 0073-4918

US ISBN 1-882932-30-7

P0847839-.6M-09/2013

(C) 2013 University of Illinois Board of Trustees. All rights reserved.

Printed with soy ink on recycled and recyclable paper.

The University of Illinois will not engage in discrimination or harassment against any person because of race, color, religion, national origin, ancestry, age, marital status, disability, sexual orientation including gender identity, unfavorable discharge from the military or status as a protected veteran and will comply with all federal and state nondiscrimination, equal opportunity and affirmative action laws, orders and regulations. This nondiscrimination policy applies to admissions, employment, access to and treatment in University programs and activities.

University complaint and grievance procedures provide employees and students with the means for the resolution of complaints that allege a violation of this Statement. Inquiries or complaints may be addressed to the Director and Assistant Chancellor, Office of Equal Opportunity and Access, 601 East John Street, Swanlund Administration Building, (217) 333-0885, fax (217) 244-9136, TTY (217) 244-9850 or the Associate Provost and Director, Academic Human Resources, Henry Administration Building, (217) 333-6747, fax (217) 244-5584. For other University of Illinois information, contact University Directory Assistance at 333-1000. 


\title{
A Decade of Monitoring on Pool 26 of the Upper Mississippi River \\ System:
}

\author{
Water Quality and Fish Data from the
}

Upper Mississippi River Restoration Environmental

Management Program

\author{
John H. Chick ${ }^{1}$ \\ Lori A. Soeken-Gittinger ${ }^{1}$ \\ Eric N. Ratcliff ${ }^{1}$ \\ Eric J. Gittinger ${ }^{1}$ \\ Benjamin J. Lubinski ${ }^{1}$ \\ Rob Maher ${ }^{2}$ \\ ${ }^{1}$ Illinois Natural History Survey \\ National Great Rivers Research and Education Center \\ 1 Confluence Way \\ East Alton, Illinois 62024
}

${ }^{2}$ Illinois Department of Natural Resources 


\section{A Decade of Monitoring on Pool 26 of the Upper Mississippi River System:}

Water Quality and Fish Data from the

Upper Mississippi River Restoration Environmental

Management Program

John H. Chick

Lori A. Soeken-Gittinger

Eric N. Ratcliff

Eric J. Gittinger

Benjamin J. Lubinski

Rob Maher 


\section{CONTENTS}

Acknowledgments

vi

Prologue: A Decade of Monitoring

Chapter 1: Setting the Stage - The Environmental Setting and Water Quality Trends of Pool 26

Chapter 2: Population Trends for Selected Fishes in Pool 26 of the Upper Mississippi River

Chapter 3: Exploring Fishery Independent (LTRMPP) Data as a Tool to Evaluate the Commercial Fishery in Pool 26 of the Mississippi River

Chapter 4: Evaluating Relationships between Environmental Factors and the Fish Community in Pool 26 of the Mississippi River

Key Findings from a Decade of Monitoring on Pool 26 of the Upper

Mississippi River

Epilogue: Is Long-term Ecological Monitoring Possible? .403

Appendix A: Sample Sizes for Yearly Graphs ............................................404

Appendix B: Sample Sizes for Seasonal Graphs ........................................408

Appendix C: Results of Statistical Regression Analyses on Yearly Means .....414

Appendix D: Further Details on Statistical Analyses ..................................415 


\section{ACKNOWLEDGMENTS}

Our partners in the UMRR-EMP Long Term Monitoring Program have assisted us with data collection, data management, analyses, manuscript review, and many other ways too numerous to mention. In particular, we thank Jeff Houser, Brian Ickes, Michael Jawson, Barry Johnson, Jim Rogala, Jennie Sauer, and Dave Soballe from the USGS Upper Midwest Environmental Sciences Center; Jim Fischer from the Wisconsin Department of Natural Resources; and Marvin Hubbell and Karen Hagerty of the U.S. Army Corps of Engineers. Mark Pegg, Rob Colombo, and three anonymous reviewers provided valuable comments and criticisms of earlier drafts of these papers. Many former employees of the Illinois Natural History Survey contributed to these papers. Although we can't list everyone, we do need to specifically thank Robert Cosgriff, Kathy McKeever, Brian Macias, and Richard Sparks. 
PROLOGUE: A Decade of Monitoring

Since 1991, the Illinois Natural History Survey has operated the Great Rivers Field Station, one of six field stations associated with the Long Term Resource Monitoring Program (LTRMP) of the Upper Mississippi River Restoration Environmental Management Program. This bulletin presents detailed findings for water quality and fish monitoring from 1994 to 2004 in Pool 26 of the Upper Mississippi River System (UMRS) collected and analyzed by scientists at the Great Rivers Field Station. We present this information with the goals of 1) demonstrating the value of these data for management of the natural resources of the UMRS, 2) to serve as an easily accessible vehicle for persons searching for information on environmental conditions in this reach of the UMRS, and 3) to generate hypotheses and questions that can be addressed further in future analyses of LTRMP data and/or through focused research studies.

We hope that the findings we present will be useful to river scientists and managers, but we are also hopeful that nonscientists, such as nongovernmental organizations, decision makers, and the general public, will also find this work informative. With this in mind, we have limited ourselves to presenting only basic statistical analyses (e.g., graphs of central tendency and linear regression) with the exception of the last chapter. Long-term monitoring data for natural resources are rare and our understanding of the ecology of great rivers lags far behind most other ecosystems. Improving our management of these important natural resources will require more than the support of scientists and managers; society at large ultimately provides the funding necessary for these efforts and it needs to be informed so that they can judge the value and efficacy of programs such as the LTRMP. We hope that this bulletin will be informative to a wide audience. 
Chapter 1: Setting the Stage - The Environmental

Setting and Water Quality Trends of Pool 26

Lori A. Soeken-Gittinger and John H. Chick

\begin{abstract}
We present information gleaned from 10 years of data collected by the water quality component of the Upper Mississippi River Restoration Environmental Management Program's Long Term Resource Monitoring Program (LTRMP) from Pool 26 of the Upper Mississippi River System (UMRS). The Pool 26 reach of the UMRS includes the confluence with the Illinois River, and the confluence with the Missouri River just downstream of Mel Price Locks and Dam. The surrounding communities in both Illinois and Missouri benefit greatly from the natural resources provided by these rivers. We estimate that annual expenditures are $\$ 84$ and $\$ 55$ million for fishing and hunting, respectively, in the region surrounding Pool 26 based on license sales and state expenditure data from the U.S. Fish and Wildlife Service. Additionally, there is a commercial fishery active in Pool 26, recreational boating, and the UMRS provides drinking water for many municipalities in this region. Finally, the Upper Mississippi River System is a major transportation system, and Pool 26 receives the greatest amount of barge traffic for any river reach in the UMRS. The LTRMP began collecting data in 1988, but the first years of the program were experimental. Currently followed monitoring protocols for water quality and fish monitoring were adopted in 1993; however, a major flood event in that year prevented full data collection for that year. Data from the LTRMP water quality component demonstrate that Pool 26 is a highly productive river reach. Long-term averages of chorophyll-a, total phosphorous, total nitrogen, and total inorganic solids are comparable to levels in eutrophic to highly eutrophic lakes. The average current velocity in the main channel of the Mississippi River in Pool 26 ranges from $0.364-0.414 \mathrm{~m} / \mathrm{sec}$. during the summer and fall. Even during the lowest discharge levels in a year, the reach has a residence time no longer than 2.7 days. Discharge was significantly related to many water quality parameters, including Secchi depth, turbidity, total suspended solids, total nitrogen, nitrate-nitrite, and total phosphorus. We observed a significant linear increase in mean water temperature in the main channel from 1994 to 2004 . When these data were analyzed by season, positive linear trends were found during the spring $\left(0.515^{\circ} \mathrm{C}\right.$ per year) and fall $\left(0.646^{\circ} \mathrm{C}\right.$ per year). Continued monitoring is necessary to determine if these observations represent short term fluctuations or long-term trends and to detect any related effects on this river reach.
\end{abstract}




\section{Introduction}

A river with a natural flow regime is a rarity today. Due to human alterations, most large rivers in North America and around the globe have become a series of impoundments, making their status as true rivers questionable (Cummins 1972). Rivers and their associated aquatic habitats have been extensively altered in North America, largely because of increased human population and the associated degradation of aquatic resources (Naiman and Bilby 1998). Dredging and channelization to aid navigation, dams for hydropower and navigation (Bednarek 2001), levees to prevent the inundation of floodplains (Sparks 1995), and diversion of water for irrigation (Dudgeon 1992) have altered the natural flow regimes, impacted native species, affected water quality, and even increased duration and levels of the flooding they were designed to prevent (Poff et al. 1997). The Upper Mississippi River System (UMRS) is no exception to these trends.

The UMRS, which extends from the Minneapolis-St. Paul, Minnesota area to the confluence with the Ohio River near Cairo, Illinois, is one of the few large floodplain-river ecosystems that retains its seasonal flood pulses and has over $50 \%$ of its original floodplain area intact (Delaney and Craig 1997; Sparks et al. 1998). Prior to human alteration, the river was shallow and swift, with snags, sandbars, and rapids, and was navigable to St. Paul only during highwater stages (Holland-Bartels 1992). Navigation alterations such as snag removal, sandbar dredging, and the excavation of rapids began around 1824 (Delaney and Craig 1997; Sparks et al. 1998). In 1878, a navigation improvement project authorized a $1.37-\mathrm{m}$ - (4.5-ft.-) deep navigation channel, with maintenance of the channel provided by bank revetments, longitudinal dikes, and closing dams. A 1.83-m (6-ft.) channel was authorized in 1907, created primarily through construction of numerous wing dikes and more closing dams (Delaney and Craig 1997. Patrick 1998).

The most dramatic change in the UMRS began in 1930, with the authorization of a $2.75-\mathrm{m}$ (9-ft.-) deep navigation channel (Patrick 1998).
Revetments and dikes were not sufficient to maintain a channel of this depth, so a series of 26 locks and dams were constructed allowing navigation of the river during times that were previously low water periods (Holland-Bartels 1992, Patrick 1998). There are significant impoundment effects associated with the locks and dams, including an increase in water surface area, the stabilization of water elevations in portions of each reach, and transformation of intermittent backwater areas into permanent lakes (Fremling and Claflin 1984, HollandBartels 1992, Soballe et al. 2002). These backwater habitats are extensive and highly productive; however, the same impoundments that created them are also causing sedimentation and eutrophication in these productive backwaters (Patrick 1998).

The UMRS remains a productive floodplain river, but it is also a working river with over 126 million tons of cargo transported along its length and tributaries each year (Sparks et al. 1998). In addition to serving as a transportation system, the UMRS also provides valuable recreational resources and is nationally important for tourism. Carlson (1993) reported that outdoor recreation on the UMRS (including fishing, hunting, and nonconsumptive uses) generates $\$ 1.2$ billion each year for the U.S. economy, with recreational enthusiasts making over 11 million visits each year (Black et al. 1999).

Pool 26 is a 64-km (40-mile) reach of the UMRS, beginning below Lock and Dam No. 25 at river mile (RM) 241.4 near Cap au Gris, Missouri, and ending at Melvin Price Locks and Dam at Alton, Illinois (RM 200.8; Fig. 1). This reach includes the confluence with an additional large floodplain river, the Illinois River, and the confluence with the Missouri River is just downstream of Melvin Price Locks and Dam. Pool 26 retains about $31 \%$ connectivity between the river and its historical floodplain (Theiling et. al 2000). The surrounding communities in both Illinois and Missouri benefit greatly from the natural resources provided by these rivers. For example, $3.9 \%$ of all Illinois and $11 \%$ of all Missouri fishing licenses are purchased in the counties surrounding Pool 


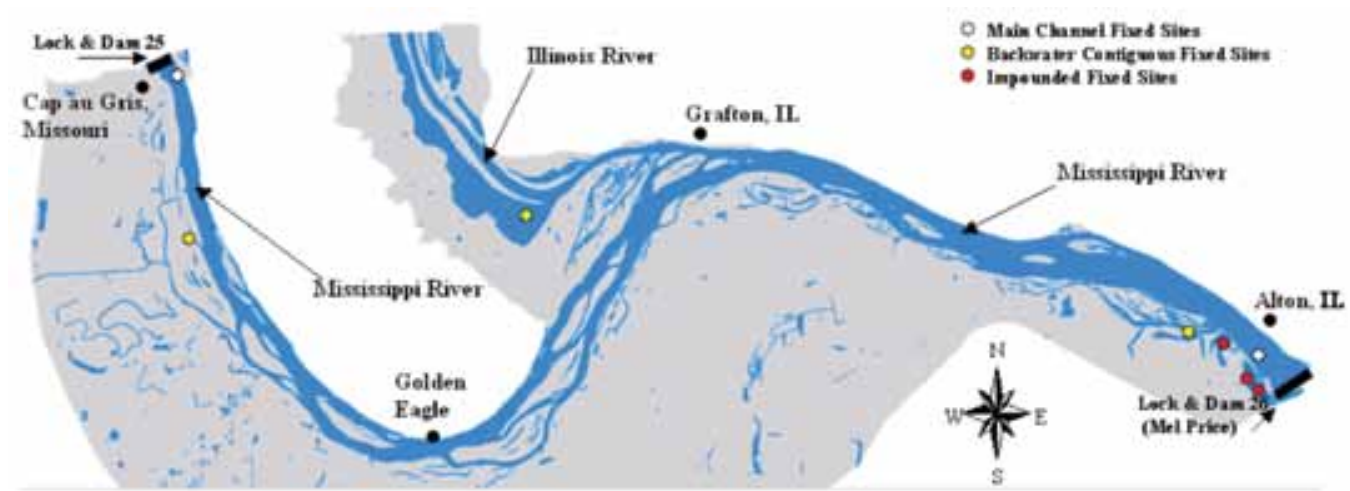

Figure 1. Pool 26 of the Upper Mississippi River showing the locations of fixed sites for the main channel (white circles), contiguous backwaters (yellow circles), and impounded zone (red circles).

26, along with $6.1 \%$ of Illinois and $13 \%$ of Missouri hunting licenses (Illinois Department of Natural Resources 1998, Greg Jones, Missouri Department of Natural Resources, pers. comm.). Using state totals from the U.S. Fish and Wildlife Service's national survey data from 2001, this level of fishing and hunting should generate approximately $\$ 51$ million in related expenditures in Illinois, and \$139 million in related expenditures in Missouri (U.S. Fish and Wildlife Service 2002). The largest state park in Illinois, Pere Marquette State Park, is located at the confluence of the Mississippi and Illinois rivers and has been estimated to bring in $\$ 22$ million a year to the local economies (Illinois Department of Natural Resources 1998). Additionally, there is a commercial fishery active in Pool 26 (see Chapter 3 ), recreational boating, and the rivers provide drinking water for nearly all of the surrounding municipalities.

\section{The Long Term Resource Monitoring Program}

In 1993, Melvin Price Locks and Dam replaced the original Lock and Dam 26, which was demolished when the new structure was completed, and was the first original lock and dam installation to be replaced with larger, 1,200-foot locks (Soballe et al. 2002; Fig. 2). The plans for this construction, along with a growing realization of the need to effectively manage and monitor the UMRS ecosystem, brought about a congressional authorization (Water Resources Development Acts of 1986 and 1999; Public Law 99-662) to fund the U.S. Army Corps of Engineers to conduct the Upper Mississippi River Restoration Environmental Management Program for the UMRS, which includes the Long Term Resource Monitoring Program (LTRMP). The LTRMP began in 1988, and is intended to monitor and evaluate long-term changes in selected physical, chemical, and biological characteristics, and provide decision makers with information to maintain the UMRS as a viable ecosystem with multiple uses (Soballe et al. 2002; USFWS 1993).

The study area of the LTRMP includes the Mississippi River from Cairo, Illinois, to the head of navigation near St. Paul, Minnesota (Soballe et al. 2002). Six selected reaches (Regional Trend Areas) in the UMRS are monitored for water quality, macroinvertebrates, fisheries, and aquatic vegetation data. The Illinois Natural History Survey's Great Rivers Field Station (GRFS) monitors Pool 26 for the LTRMP, and is one of six field stations associated with the program. In addition to the main channel, all of the major tributaries of the Mississippi and Illinois rivers in these six reaches are monitored, along with side channels, backwater lakes, and impounded areas (Soballe et al. 2002). This chapter provides a basic physical and chemical description of Pool 26 of the UMRS based on 10 years of monitoring data collected through the LTRMP. 


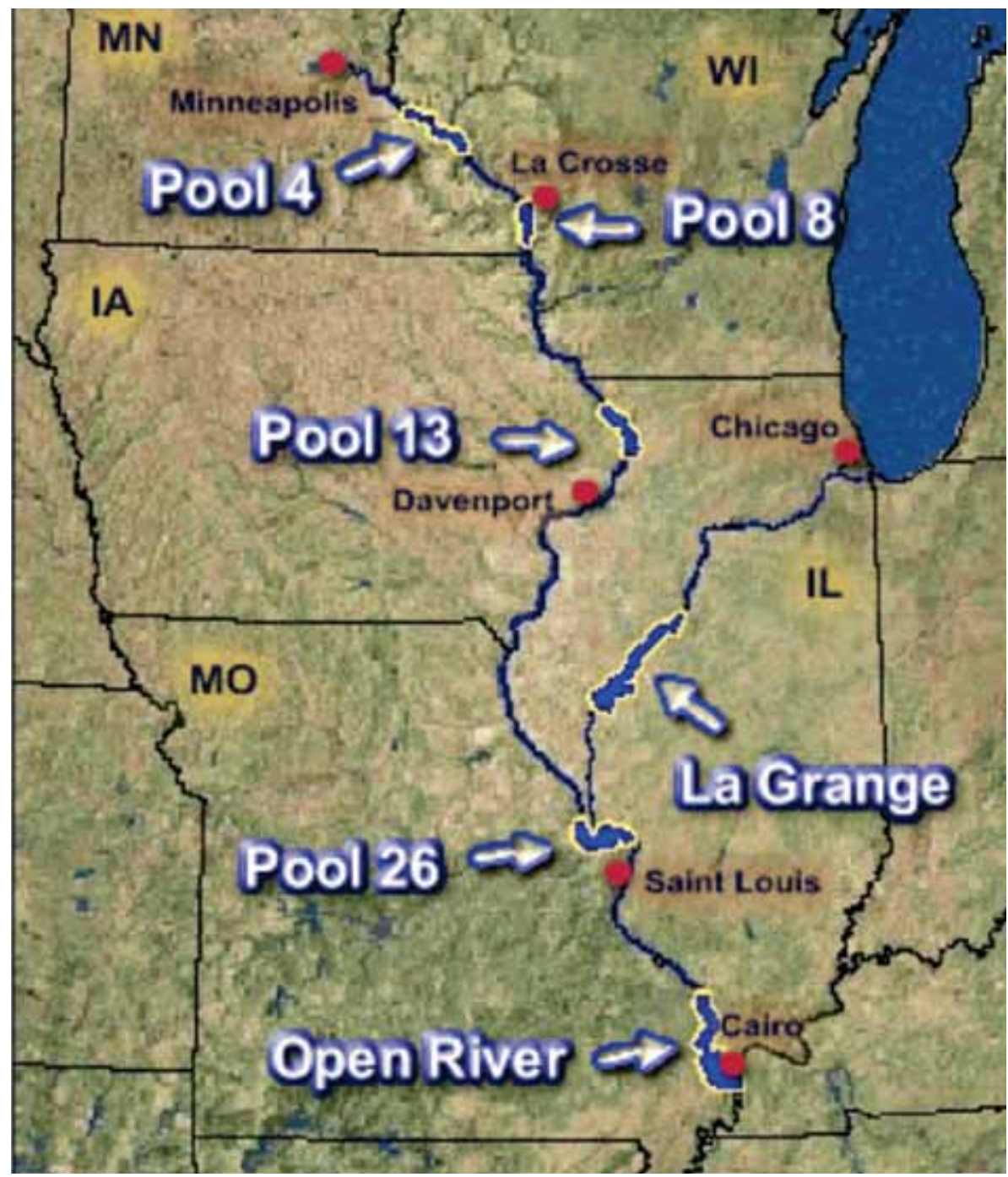

Figure 2. The six LTRMP study areas on the Upper Mississippi River (graphic courtesy of UMESC-USGS).

\section{Methods}

We examined seasonal patterns and trends in annual averages of key water quality parameters sampled by the GRFS water quality team in Pool 26 of the UMRS for the LTRMP. Soballe and Fischer (2004) present detailed descriptions of the LTRMP water quality design and procedures, so only basic information will be provided here. Sampling by the GRFS water quality team includes Pool 26, portions of the Mississippi River below Mel Price Locks and Dam, the Missouri River, the Illinois River, and other tributaries (Soballe et al. 2002). For the purposes of this bulletin, only sites within Pool 26 were analyzed. The LTRMP water quality component collects information on a selected set of physical and chemical features of the UMRS with the purpose of identifying, interpreting, and/or predicting long- and short-term patterns and trends. Water quality monitoring in the early years of the program (1988-1991) was confined to fixed sites and limited to in situ physical and chemical measurements. Beginning in June 1993, a new LTRMP sampling design was implemented, including expanded 
fixed sites, stratified random sampling (SRS), and an enhanced set of in situ field measurements and laboratory analysis of chemical constituents (Soballe et al 2002). A more detailed examination of field and laboratory methods is presented in Soballe and Fisher (2004).

Fixed site locations in the present design monitor major inflows and outflows in the study areas, as well as locations of special significance on a biweekly basis. The SRS sampling is conducted seasonally in four, two-week episodes; winter (January/February), spring (April/May), summer (July/August), and fall (October). Each SRS episode in Pool 26 has 121 sites randomly selected from 6 major habitat areas. Fixed site and SRS data used in these analyses were collected from 1994-2004, except that SRS and fixed site sampling were not conducted during the year 2003 due to budget cuts. Only surface samples $(\leq 20$ $\mathrm{cm}$ below surface) were used in our analyses. We focused on four major habitat areas for our analyses: main channel, side channel (sampled during SRS only), contiguous backwaters, and areas impounded by the current or previous locks and dams. The parameters addressed in this chapter are limited to discharge $\left(\mathrm{ft}^{3} / \mathrm{sec}\right)$, temperature $\left({ }^{\circ} \mathrm{C}\right)$, dissolved oxygen $(\mathrm{mg} / \mathrm{L}), \mathrm{pH}$ ( $\mathrm{pH}$ units), conductivity $(\mu \mathrm{S} / \mathrm{cm})$, chlorophyll-a $(\mu \mathrm{g} / \mathrm{L})$, Secchi depth $(\mathrm{cm})$, turbidity (nephelometric turbidity units - NTU), suspended solids $(\mathrm{mg} / \mathrm{L})$, total nitrogen $(\mathrm{mg} / \mathrm{L})$, nitrate plus nitrate nitrogen $(\mathrm{mg} / \mathrm{L})$, total phosphorous $(\mathrm{mg} / \mathrm{L})$, and soluble reactive phosphorous $(\mathrm{mg} / \mathrm{L})$. Some additional water quality parameters and measurements have been or are currently collected and/or measured by the LTRMP water quality component but are not addressed in this chapter. Soballe and Fischer (2004) provide a full listing of all parameters measured for LTRMP.

Because fixed sites are sampled on a continuous basis throughout the year, we used these data to examine seasonal patterns, using only sites that were sampled throughout the entire study period (1994-2004). Fixed sites from three of the four major habitat areas mentioned above (side channels are not sampled in fixed site sampling) were used, including two main channel sites, three contiguous backwater sites, and three impounded sites (Fig. 1). No sites were excluded for any reason other than not being sampled over the entire sampling period. Sample sizes for fixed site monthly means and SRS episode means can be found in Appendix A. Fixed-site means were calculated by month, and SRS means were calculated by seasonal episode (Appendix D) and plotted between the two months they were sampled (e.g., between January and February for the winter episode). Cumulative percentages were generated using main channel SRS data only. For the dissolved oxygen cumulative percentage graph, $20 \mathrm{mg} / \mathrm{L}$ was considered the maximum: any reading above $20 \mathrm{mg} / \mathrm{L}$ was given a reading of $20 \mathrm{mg} / \mathrm{L}$ (this is due to a change in Hydrolab measurement devices and the maximum reading they are able to record).

We used regression to test for trends in annual means of water quality parameters from SRS data (surface measurements only), and ran regression analyses for each habitat area separately (Appendices B, C). Surface measurements were used because water in major habitats of Pool 26 (main channel, side channels, backwater lakes, and impounded zone) rarely stratifies. Because we focused our analyses on particular habitat areas, rather than poolwide (e.g., across habitat) trends, standard arithmetic means are appropriate. These analyses were undertaken with the goal of pattern identification, rather than hypothesis testing. As each point represents a yearly mean, no adjustment was made in the regression analysis for seasonality. Ten years is insufficient for a more thorough time series analysis, especially given the quarterly sampling scheme used for SRS sampling. We ran additional regressions of water temperature trends using fixed site data, as a follow up to the analysis using SRS data. Additional regression analyses were performed to test for relationships between select water quality parameters, and between water quality parameters and annual discharge. We used yearly means of water quality from SRS main channel samples, and tested for log-linear relationships. Discharge data were obtained through the U.S. Geological Survey, measured at Grafton, Illinois. 


\section{Results and Discussion}

\section{General Description of Pool 26}

Pool 26 of the UMRS is a major junction in the Mississippi River basin. The Illinois River, which enters the UMRS within Pool 26, strongly influences limnological conditions below its mouth (Soballe et al. 2002). Several other tributaries also enter the Mississippi River in this reach, and though their discharges ous backwaters in the reach have been leveed off from the river, with control structures used to regulate their connection to the river (Soballe et al 2002). Water levels are currently managed to maintain the $2.75-\mathrm{m}(9-\mathrm{ft}$.) navigation channel. Seasonal variation in water levels over much of the reach has been greatly reduced compared to conditions before the construction of Lock and Dam 26 (Fig. 3A). There are no longer true low water periods (which previously allowed for drying and sediment compaction

Table 1. Characteristics of different trophic levels in lakes (Wetzel 1983) and Pool 26 (LTRMP; Pool 26 data ranges based on main channel yearly averages from 1994-2004).

\begin{tabular}{lcccc}
\hline Trophic Type & $\begin{array}{c}\text { Chlorophyll-a } \\
\left(\mathrm{mg} / \mathrm{m}^{3}\right)\end{array}$ & $\begin{array}{c}\text { Total Phosphorous } \\
(\mu \mathrm{g} / \mathrm{L})\end{array}$ & $\begin{array}{c}\text { Total Nitrogen } \\
(\mu \mathrm{g} / \mathrm{L})\end{array}$ & $\begin{array}{c}\text { Total } \\
\text { Inorganic Solids } \\
(\mathrm{mg} / \mathrm{L})\end{array}$ \\
\hline Oligotrophic & $<1-3$ & $<1-5$ & $<1-250$ & $2-15$ \\
Mesoeutrophic & $2-15$ & $10-30$ & $500-1100$ & $100-500$ \\
Eutrophic & $10-500$ & $10-30$ & $500-1100$ & $100-500$ \\
Hypereutrophic & $10-500$ & $30->5000$ & $500->15000$ & $400-60000$ \\
Dystrophic & $<1-10$ & $<1-10$ & $<1-500$ & $5-200$ \\
Pool 26 & $19-40$ & $164-252$ & $3239-4148$ & $35-125$ \\
& & & & \\
\hline
\end{tabular}

are minor compared to the Illinois River, their inputs can dramatically change the limnological conditions in the Mississippi River after heavy rainfall because these streams primarily drain agricultural and urban areas (Soballe et al 2002).

Pool 26 is a highly productive river reach. Long-term averages of chorophyll-a, total phosphorous, total nitrogen, and total inorganic solids all fall into Wetzel's (1983) categories for eutrophic to highly eutrophic lakes (Table 1). This productivity directly supports a planktonic food web that includes filter-feeding fishes (gizzard shad, bigmouth buffalo, and paddlefish; Chick et al. 2006), filter-feeding mussels (Cummings and Mayer 1992), and planktivorous macroinvertebrates (Sauer 2004), and indirectly supports any organisms that consume these filter feeders.

The total water surface area of the reach is about 9,300 hectares (ha), with 4,900 ha in the main and side channels. Many of the contigu- in the backwaters and channel border areas) as a result of maintaining the $2.75-\mathrm{m}$ depth of the navigation channel.

Like most impounded reaches on the UMRS, Pool 26 consists of three distinct areas: tailwater, middle, and impounded (i.e., furthest downstream). Sparks (1995) demonstrated the water level regime in Pool 26 varies among these three areas (Fig. 3B). The tailwater area, located just downstream from Dam 25, is least altered and still maintains a natural flood pulse. The magnitude of seasonal variation decreases in the middle of the reach, and the annual hydrograph is often reversed in the impounded zone and the pool is drawn down so as not to exceed the limiting stage at Grafton, Ill. When approaching a discharge of $210,000 \mathrm{cfs}$, the pool at the dam must be lowered to 414.0 feet NGVD to accomplish the above purpose. When flows exceed $210,000 \mathrm{cfs}$, all gates are opened fully and open-river conditions exist. It can be seen that a "hinge" of five feet exists at the 


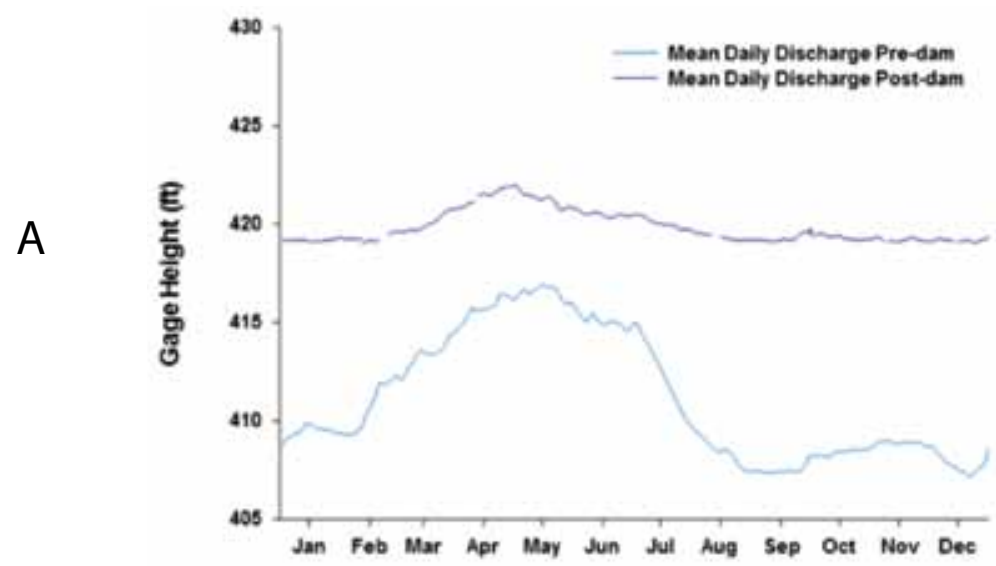

B
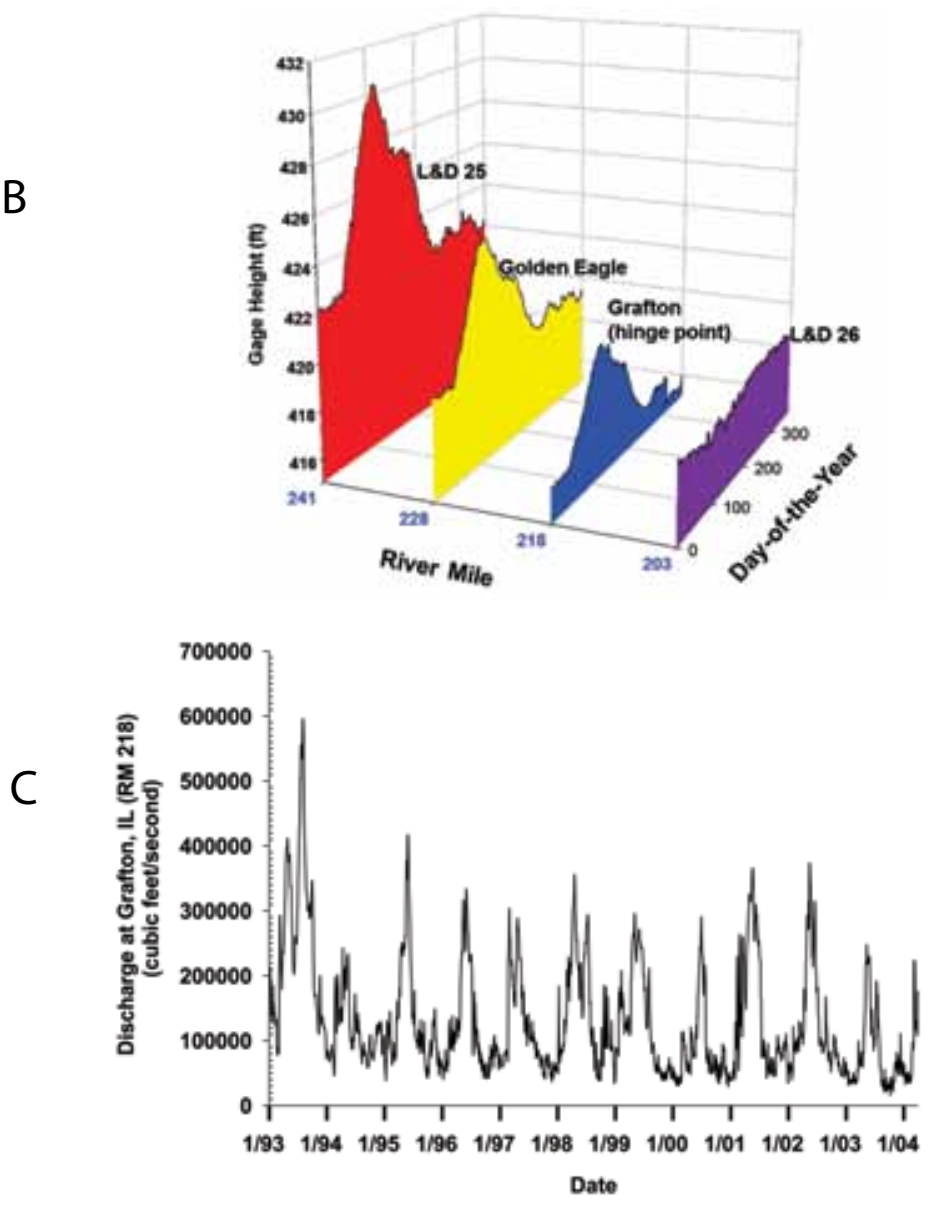

Figure 3. Stage height and discharge data for Pool 26. A) Mean daily gage height of the Mississippi River at Grafton, Illinois, pre- and post-dam construction, B) mean daily elevation (1942-1990) at the tailwaters (Locks \& Dam 25, RM 241), Golden Eagle (RM 228), Grafton, Illinois (hinge point, RM 212), and Alton, Illinois (headwaters of Lock \& Dam 26, RM 203). Note that at Locks and Dam 26, water elevation drops in spring instead of rising due to the method of water control (Adapted from Sparks 1995), C) mean daily discharge (feet ${ }^{3} /$ second) at Grafton, Illinois (hinge point, RM 218) 1993-2004. 
dam (419.0 to 414.0 feet NGVD) as discharges increase from minimum flows to those providing uncontrolled navigation depth.

Although there has been an obvious change in the flow regime of the river since the construction of levees and the locks and dams, it is a mistake to view the navigation pools of the UMRS as lakes or reservoirs. For comparison, we looked at flow rates and retention times in hydroelectric reservoirs on the Savannah River (Georgia, U.S.A), each of which is about 35 miles in length, which is similar to the length of Pool 26. Flow rates in reservoirs on the Savannah River range from $0.005-0.012 \mathrm{~m} /$ sec. (Wilde 1998). The average flow rates in the main channel of the Mississippi River in Pool 26 range from $0.364-0.414 \mathrm{~m} / \mathrm{sec}$. (as measured by the LTRMP). Although there are impoundment effects on this reach, Pool 26 is more riverine in character, with swifter flow and seasonal floods, compared to most reservoirs. The total volume of water held in Pool 26 during bank full conditions is about 450 million $\mathrm{m}^{3}$ (James Rogala, U.S. Geological Survey, pers. comm.). During high discharge levels, dam gates are completely out of the water and offer little impediment to flow. Even during the lowest discharge levels in a year, $\left(\sim 1,900 \mathrm{~m}^{3} /\right.$ sec. (James Rogala, U.S. Geological Survey, pers. comm.), the reach has a residence time of 2.7 days. By comparison, the Savannah River reservoirs have residence times ranging from 100 to 300 days (Wilde 1998).

\section{The Water Quality of Pool 26}

Discharge: The seasonal patterns of many water quality parameters are strongly influenced by temperature and river discharge. River discharge reflects precipitation patterns and inputs from the watershed, and affects water residence time, all of which affect most water quality parameters. Discharge in Pool 26 peaks at over $300,000 \mathrm{ft}^{3} / \mathrm{sec}$ in springtime (May and June), and reaches minimum levels under $50,000 \mathrm{ft}^{3} /$ sec in September-October and DecemberJanuary (Fig. 3C). The highest discharge over the study period occurred during the 1993 flood, which also extended much later into the summer than is typical for a spring flood in the reach (Fig. 3C).

Temperature and Dissolved Oxygen: Water temperature and dissolved oxygen influence many physical and chemical characteristics of water, and play a large role in habitat suitability for many aquatic organisms. Temperature affects the presence or absence of species, growth rates, and the ability of organisms to tolerate disturbance and stress (Soballe et al. 2000). Inflows from groundwater and tributaries can have marked local and poolwide effects on both temperature and dissolved oxygen levels in the reach. At main channel sites and most side channel sites in Pool 26, thermal stratification is prevented by turbulent flow. Thermal stratification is slightly more common in off-channel sites, particularly at sites with low current velocities (backwaters and impounded areas), but is still rare because the majority of backwater and impounded sites are shallow and well mixed.

LTRMP temperature data show high seasonality, and very little difference in seasonal temperature regimes among strata, with little inter-annual variation for any given month (Fig. 4A). Water temperatures from November through March are below $10^{\circ} \mathrm{C}$ and rise above $25^{\circ} \mathrm{C}$ in July and August in all habitat areas. In the main channel, temperature is above $10^{\circ} \mathrm{C}$ $\sim 85 \%$ of the year (Fig. 4B). The main channel of the Mississippi River in Pool 26 rarely freezes completely due to both temperature and the effects of barge traffic: barge traffic breaks apart ice and inhibits solid ice formation in most of the main channel during winter months.

Yearly temperature averages in main channel sites increased significantly ( $\mathrm{P} \leq 0.0354$; Appendix C) from 1994-2004 (Fig. 5). Because this trend appeared to be influenced greatly by warmer water temperature in 2004, we examined annual trends for each season in the main channel using fixed sites (Fig. 6). Significant positive trends for water temperature were found for both the spring $(\mathrm{P} \leq 0.001)$ and fall $(\mathrm{P} \leq 0.023)$, and these trends in annual water temperature are consistent with local air temperature records (Tucker et al. 2008). Increases 


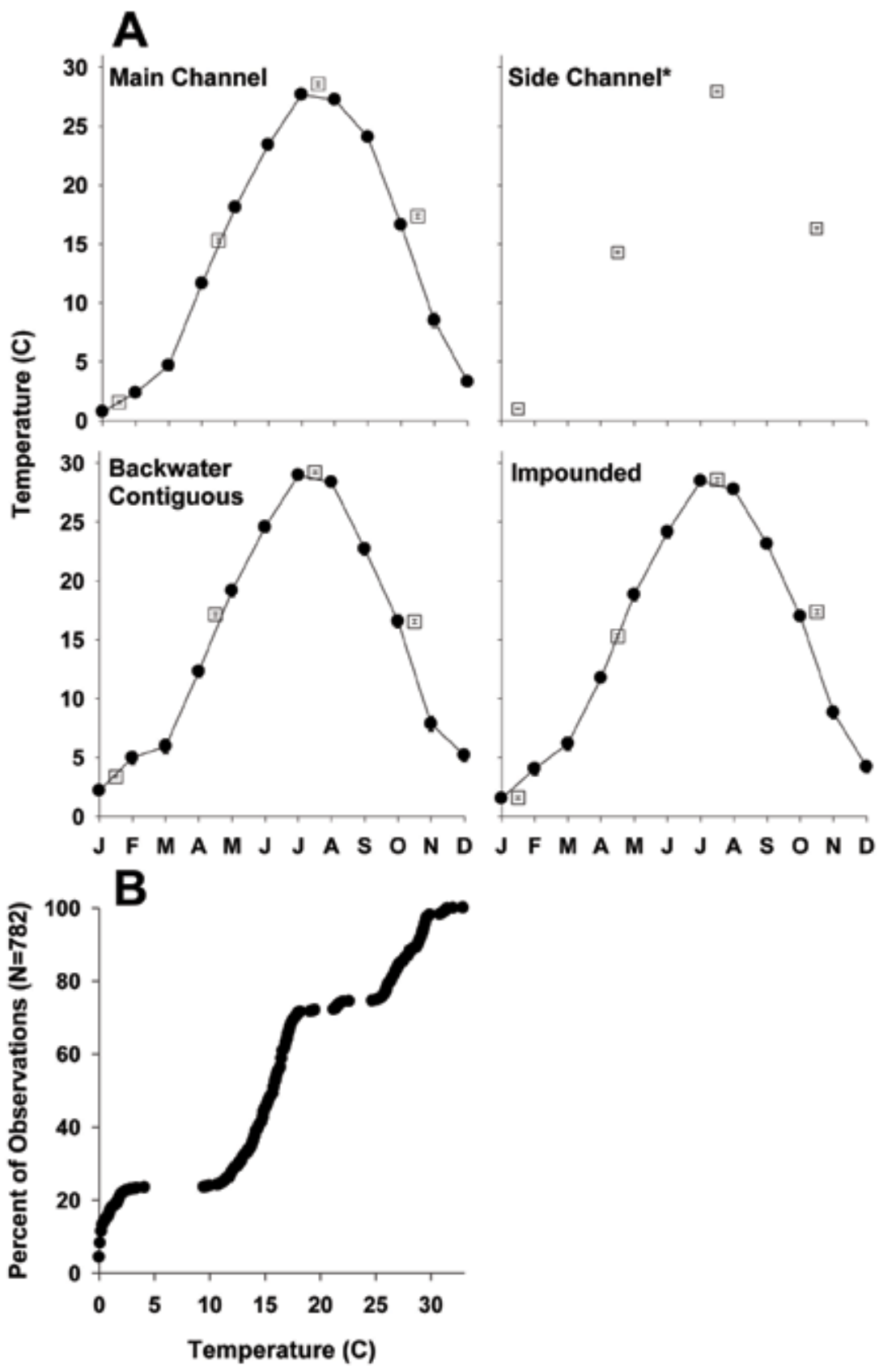

Figure 4. Water temperature data for Pool 26. A) Seasonal patterns: means in temperature $\left({ }^{\circ} \mathrm{C}\right)$ in major habitat areas of Pool 26 (1993-2004). Monthly means $(\bullet)$ are from fixed site sampling. Stratified random sampling (SRS) points (ㅁ) are plotted quarterly between the 2 months that the two-week SRS episode spans. Error bars represent +/one standard error. Sample sizes can be found in Appendix A. *note that side channels are not sampled in the fixed site sampling regime. B) Cumulative percentages of surface temperature readings in the main channel of Pool 26 (SRS data only). 


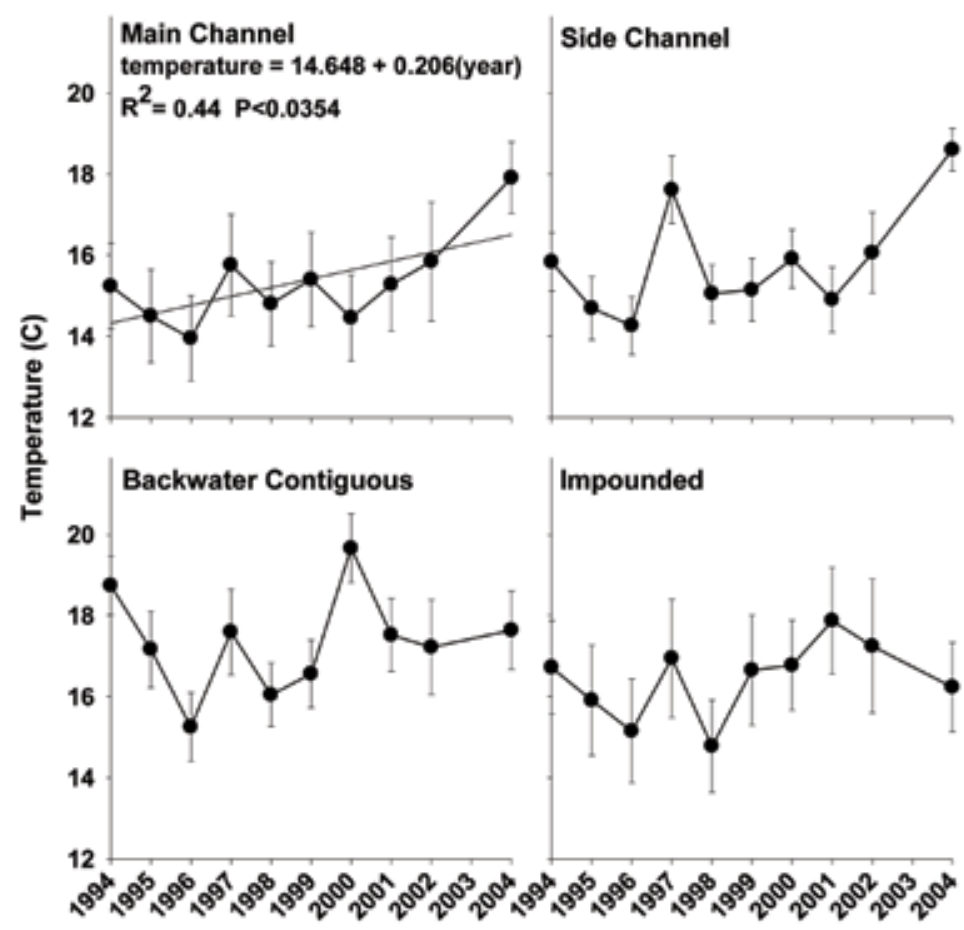

Figure 5. Yearly means in temperature in major habitat areas of Pool 26 (SRS data only). Error bars represent $+/$ - one standard error. Sampling was not conducted in 2003. Sample sizes can be found in Appendix B, and statistical results of regressions can be found in Appendix C.

Figure 6. Yearly means in
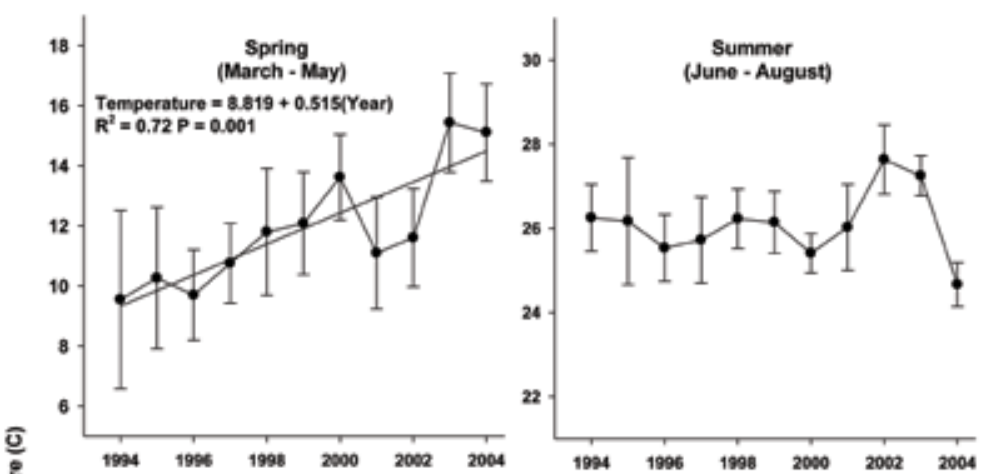
temperature in the main channel of Pool 26 (fixed data only) by season. Error bars represent $+/$ - one standard error. Sampling was not conducted in 2003. Sample sizes can be found in Appendix B, and statistical results of regressions can be found in Appendix C.
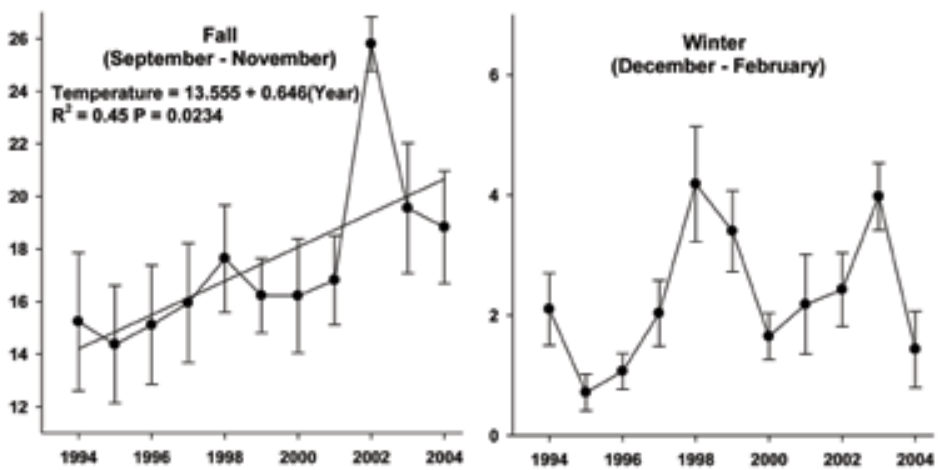
in average water temperature could have marked effects on the flora and fauna found in the reach, including changes in reproductive patterns (Tucker et al. 2008), northward expansions of southern species into Pool 26, and local extirpation of species that prefer cooler temperatures.

Like temperature, dissolved oxygen is a major determinant of habitat suitability for many aquatic species. Because LTRMP procedures emphasize midday sampling, LTRMP temperature and dissolved oxygen (DO) data are closer to a daily maximum rather than daily average values. As expected, both temperature and dissolved oxygen exhibit extreme seasonality in Pool 26. Oxygen's solubility in water decreases with increasing water temperature and DO concentration is dependent upon exchange with the atmosphere, photosynthesis, respiration, and various chemical reactions (Wetzel 1983, Soballe et al 2000). During winter months (November-March), mean monthly dissolved oxygen levels in all habitat areas of Pool 26 are near or above saturation levels (above $10 \mathrm{mg} / \mathrm{L}$; Fig. 7A). Low levels of DO coincide with high temperatures in summer months. Dissolved oxygen concentrations in summer months usually do not fall below $5 \mathrm{mg} / \mathrm{L}$ in the main channel, side channel, backwater contiguous, and impounded areas; the level considered by the EPA to be impaired for most aquatic organisms. Across all samples, we found a strong negative relationship between $\mathrm{DO}$ and temperature in Pool 26 (Fig. 7B). Main channel dissolved oxygen levels are above $5 \mathrm{mg} / \mathrm{L}>95 \%$ of the time, and above $10 \mathrm{mg} / \mathrm{L} 50 \%$ of the time (Fig. 7C).

Dissolved oxygen concentrations and extremes in temperature can be important in shallow areas and/or areas with low flow, where high water temperature, ice cover, or rapid respiration can result in DO levels below 5 $\mathrm{mg} / \mathrm{L}$ (Soballe et al 2000). Anoxic conditions $(<1 \mathrm{mg} / \mathrm{L})$ have not been detected by LTRMP sampling at any site in Pool 26. We detected no significant changes in the dissolved oxygen concentration in the reach over the last 10 years (Fig. 8; Appendix C). Dissolved Oxygen concentration was fairly consistent among years in the main and side channels, whereas backwaters and impounded areas showed more variation year to year.

pH and Conductivity: Water throughout the UMRS is generally a hard to very hard calcium-magnesium bicarbonate system with $\mathrm{pH}$ ranges from circumneutral to alkaline (Patrick 1998). Natural waters generally have $\mathrm{pH}$ values in the range of 4-9; the UMRS generally exhibits $\mathrm{pH}$ values above 6.5 , usually between 6.5 and 8.5 (Soballe et al. 2000; Fig. 9B). Throughout Pool 26, mean $\mathrm{pH}$ drops very slightly in spring and early summer, likely as a result of precipitation patterns, and then exhibits a small rise between June and August (Fig. 9A). In Pool 26, all $\mathrm{pH}$ readings in the main channel were between 6 and 10 (Fig. 9B), and $50 \%$ were $>8$. pH readings were very consistent among years in all habitats, and we found no significant trends over the study period (Fig. $10)$.

Conductivity (the ability of water to conduct an electric current) is strongly proportional to the concentrations of major ions dissolved in the water (Wetzel 1983). The UMRS generally exhibits high conductivities (Patrick 1998). Conductivity is known to affect the efficiency of electrofishing (Hill and Willis 1994), and is measured by the LTRMP fish component to determine the amount of power used to electrofish efficiently. The Illinois River has a mean summer main channel conductivity of $640 \mu \mathrm{S} /$ $\mathrm{cm}$, compared to a Pool 26 main channel summer mean of $469 \mu \mathrm{S} / \mathrm{cm}$. The Illinois River increases the conductivity of Pool 26 below its confluence with the Mississippi (Bierman 2005). Conductivity readings in main channel, backwater contiguous, and impounded areas drop in winter and fall, and appear to do so in side channels as well, though there are not enough data to state this conclusively (Fig. 11A). Ninety percent of observed main channel conductivity readings were between 200 and $600 \mathrm{mS} / \mathrm{cm}$ (Fig. 11B). Yearly conductivity averages showed no significant trends over the study period (Fig. 12).

(continued on page 339) 

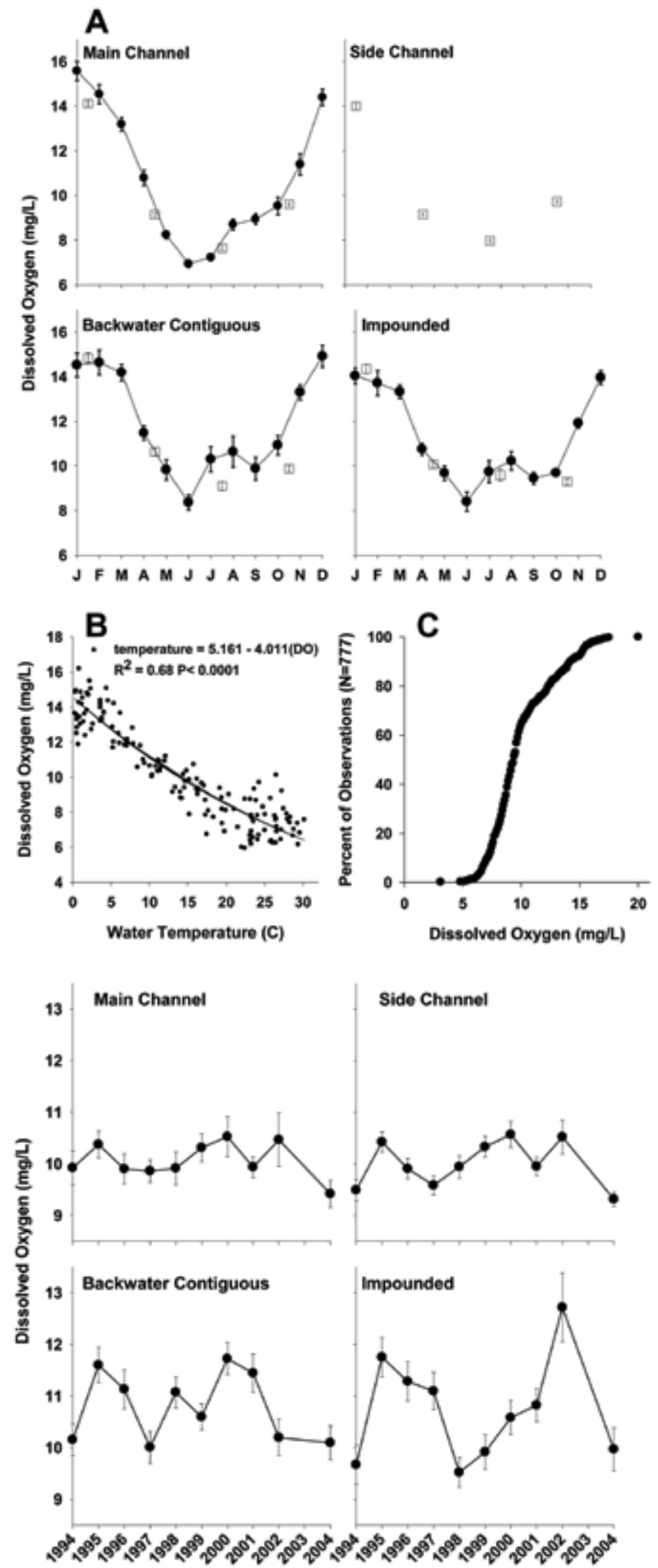

Figure 7. Dissolved oxygen data for Pool 26. A) Seasonal patterns: means in dissolved oxygen $(\mathrm{mg} / \mathrm{L})$ in major habitat areas of Pool 26 (1993-2004). Monthly means $(\bullet)$ are from fixed site sampling. Stratified random sampling (SRS) points ( $\square$ ) are plotted quarterly between the two months that the two-week SRS episode spans. Error bars represent +/- one standard error. Sample sizes can be found in Appendix A. *note that side channels are not sampled in the fixed site sampling regime. B) Relationship between dissolved oxygen and water temperature in the main channel of Pool 26, UMRS (SRS data only). C) Cumulative percentages of surface dissolved oxygen readings in the main channel of Pool 26 (SRS data only).

Figure 8. Yearly means in dissolved oxygen in major habitat areas of Pool 26 (SRS data only). Error bars represent +/- one standard error. Sampling was not conducted in 2003. Sample sizes can be found in Appendix B and statistical results of regressions can be found in Appendix C. 

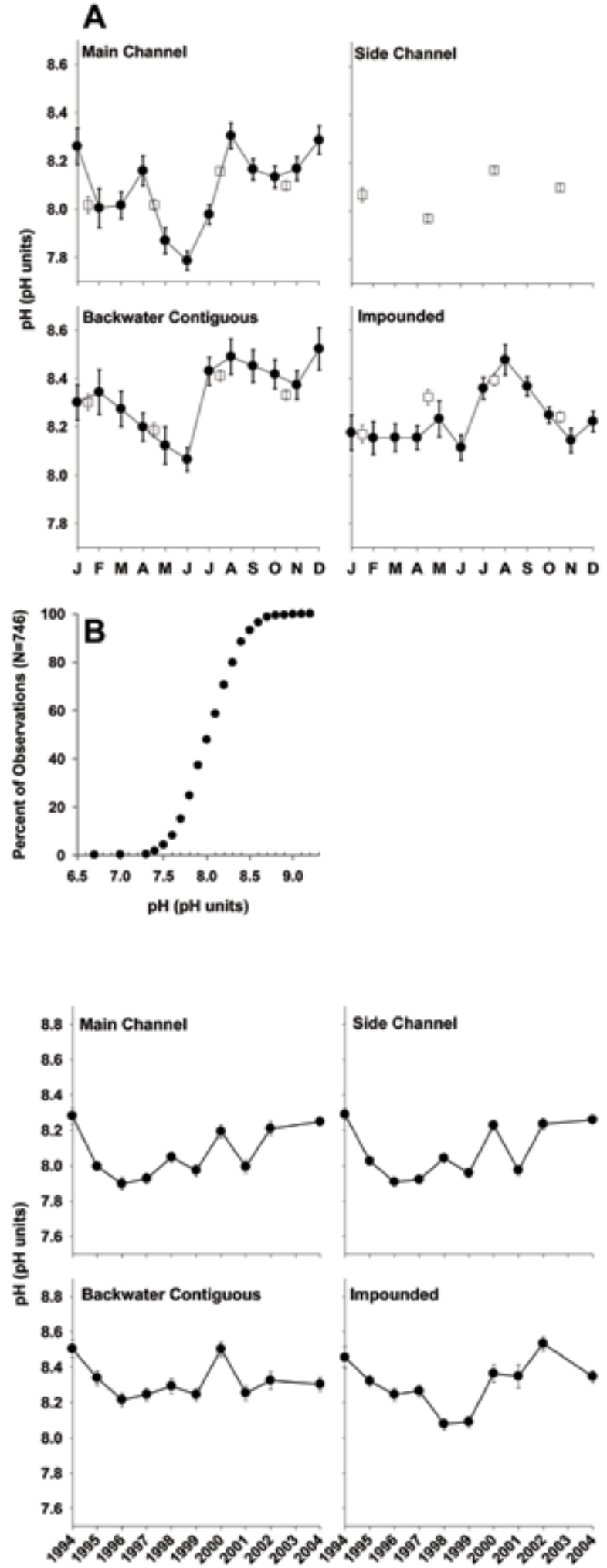

Figure 9. Hydrogen ion concentration $(\mathrm{pH})$ data for Pool 26. A) Seasonal patterns: means in $\mathrm{pH}$ ( $\mathrm{pH}$ units) in major habitat areas of Pool 26 (1993-2004). Monthly means $(\bullet)$ are from fixed site sampling. Stratified random sampling (SRS) points ( $\square$ ) are plotted quarterly between the two months that the two-week SRS episode spans. Error bars represent $+/$ - one standard error. Sample sizes can be found in Appendix A. *note that side channels are not sampled in the fixed site sampling regime. B) Cumulative percentages of surface $\mathrm{pH}$ readings in the main channel of Pool 26 (SRS data only). Note that because readings are recorded in increments of $0.1 \mathrm{pH}$ units (indicated by grey lines), each point represents more than one observation.

Figure 10. Yearly means in $\mathrm{pH}$ in major habitat areas of Pool 26 (SRS data only). Error bars represent +/- one standard error. Sampling was not conducted in 2003. Sample sizes can be found in Appendix B and statistical results of regressions can be found in Appendix C. 


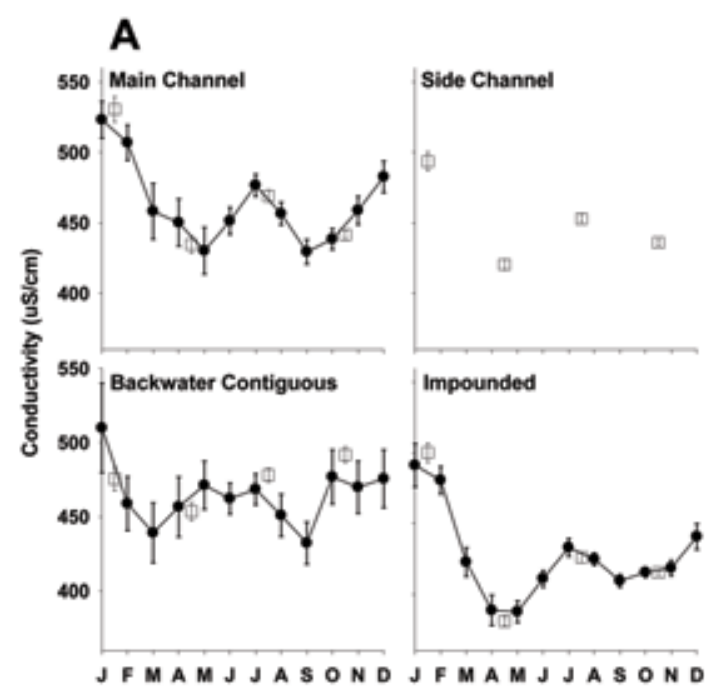

B
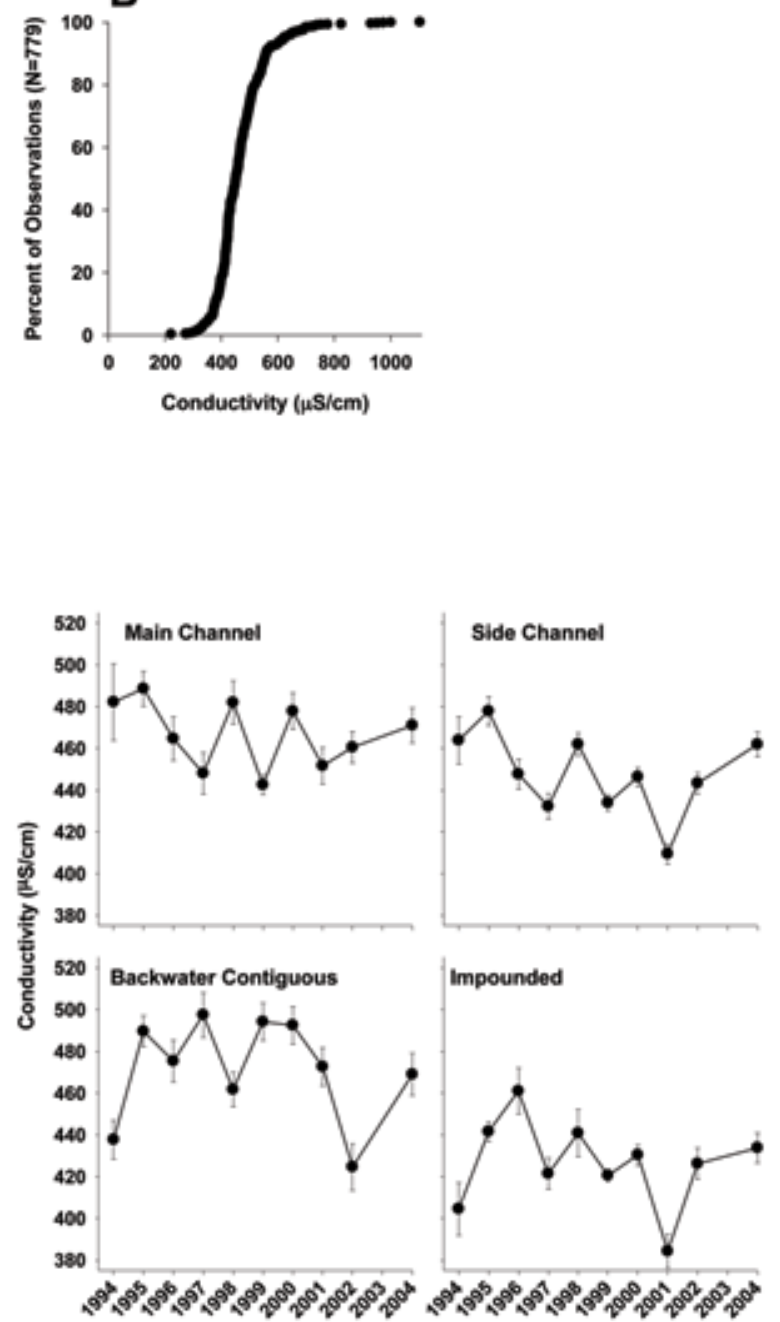

Figure 11. Water conductivity data for Pool 26. A) Seasonal patterns: means in conductivity $(\mu \mathrm{S} / \mathrm{cm})$ in major habitat areas of Pool 26 (1993-2004). Monthly means $(\bullet)$ are from fixed site sampling. Stratified random sampling (SRS) points ( $\square$ ) are plotted quarterly between the two months that the two-week SRS episode spans. Error bars represent +/- one standard error. Sample sizes can be found in Appendix A. *note that side channels are not sampled in the fixed site sampling regime. B) Cumulative percentages of surface conductivity readings in the main channel of Pool 26 (SRS data only).

Figure 12. Yearly means in conductivity in major habitat areas of Pool 26 (SRS data only). Error bars represent +/- one standard error. Sampling was not conducted in 2003. Sample sizes can be found in Appendix B and statistical results of regressions can be found in Appendix C. 

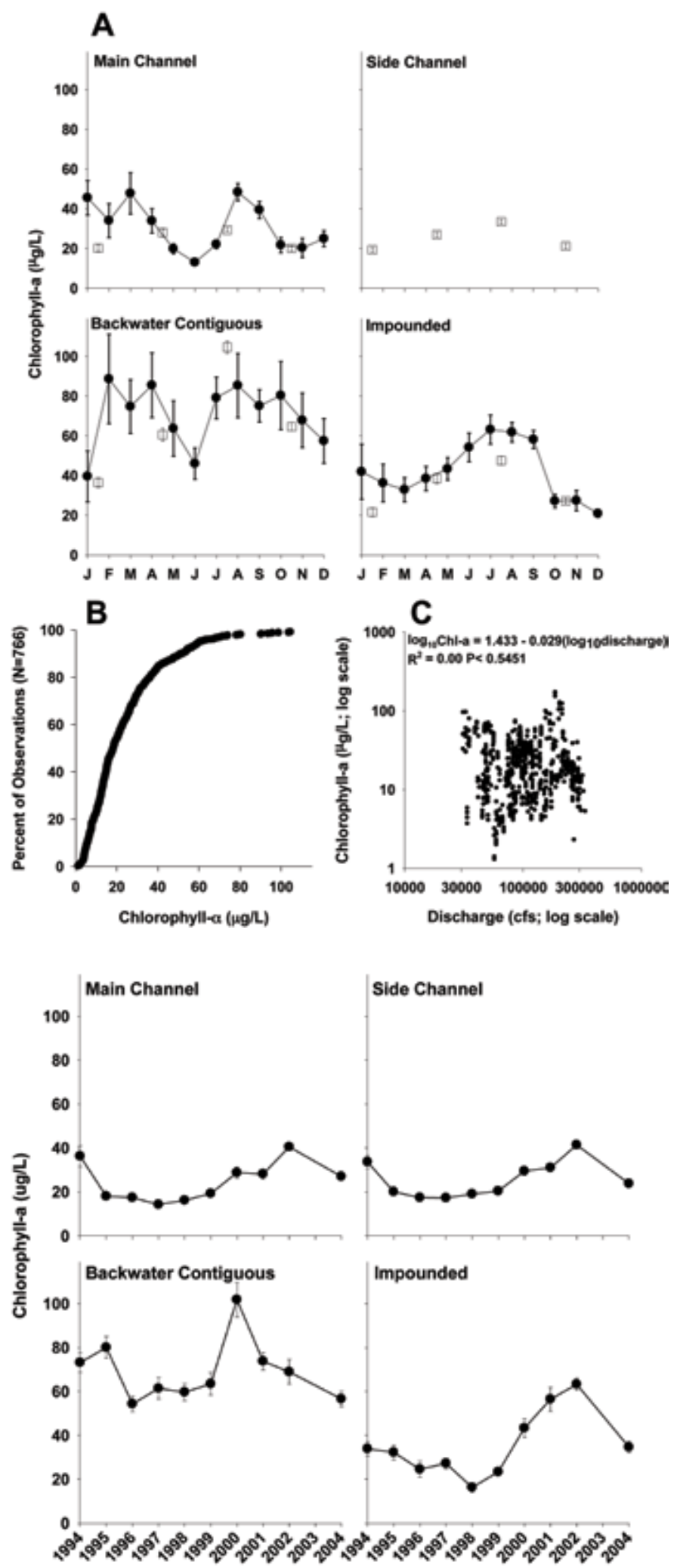

Figure 13. Chlorophyll-a data for Pool 26. A) Seasonal patterns: means in chlorophyll-a (mg/L) in major habitat areas of Pool 26 (1993-2004). Monthly means (•) are from fixed site sampling. Stratified random sampling (SRS) points ( $\square$ ) are plotted quarterly between the two months that the two-week SRS episode spans. Error bars represent +/- one standard error. Sample sizes can be found in Appendix A. *note that side channels are not sampled in the fixed site sampling regime. B) Cumulative percentages of surface chlorophyll-a readings in the main channel of Pool 26 (SRS data only). C) Relationship between chlorophyll-a and discharge in the main channel of Pool 26, UMRS.

Figure 14. Yearly means in chlorophyll-a in major habitat areas of Pool 26 (SRS data only). Error bars represent +/- one standard error. Sampling was not conducted in 2003. Sample sizes can be found in Appendix B and statistical results of regressions can be found in Appendix $\mathrm{C}$. 
Chlorophyll-a: Phytoplankton is a major food source of many organisms in the river, including mussels, invertebrates, and some fish (Soballe et al. 2000). Chlorophyll-a (Chl-a) levels can be used as an indicator of phytoplankton biomass in water. Peaks in Chl-a levels occur in early spring and late summer in the main channel and contiguous backwater lakes (Fig. 13A). Impounded areas do not show an early spring peak in Chl-a, but do show a significant peak during the summer (Fig. 13A). Backwater areas in Pool 26 are highly productive, exhibiting a great deal of seasonal variation in Chl-a (Fig. 13A). Main channel Chl-a levels were at or below $40 \mu \mathrm{g} / \mathrm{L} \sim 80 \%$ of the time (Fig. 13B). We found no significant relationship between Chl-a and discharge in the main channel (Fig. 13C) and we did not detect any significant trends in Chl-a levels in the reach over the study period (Fig. 14; Appendix C).

\section{Secchi, Turbidity, and Suspended Solids:}

Large rivers such as the Mississippi are almost always turbid, with clouds of sediment that are continually resuspended by strong currents resulting in low transparencies and Secchi depths (Horne and Goldman 1994). Secchi depth is an established and convenient way to measure water clarity, correlating reasonably well with turbidity, suspended solids, visual light extinction, and light availability for plant growth (Cole 1979, Soballe et al 2000). Secchi depth is often measured in meters, especially in highly oligotrophic lakes where Secchi depths can be as high as $30 \mathrm{~m}$; however, in large rivers like the Mississippi, Secchi depth is most often measured in centimeters because of high sediment loads (Horne and Goldman 1994). Secchi depths in Pool 26 generally range from 20-70 $\mathrm{cm}$ (Figs. 15A and 15B) with around 50\% of the Secchi depths in the main channel at or below $50 \mathrm{~cm}$ (Fig. 15B). Secchi depths are deepest in the winter, and the shallowest in spring (Fig. 15A), coinciding with the spring flood and the influx of sediment and debris into rivers and backwaters. As with many water quality parameters measured by the LTRMP, Secchi depth in the main channel was correlated with discharge; lower discharge generally results in greater Secchi depths while higher discharge results in smaller Secchi depth readings (Fig. $15 \mathrm{C})$. Mean annual secchi depth varied greatly among years in the main channel, side channels, and impounded areas (Fig. 16). They were lower and more consistent in contiguous backwaters. We found no significant trends in yearly Secchi depth averages over the study period (Fig. 16; Appendix C).

In Pool 26, Secchi depth readings in the main channel were negatively correlated with turbidity and suspended solids levels (Figs. 17A and 17B, respectively. Low Secchi depth and high levels of suspended solids often limit photosynthesis in the main channel (Horne and Goldman 1994). There is not a significant correlation between Secchi depth and Chl-a levels in the main channel of Pool 26 (Fig. 17C). In the main channel, turbidity correlated directly with suspended solids in Pool 26 (Fig. 17D). Similar to findings in other freshwater ecosystems (Wetzel 1983), our data suggest that both Secchi depth and turbidity are accurate predictors of total suspended solids.

Turbidity in the UMRS varies both longitudinally and among habitats, with sediment concentrations increasing downstream due to inputs from tributaries in Iowa and Illinois (Patrick 1998). Average river turbidities in the main and side channels of Pool 26 range from 30-120 NTU, with highest turbidities seen during spring flooding (March-June; Fig. 18A). Backwater contiguous areas show higher variability in winter and early spring (January-March), with particularly high variability in January (Fig. 18A). The Mississippi is considered a highly turbid river and only $\sim 30 \%$ of main channel turbidity readings during our study period were below 20 NTU (Fig. 18B). Lower river turbidities are seen during winter months, a result of lower flows and ice cover (Patrick 1998). Discharge generally correlated with turbidity (Fig. 18C), and main channel turbidities tend to drop off in June after spring flooding generally subsides (Fig. 18A). Turbidity levels vary greatly from year to year throughout the reach, most noticeably in main and side channel areas (Fig. 19). We found no significant trends in turbidity over the study period in any habitat area (Appendix C). 


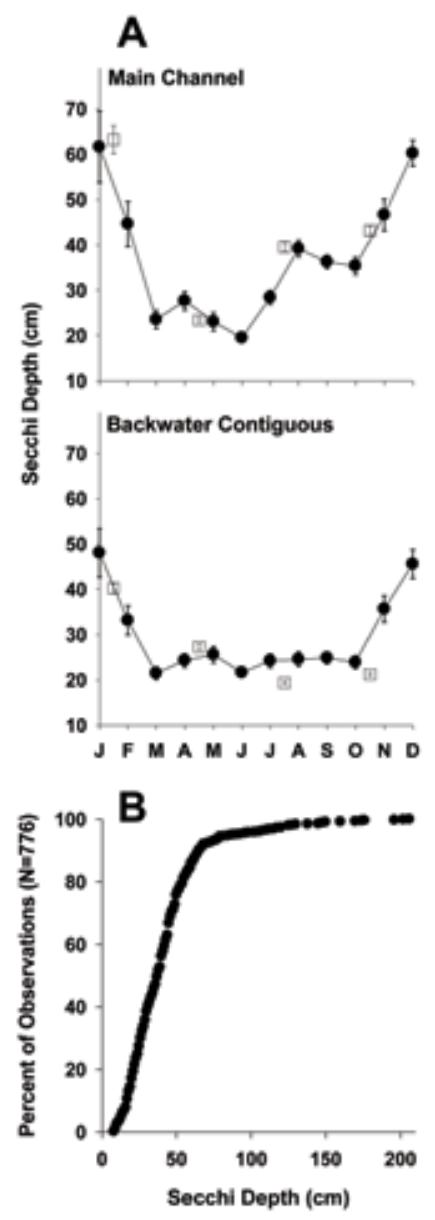

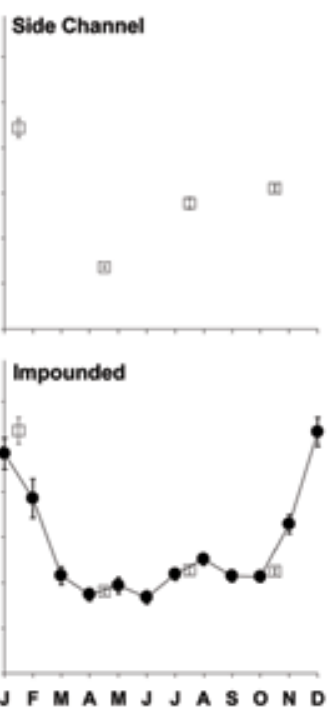

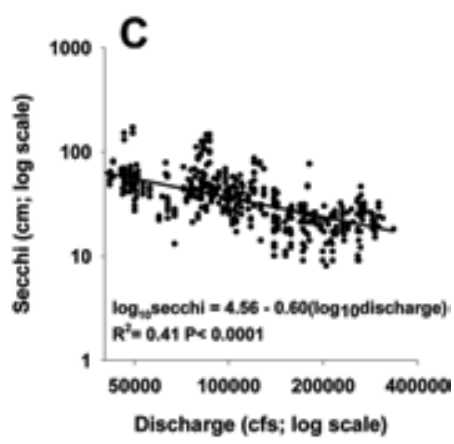

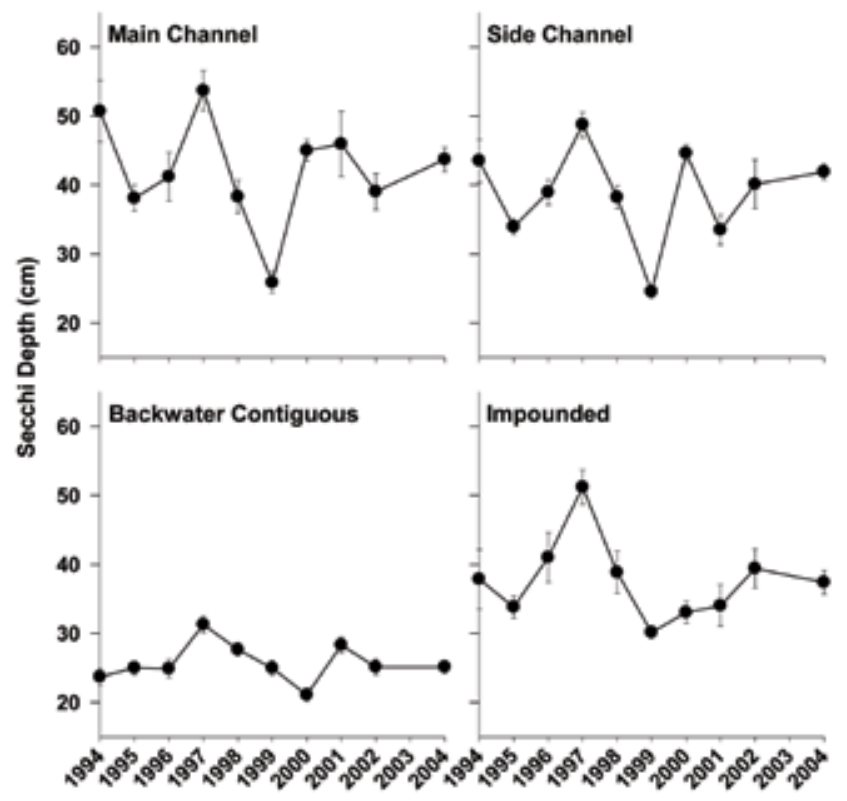

Figure 16. Yearly means in Secchi depth in major habitat areas of Pool 26 (SRS data only). Error bars represent $+/$ - one standard error. Sampling was not conducted in 2003. Sample sizes can be found in Appendix B and statistical results of regressions can be found in Appendix $\mathrm{C}$.

Figure 15. Secchi depth data for Pool 26. A) Seasonal patterns: means in Secchi depth $(\mathrm{cm})$ in major habitat areas of Pool 26 (1993-2004). Monthly means (•) are from fixed site sampling. Stratified random sampling (SRS) points ( $\square$ ) are plotted quarterly between the two months that the two-week SRS episode spans. Error bars represent +/- one standard error. Sample sizes can be found in Appendix A. *note that side chansite sampling regime. B) Cumulative percentages of surface Secchi depth readings in the main channel of Pool 26 (SRS data only). C)

Relationship between Secchi depth and discharge in the main channel of Pool 26, UMRS. 

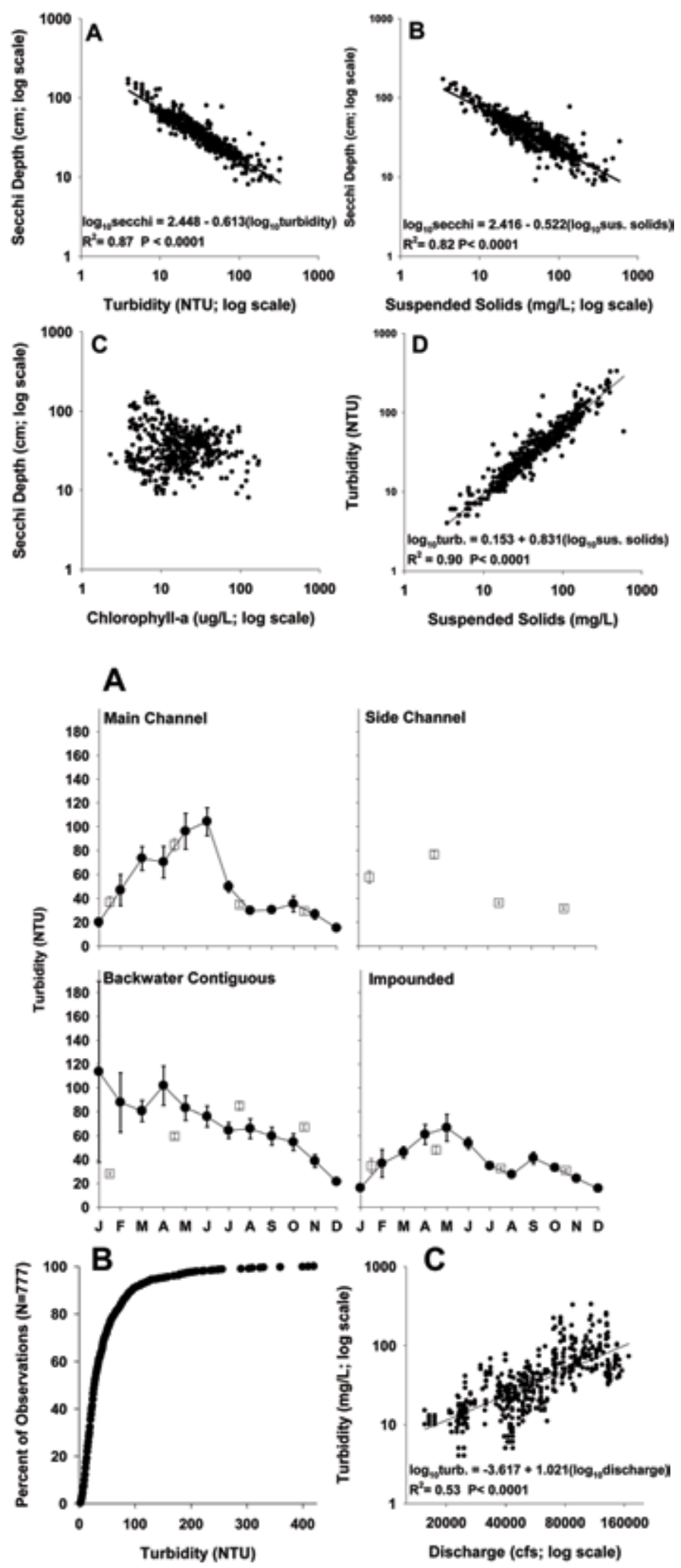

Figure 17. The relationship between Secchi depth with A) turbidity, B) suspended solids, and C) chlorophyll-a in the main channel of Pool 26, UMRS. D) The relationship between turbidity and suspended solids in the main channel of Pool 26, UMRS.

Figure 18. Turbidity data for Pool 26. A) Seasonal patterns: means in turbidity (NTU) in major habitat areas of Pool 26 (1993-2004). Monthly means $(\bullet)$ are from fixed site sampling. Stratified random sampling (SRS) points ( $\square$ ) are plotted quarterly between the two months that the two-week SRS episode spans. Error bars represent +/- one standard error. Sample sizes can be found in Appendix A. *note that side channels are not sampled in the fixed site sampling regime. B) Cumulative percentages of surface turbidity depth readings in the main channel of Pool 26 (SRS data only). C) Relationship between turbidity and discharge in the main channel of Pool 26, UMRS. 
As in most large rivers, sediment dynamics are a central feature in the structure and functioning of the UMRS: suspended sediment is the main determinant of turbidity in the system (Soballe et al. 2000). Sedimentation is the principal cause of degradation and loss of backwater habitat in the UMRS (Nielsen et al. 1984). Sediment yields in the southern part of the UMRS are approximately 200-500 times greater than in the northern areas (Nielsen et al. 1984). This increase is due to changes in land use, topography, runoff and soils. For example, the proportion of the watershed in cultivation increases by $30 \%-40 \%$ from the far northern reaches of the river to the south, and runoffper-unit-area increases accordingly (Nielsen et al. 1984). High levels of suspended solids, like those found in the main channel in Pool 26 , increase the cost of treatment for municipal and industrial water supply uses, and are also aesthetically undesirable, affecting recreation and tourism (Soballe et al. 2000).

Suspended solids levels in the main channel are highest during the spring flood period (March-June), when they are as much as three times higher than during the rest of the year (Fig. 20A). Similarly, suspended solids levels in side channels, backwaters, and impounded areas are also higher in the spring, and there is often a small increase in the fall (September-October), likely corresponding with runoff from fall rainstorms. Impounded areas with low flow have markedly lower levels of suspended solids, particularly during the spring flood period. During the spring flood and sometimes in the fall as well, contiguous backwater areas receive input from the main channel and show elevated levels of suspended solids. Around $60 \%$ of suspended solids observations in Pool 26 were below $100 \mathrm{mg} / \mathrm{L}$ (Fig. 20B). As with turbidity, suspended solids levels are related to discharge (Fig. 20C), with high discharge correlating to high levels of suspended solids. Suspended solid levels show high variation from year to year (Fig. 21), particularly in the main and side channel areas of the reach. As with turbidity and Secchi depth, we did not find a significant trend in suspended solids levels over the study period (Fig. 21; Appendix C).
Nitrogen and Phosphorous: The UMRS is highly eutrophic, and concentrations of nitrogen, phosphorous, and silica are generally not limiting to primary production (Patrick 1998). Total nitrogen levels in the reach were between $2-5 \mathrm{mg} / \mathrm{L} \sim 80 \%$ of the time (Fig. 22B). Total nitrogen (both particulate and dissolved) concentrations are generally highest in the main channel of the river during the spring flood period, which is expected as soluble plant nutrients are present at high levels in flood waters (Horne and Goldman 1994), and this pattern holds true for other habitat types as well (Fig. 22A). Total nitrogen levels drop in late summer, are lowest in fall (Fig. 22A), and vary little from year to year throughout the reach $(\sim 1 \mathrm{mg} / \mathrm{L}$ yearly differences in all habitat types; Fig. 23). Total nitrogen levels were significantly correlated with discharge (Fig. 22C), though this relationship explained only $30 \%$ of variation. We found no significant trends in total nitrogen levels over the study period within the reach (Fig. 23; Appendix C).

The LTRMP also measures nitrate plus nitrite concentrations (referred to as nitrate-nitrite). Nitrate is the most common form of nitrogen and is the form most used by phytoplankton during the spring bloom (Horne and Goldman 1994). As with total nitrogen, nitrate-nitrite concentrations in most habitats drop in late summer and are lowest in fall (Fig. 24A). Nitrate-nitrite levels are significantly correlated with discharge (Fig. 24C); however, this relationship explained only $24 \%$ of variation, thus discharge does not appear to be driving force in total nitrogen levels in the reach. Nitrate-nitrate nitrogen levels vary around $1.5-2.0 \mathrm{mg} / \mathrm{L}$ from year to year in the reach, and as with total nitrogen, we found no significant trends in nitrate-nitrate over the study period (Fig. 25; Appendix C).

The LTRMP measures both total phosphorous and soluble reactive phosphorous. Total phosphorous levels varied little in the main channel and backwaters of Pool 26, with a slight increase in spring to early summer and a decrease in total phosphorous over winter months (November-January; Fig. 26A). Total phosphorous levels in the main channel range from $0.1-0.4 \mathrm{mg} / \mathrm{L}$ over $90 \%$ of the time (Fig. 

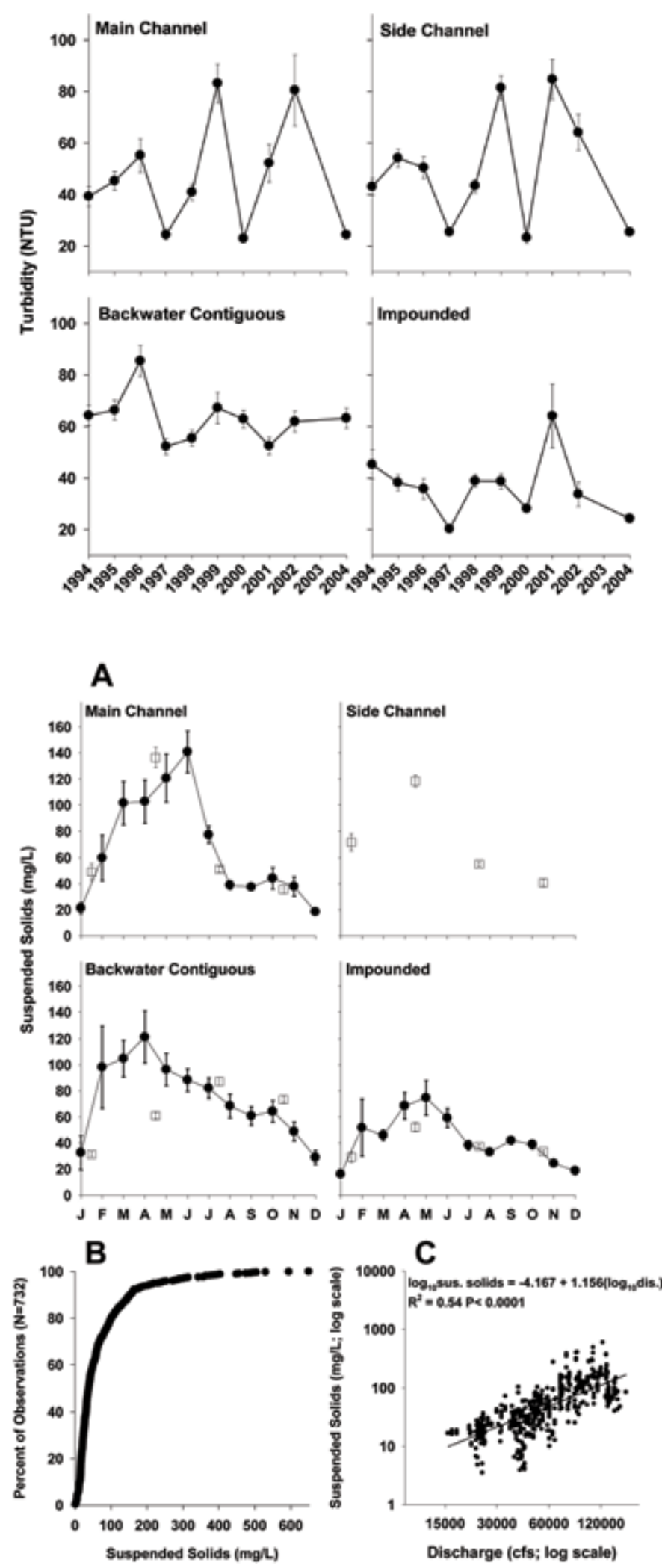

Figure 19. Yearly means in turbidity in major habitat areas of Pool 26 (SRS data only). Error bars represent +/- one standard error. Sampling was not conducted in 2003. Sample sizes can be found in Appendix B and statistical results of regressions can be found in Appendix C.

Figure 20. Suspended solids data for Pool 26. A) Seasonal patterns: means in suspended solids $(\mathrm{mg} / \mathrm{L})$ in major habitat areas of Pool 26 (1993-2004). Monthly means (•) are from fixed site sampling. Stratified random sampling (SRS) points $(\square)$ are plotted quarterly between the two months that the two-week SRS episode spans. Error bars represent +/- one standard error. Sample sizes can be found in Appendix A. *note that side channels are not sampled in the fixed site sampling regime. B) Cumulative percentages of surface suspended solids depth readings in the main channel of Pool 26 (SRS data only). C) Relationship between suspended solids and discharge in the main channel of Pool 26, UMRS. 

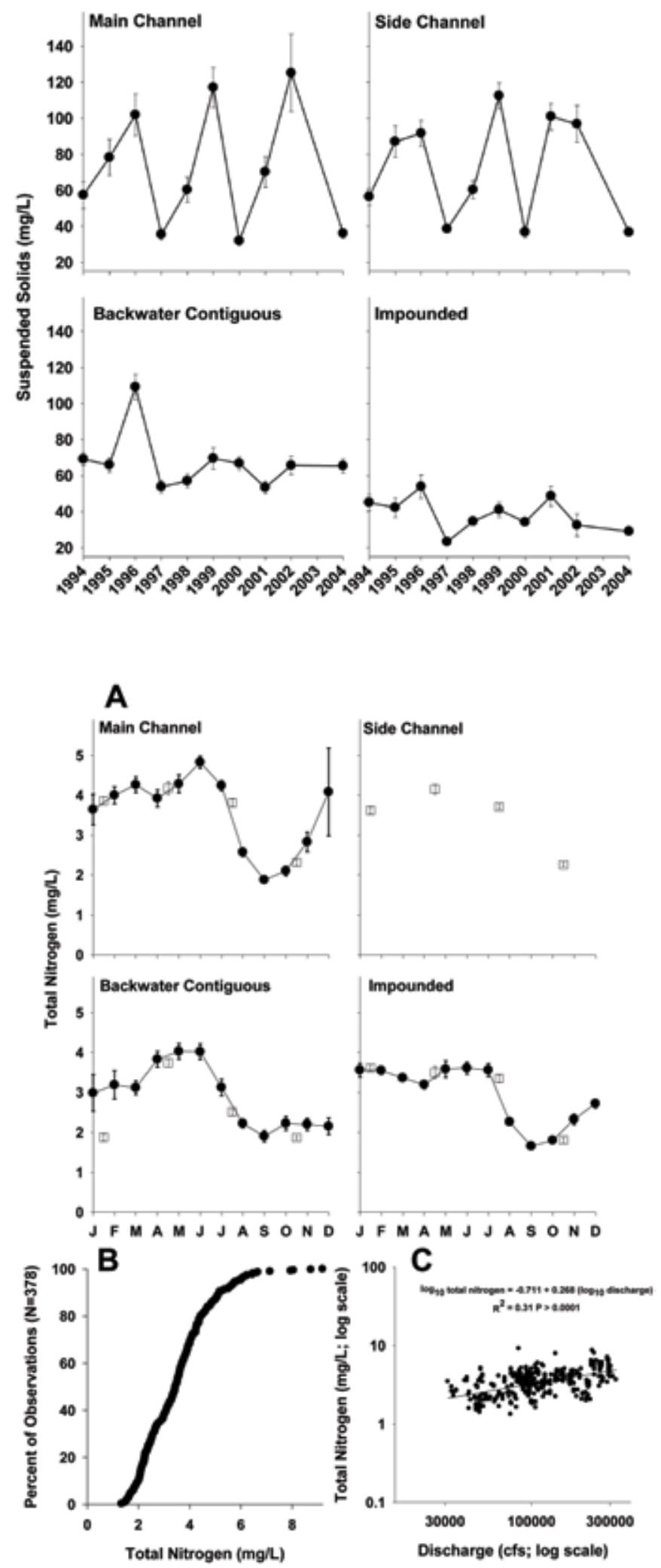

Figure 21. Yearly means in suspended solids in major habitat areas of Pool 26 (SRS data only). Error bars represent +/- one standard error. Sampling was not conducted in 2003. Sample sizes can be found in Appendix B and statistical results of regressions can be found in Appendix $\mathrm{C}$.

Figure 22. Total nitrogen data for Pool 26. A) Seasonal patterns: means in total nitrogen $(\mathrm{mg} / \mathrm{L})$ in major habitat areas of Pool 26 (1993-2004). Monthly means (•) are from fixed site sampling. Stratified random sampling (SRS) points $(\square)$ are plotted quarterly between the two months that the two-week SRS episode spans. Error bars represent +/- one standard error. Sample sizes can be found in Appendix A. *note that side channels are not sampled in the fixed site sampling regime. B) Cumulative percentages of surface total nitrogen readings in the main channel of Pool 26 (SRS data only). C) Relationship between total nitrogen and discharge in the main channel of Pool 26, UMRS. 

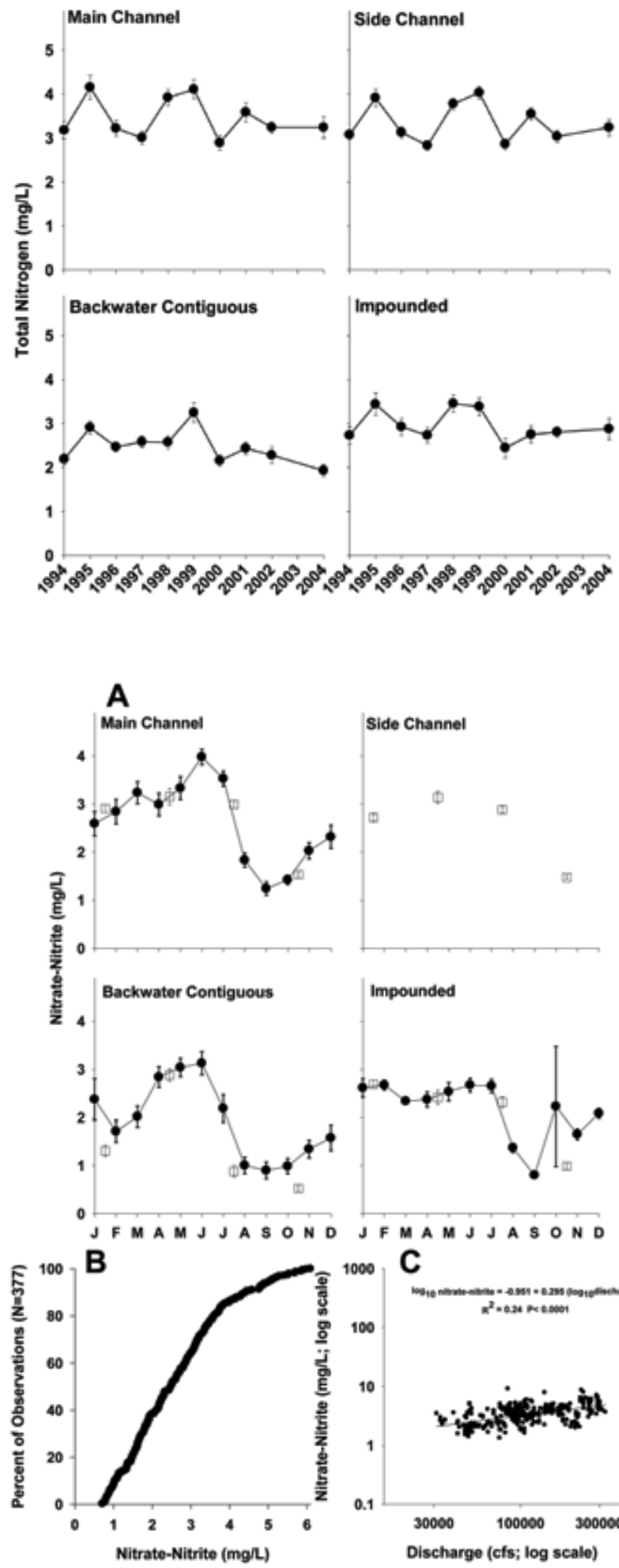

C

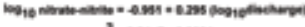

$x^{2}=0.04000001$

100

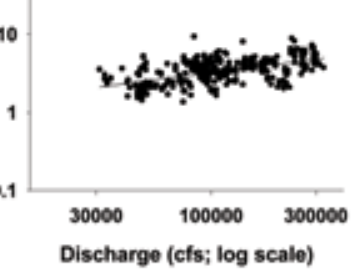

Figure 23. Yearly means in total nitrogen in major habitat areas of Pool 26 (SRS data only). Error bars represent +/- one standard error. Sampling was not conducted in 2003. Sample sizes can be found in Appendix B and statistical results of regressions can be found in Appendix C.

Figure 24. Nitrate-nitrite nitrogen data for Pool 26. A) Seasonal patterns: means in nitrate-nitrite nitrogen $(\mathrm{mg} / \mathrm{L})$ in major habitat areas of Pool 26 (1993-2004). Monthly means (•) are from fixed site sampling. Stratified random sampling (SRS) points ( $\square$ ) are plotted quarterly between the two months that the two-week SRS episode spans. Error bars represent +/- one standard error. Sample sizes can be found in Appendix A. *note that side channels are not sampled in the fixed site sampling regime. B) Cumulative percentages of surface nitrate-nitrite nitrogen readings in the main channel of Pool 26 (SRS data only). C) Relationship between nitrate-nitrite nitrogen and discharge in the main channel of Pool 26, UMRS. 

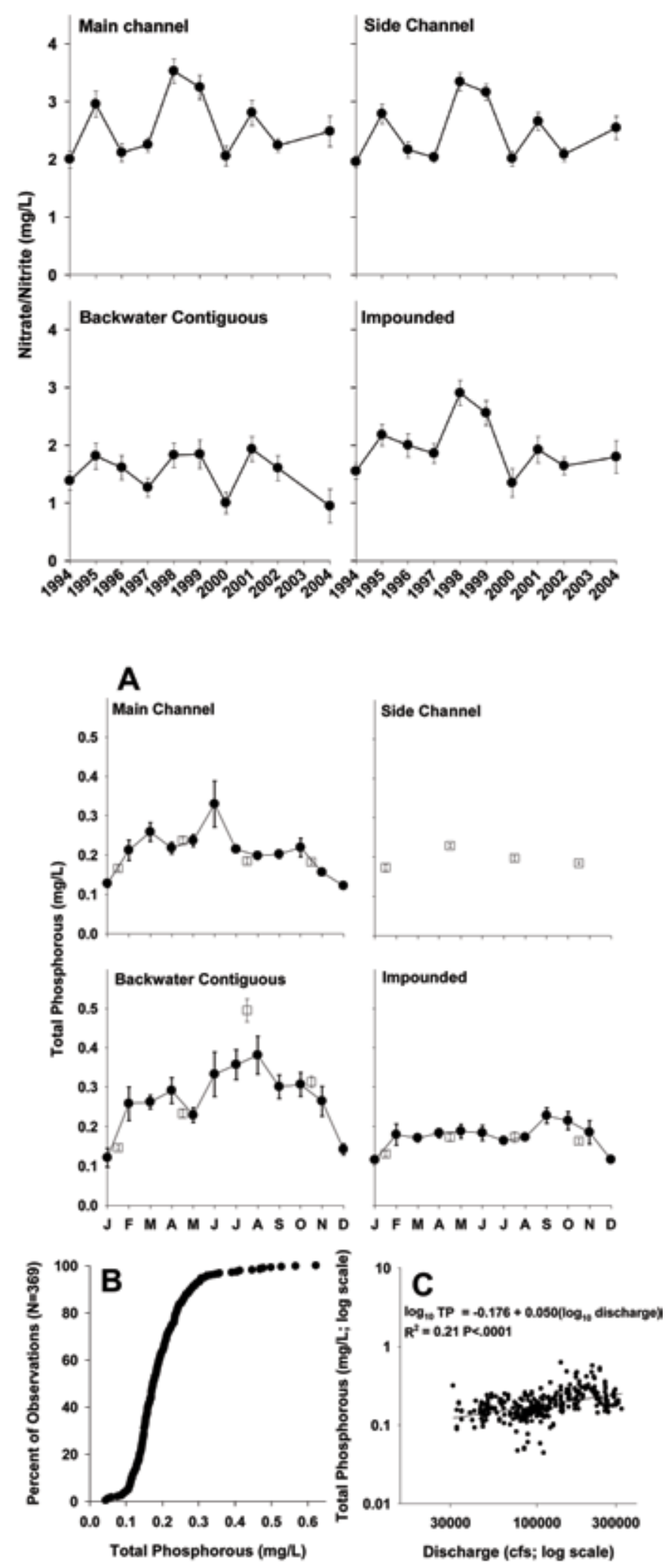

Figure 25. Yearly means in nitratenitrite nitrogen in major habitat areas of Pool 26 (SRS data only). Error bars represent $+/$ - one standard error. Sampling was not conducted in 2003. Sample sizes can be found in Appendix B and statistical results of regressions can be found in Appendix $\mathrm{C}$.

Figure 26. Total phosphorus data for Pool 26. A) Seasonal patterns: means in total phosphorous (mg/L) in major habitat areas of Pool 26 (1993-2004). Monthly means (•) are from fixed site sampling. Stratified random sampling (SRS) points ( $\square$ ) are plotted quarterly between the two months that the two-week SRS episode spans. Error bars represent +/- one standard error. Sample sizes can be found in Appendix A. *note that side channels are not sampled in the fixed site sampling regime. B) Cumulative percentages of surface total phosphorous readings in the main channel of Pool 26 (SRS data only). C) Relationship between total phosphorous and discharge in the main channel of Pool 26, UMRS. 

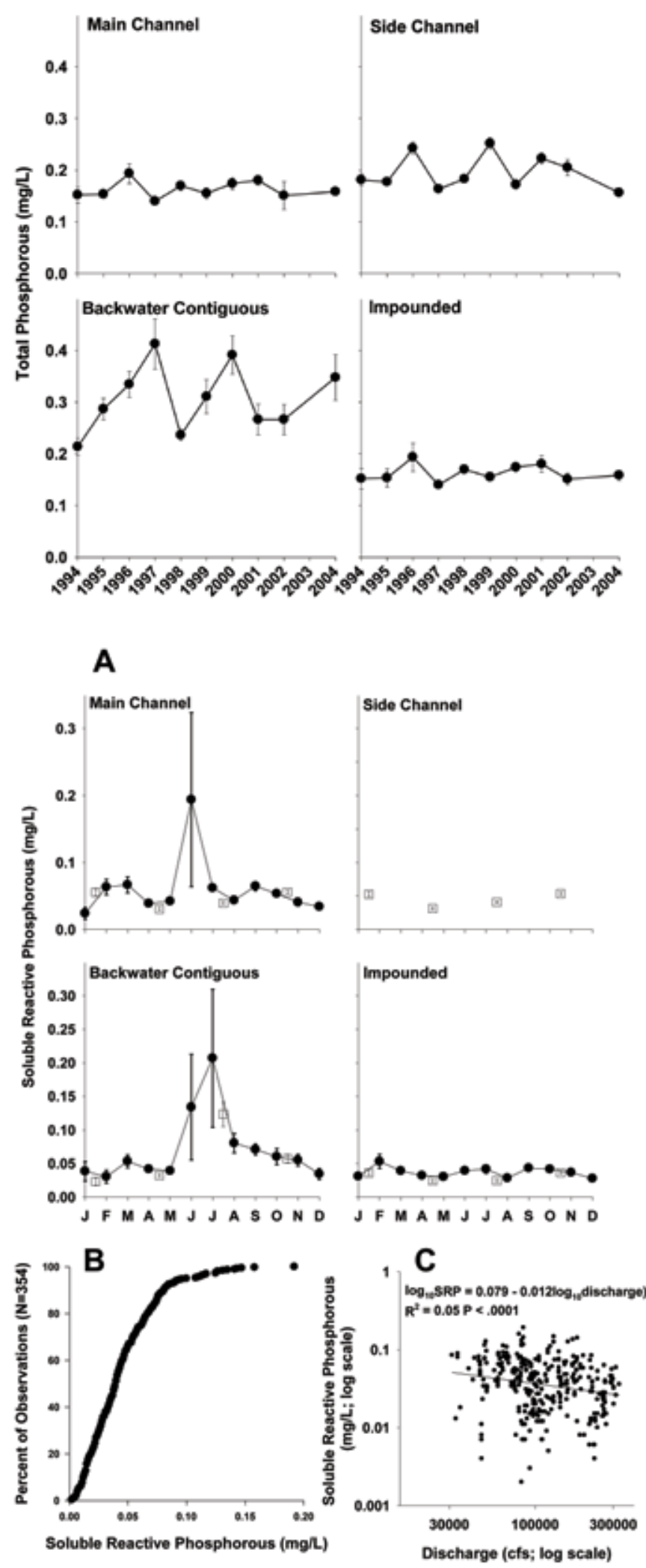

Figure 27. Yearly means in total phosphorous in major habitat areas of Pool 26 (SRS data only). Error bars represent + /- one standard error. Sampling was not conducted in 2003. Sample sizes can be found in Appendix B and statistical results of regressions can be found in Appendix C.

Figure 28. Soluble reactive phosphorus data for Pool 26.

A) Seasonal patterns: means in soluble reactive phosphorous $(\mathrm{mg} / \mathrm{L})$ in major habitat areas of Pool 26 (1993-2004). Monthly means $(\bullet)$ are from fixed site sampling. Stratified random sampling (SRS) points ( $\square$ ) are plotted quarterly between the two months that the two-week SRS episode spans. Error bars represent $+/$ - one standard error. Sample sizes can be found in Appendix A. *note that side channels are not sampled in the fixed site sampling regime. B) Cumulative percentages of surface soluble reactive phosphorous readings in the main channel of Pool 26 (SRS data only). C) Relationship between soluble reactive phosphorous and discharge in the main channel of Pool 26, UMRS. 
26B). Total phosphorous levels are significantly correlated with discharge in the main channel (Fig. 26C), but this relationship explains only $21 \%$ of the variation and does not appear to be a major factor in phosphorous levels in the main channel. Total phosphorous levels fluctuate between years in backwater areas (Fig. 27), but total phosphorous levels do not vary greatly from year to year in main and side channel areas of the reach (Fig. 27; Appendix C).

Soluble reactive phosphorous (SRP) (also referred to as orthophosphate) measures chemical forms that are generally suitable for immediate uptake by bacteria, algae, and aquatic macrophytes (Soballe et al. 2000). Soluble reactive phosphorous in Pool 26 appears to be quite variable in June and July in main channel and backwater contiguous habitats (Fig. 28A). It is unknown whether this is true of side channels as well, as side channels are not sampled monthly and the June-July variation falls between SRS events. This variation does not occur in impounded areas. With the exception of June and July, SRP does not vary greatly in the reach, and $>95 \%$ of SRP readings in the main channel are between 0 and $0.10 \mathrm{mg} / \mathrm{L}$ (Fig. 28B). As with total phosphorous, SRP is significantly correlated with discharge but the relationship is extremely weak $\left(\mathrm{R}^{2}=0.05\right.$; Fig.
28C). Soluble reactive phosphorous levels vary little from year to year, (with the exception of backwater contiguous areas, particularly in 1997 (Fig. 29), and we found no significant trends in SRP levels in any habitat (Appendix C).

\section{Conclusions}

Our description of the water quality of Pool 26 is not exhaustive, but merely the first step to more detailed investigations. Some areas of future research include, but are not limited to, investigations into the cause of both monthly and yearly variations in a number of parameters, investigations into the effect of discharge on water quality parameters, time-series trend analysis, which may pick up more subtle trends, and the effects of selected water quality parameters on each other and on the flora and fauna of the reach. A detailed look into tributary influences on water quality parameters, particularly the Illinois River, is also an area we believe would be conducive to our better understanding of the pool. Additionally, multivariate analyses of suites of water quality parameters could help determine interactions among parameters and help to explain some of the trends seen in our basic analyses.

Pool 26 is a very productive and turbid reach of the Mississippi River. Chorophyll-a, total phosphorous, and total nitrogen concentrations are usually at levels associated with eutrophic to highly eutrophic lakes. Secchi depth usually is less than $50 \mathrm{~cm}$, and turbidity and total suspended solid levels are generally high. River discharge was strongly correlated with Secchi, turbidity, and total suspended solids, but was only weakly associated with nutrient concentrations. The most obvious trend detected by our water quality sampling is the increase in water temperature in the main channel of the reach over the study period, particularly during the spring and fall. Whether this is a short-term fluctuation in average temperatures or part of a long-term trend is unknown at this point, but certainly continued monitoring is necessary to learn more about this trend and what possible effects it could have on the reach.

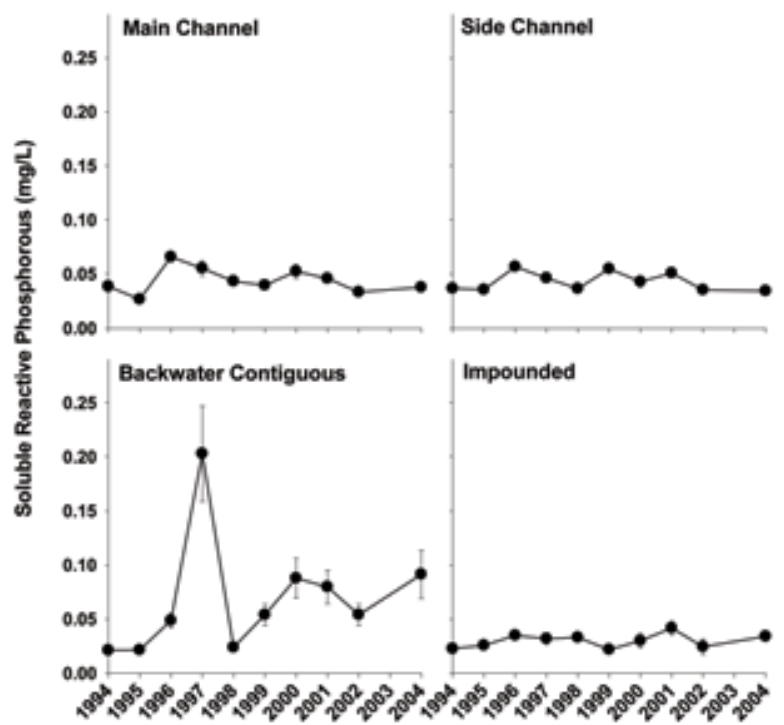

Figure 29. Yearly means in soluble reactive phosphorous in major habitat areas of Pool 26 (SRS data only). Error bars represent $+/$ - one standard error. Sampling was not conducted in 2003. Sample sizes can be found in Appendix B and statistical results of regressions can be found in Appendix C. 


\section{Literature Cited}

Bednarek, A.T. 2001. Undamming rivers: a review of the ecological impacts of dam removal. Environmental Management 27:803-814.

Bierman, D.W. 2005. Tributaries and their influence on water quality spatial patterns. Chapter 6 in J.N. Houser, ed. 2005. Multiyear synthesis of limnological data from 1993 to 2001 for the Long Term Resource Monitoring Program. Upper Midwest Environmental Sciences Center, La Crosse, Wisconsin. LTRMPP Technical Report 2005-T003. 59 pp.

Black, R., B. McKenney, A. O'Connor, E. Gray, and R. Unsworth. 1999. Economic profile of the Upper Mississippi River region. Report to U.S. Fish and Wildlife Service. Industrial Economics, Inc. Cambridge.

Carlson, B. 1993. Economic impacts of recreation, Upper Mississippi River system. Report, U.S. Army Corps of Engineers, St. Paul District, St. Paul.

Chick, J.H., M.A. Pegg, and T.M. Koel. 2006. Spatial patterns of fish communities in the Upper Mississippi River system: assessing fragmentation by low-head dams. River Research and Applications 22:413-427. Cole, G.A. 1979. Textbook of limnology. The C.V. Mosby Company.

Cummins, K.S., and C.A. Mayer. 1992. Field guide to the freshwater mussels of the Midwest. Illinois Natural History Survey Manual 5. 194 pp.

Cummins, K.W. 1972. What is a river? zoological description. Pages 33-52 in R.T. Oglesby, C.A. Carlson, and J.A. McCann, eds. River ecology and man. Academic Press, New York.

Delaney, R.L., and M.R. Craig. 1997. Longitudinal changes in the Mississippi River floodplain structure. U.S. Geological Survey, Project Status Report No. PSR 97-02. Onalaska, WI.

Dudgeon, D. 1992. Endangered ecosystems: a review of the conservation status of tropical Asian rivers. Hydrobiologia 248:167-191.
Fremling, C.R., and T.O. Claflin. 1984. Ecological history of the Upper Mississippi River. Chapter Two, Contaminants in the Upper Mississippi River. Butterworth, Boston.

Hill, D.H., and D.W. Willis. 1994. Influence of water conductivity on pulsed AC and pulsed DC electrofishing catch rates for largemouth bass. North American Journal of Fisheries Management 14:202-207.

Holland-Bartels, L.E. 1992. Water quality changes and their relation to fishery resources in the Upper Mississippi River. In Water quality in North American river systems. C.D. Becker and D.A. Neitzel, eds. Battelle Press, Columbus, Ohio.

Horne, A.J., and C.R. Goldman. 1994. Limnology, 2nd edition. McGraw-Hill, New York.

Illinois Department of Natural Resources. 1998. Big rivers area assessment volume 3: living resources. Natural History Survey Division, Critical Trends Assessment Program, Champaign.

McCartney, B.L. 1998. Inland navigation: locks, dams, and channels. ASCE Manuals and Reports on Engineering Practice No. 94. $349 \mathrm{pp}$.

Naiman, R.J., and R.E. Bilby. 1998. River ecology and management in the Pacific coastal region. In River ecology and management, R.J. Naiman and R.E. Bilby, eds. Springer, New York.

Nielsen, D.N., R.G. Rada, and M.M. Smart. 1984. Sediments in the Upper Mississippi River: their sources, distribution, and characteristics. Chapter 4 in Contaminants in the Upper Mississippi River, J.G. Weiner, R.V. Anderson, and D.R. McConville, eds. Proceedings of the 15th Annual Meeting of the Mississippi Research Consortium. Butterworth Publishers, Boston.

Patrick, R. 1998. Upper Mississippi River. Rivers of the United States, Volume IV, Part A: the Mississippi River and tributaries north of St. Louis. John Wiley \& Sons, New York. Poff, N.L., J.E. Allen, M.B. Bain, J.R. Karr, K.L. Prestegaard, B.D. Richter, R.E. Sparks, and J.C. Stromberg. 1997. The natural flow regime: a paradigm for river conservation and restoration. BioScience 47 (11):769-784. 
Sauer, J. 2004. Multi-year synthesis of the macroinvertebrate component from 19922002 for the Long Term Resource Monitoring Program. Final report submitted to the U.S. Army Corps of Engineers from the U.S. Geological Survey, Upper Midwest Environmental Sciences Center, La Crosse, Wisconsin. Technical Report LTRMPP 2004-T005. 31 pp. + Appendixes A-C.

Soballe, D.M., J. Fisher, R. Burdis, T. Clemment, L. Hodge-Richarson, L. Conaway, J. Frazier, D. Gould, M. Steuck, E. Ratcliff, M. Sites, J. Arnold, S. Stenzel, and R. Wright. 2000. Long Term Resource Monitoring Program Procedures: water quality monitoring. U.S. Geological Survey, Upper Midwest Environmental Sciences Center, La Crosse, WI. LTRMPP 95-P002-5.

Soballe, D.M., E. Ratcliff, B. Kerans, and T. Mihuc. 2002. Limnological monitoring on the Upper Mississippi River System, 1993-1996; Long Term Resource Monitoring Program Pool 26 Field Station. U.S. Geological Survey, Upper Midwest Environmental Sciences Center, La Crosse, WI. LTRMPP 2002-P002. 18 pp. + Appendixes A-F.

Soballe, D.M., and J.R. Fischer. 2004. Long Term Resource Monitoring Program Procedures: water quality monitoring. U.S. Geological Survey, Upper Midwest Environmental Sciences Center, La Crosse, WI. Technical Report LTRMPP 2004-T002-1. (Ref. 95-P002-5) 73 pp. + Appendices A-J. Sparks, R.E. 1995. Need for ecosystem management of large rivers and their floodplains. BioScience 45:168-182.

Sparks, R.E., J.C. Nelson, and Y. Yin. 1998. Naturalization of the flood regime in regulated rivers: the case of the upper Mississippi River. BioScience 48:706-720.

Theiling, C.H., C. Korschegen, H. De Haan, T. Fox, J. Rohweder, and L. Robinson. 2000. Habitat needs assessment for the Upper Mississippi River System: Technical Report. U.S. Geological Survey, Upper Midwest Environmental Sciences Center: La Crosse, WI.
Tucker, J.K., C.R. Dolan, J.T. Lamer, and E.A. Dustman. 2008. Climatic warming, sex ratios, and red-eared sliders (Trachemys scripta elegans) in Illinois. Chelonian Conservation and Biology 7:60-69.

U.S. Army Corps of Engineers (USACE). 1987. Hydraulic design of navigation dams. U.S. Army Corps of Engineers Engineer Manual No. 1110-2-1605.

U.S. Fish and Wildlife Service. 1993. Operating plan for the Upper Mississippi River system Long Term Resource Monitoring Program. Environmental Management Technical Center, Onalaska, WI, Revised September, 1993. EMTC 91-P002R. 179 pp. (NTIS \#PB94160199)

U.S. Fish and Wildlife Service. 2002. 2001 National survey of fishing, hunting, and wildlife-associated recreation. Department of the Interior, U.S. Fish and Wildlife Service, Washington, D.C.

Wetzel, R.G. 1983. Limnology. Saunders College Publishing, Philadelphia.

Wilde, S.B. 1998. Advective regulation of zooplankton assemblages in a reservoir series on the Savanah River, SC/GA. Ph.D. Dissertation. University of Georgia, Athens. 137 pp. 
Chapter 2: Population Trends for Selected Fishes in Pool 26 of the Upper Mississippi River

Eric N. Ratcliff, Benjamin J. Lubinski, Eric J. Gittinger, and J.H. Chick

\begin{abstract}
We examined fish population trends in Pool 26 of the Upper Mississippi River from three functional groups: game species, nongame species, and invasive species. Gizzard shad, emerald shiner, common carp, channel shiner, channel catfish, freshwater drum, and bluegill, were numerically the most commonly collected species, accounting for $75 \%$ of our total catch. For all gears and strata (including those that were discontinued), a total of 284,515 fish were collected between 1994 and 2003, including 87 species representing 20 families (Table 1). The Cyprinids were the best represented family in Pool 26, with 27 species collected. Fish monitoring data from the Long Term Resource Monitoring Program (LTRMP) revealed significant population trends in several species, most notably blue catfish, common carp, and young-of-year (YOY) size classes of largemouth bass and white crappie. Blue catfish catch-per-unit effort (CPUE) has increased dramatically beginning in 2000 , possibly related to the increase in water temperature observed by the water quality component. Common carp decreased throughout the time series, which appears to be a systemic trend (i.e., across all LTRMP reaches). LTRMP data were also useful for detecting the spread of exotic species into Pool 26, such as the population explosion of bighead and silver carp during the study period. These data also provide evidence that several species, including largemouth bass, black crappie, white bass, and common carp produced strong year classes during the flood of 1993.
\end{abstract}


Table 1. Total catch, percentage of total catch, and cumulative percentage of total catch, for each species, in Pool 26 of the Mississippi River (all gears and strata included), for the Long Term Resource Monitoring Program, 1994-2003. Table includes fish identified to family level, unidentified fish, and hybrids. Nomenclature follows Robins et al. (1991).

\begin{tabular}{|c|c|c|c|}
\hline Fish Species & $\begin{array}{l}\text { Total } \\
\text { Catch by } \\
\text { Species }\end{array}$ & $\begin{array}{l}\text { Percentage } \\
\text { of Total } \\
\text { Catch }\end{array}$ & $\begin{array}{c}\text { Cumulative } \\
\text { Percentage of } \\
\text { Total Catch }\end{array}$ \\
\hline Gizzard shad (Dorosoma cepedianum) & 108123 & 38.0 & 38.0 \\
\hline Emerald shiner (Notropis atherinoides) & 35906 & 12.6 & 50.6 \\
\hline Common carp (Cyprinus carpio) & 18569 & 6.5 & 57.1 \\
\hline Channel shiner (Notropis wickliffi) & 16753 & 5.9 & 63.0 \\
\hline Channel catfish (Ictalurus punctatus) & 12195 & 4.3 & 67.3 \\
\hline Freshwater drum (Aplodinotus grunniens) & 12069 & 4.2 & 71.6 \\
\hline Bluegill (Lepomis macrochirus) & 9232 & 3.2 & 74.8 \\
\hline Western mosquitofish (Gambusia affinis) & 8528 & 3.0 & 77.8 \\
\hline White bass (Morone chrysops) & 7902 & 2.8 & 80.6 \\
\hline River shiner (Notropis blennius) & 7294 & 2.6 & 83.1 \\
\hline Smallmouth buffalo (Ictiobus bubalus) & 6192 & 2.2 & 85.3 \\
\hline Spotfin shiner (Cyprinella spiloptera) & 5663 & 2.0 & 87.3 \\
\hline Orangespotted sunfish (Lepomis humilis) & 4423 & 1.6 & 88.9 \\
\hline Black crappie (Pomoxis nigromaculatus) & 3866 & 1.4 & 90.2 \\
\hline Shortnose gar (Lepisosteus platostomus) & 3592 & 1.3 & 91.5 \\
\hline Bullhead minnow (Pimephales vigilax) & 3227 & 1.1 & 92.6 \\
\hline Unidentified catostomidae (sucker) & 2797 & 1.0 & 93.6 \\
\hline River carpsucker (Carpiodes carpio) & 1656 & 0.6 & 94.2 \\
\hline Blue catfish (Ictalurus furcatus) & 1554 & 0.5 & 94.7 \\
\hline Largemouth bass (Micropterus salmoides) & 1068 & 0.4 & 95.1 \\
\hline White crappie (Pomoxis annularis) & 1004 & 0.4 & 95.5 \\
\hline Silverband shiner (Notropis shumardi) & 997 & 0.4 & 95.8 \\
\hline Flathead catfish (Pylodictis olivaris) & 868 & 0.3 & 96.1 \\
\hline Unidentified clupeidae (shad) & 836 & 0.3 & 96.4 \\
\hline Green sunfish (Lepomis cyanellus) & 793 & 0.3 & 96.7 \\
\hline Skipjack herring (Alosa chrysochloris) & 783 & 0.3 & 97.0 \\
\hline Unidentified cyprinidae (minnow) & 691 & 0.2 & 97.2 \\
\hline Sauger (Sander canadensis) & 667 & 0.2 & 97.4 \\
\hline Mississippi silvery minnow (Hybognathus nuchalis) & 638 & 0.2 & 97.7 \\
\hline Bigmouth buffalo (Ictiobus cyprinellus) & 597 & 0.2 & 97.9 \\
\hline Unidentified centrarchidae (sunfish) & 491 & 0.2 & 98.1 \\
\hline Red shiner (Cyprinella lutrensis) & 482 & 0.2 & 98.2 \\
\hline Threadfin shad (Dorosoma petenense) & 475 & 0.2 & 98.4 \\
\hline Silver chub (Macrhybopsis storeriana) & 456 & 0.2 & 98.5 \\
\hline Black buffalo (Ictiobus niger) & 386 & 0.1 & 98.7 \\
\hline Bighead carp (Hypopthalmichthys nobilis) & 373 & 0.1 & 98.8 \\
\hline Goldeye (Hiodon alosoides) & 293 & 0.1 & 98.9 \\
\hline Shovelnose sturgeon (Scaphirhynchus platorynchus) & 261 & $<0.1$ & 99.0 \\
\hline Brook silverside (Labidesthes sicculus) & 254 & $<0.1$ & 99.1 \\
\hline Mooneye (Hiodon tergisus) & 243 & $<0.1$ & 99.2 \\
\hline Shorthead redhorse (Moxostoma macrolepidotum) & 214 & $<0.1$ & 99.3 \\
\hline Speckled chub (Macrhybopsis aestivalis) & 211 & $<0.1$ & 99.3 \\
\hline Warmouth (Lepomis gulosus) & 191 & $<0.1$ & 99.4 \\
\hline Sand shiner (Notropis stramineus) & 157 & $<0.1$ & 99.5 \\
\hline Grass carp (Ctenopharyngodon idella) & 151 & $<0.1$ & 99.5 \\
\hline Unidentified & 139 & $<0.1$ & 99.6 \\
\hline Bowfin (Amia calva) & 119 & $<0.1$ & 99.6 \\
\hline
\end{tabular}


Table 1 (continued)

Fish Species
Total

Catch by

Species
Percentage
of Total
Catch

$<0.1$

$<0.1$

$<0.1$

$<0.1$

$<0.1$

$<0.1$

$<0.1$

$<0.1$

$<0.1$

$<0.1$

$<0.1$

$<0.1$

$<0.1$

$<0.1$

$<0.1$

$<0.1$

$<0.1$

$<0.1$

$<0.1$

$<0.1$

$<0.1$

$<0.1$

$<0.1$

$<0.1$

$<0.1$

$<0.1$

$<0.1$

$<0.1$

$<0.1$

$<0.1$

$<0.1$

$<0.1$

$<0.1$

$<0.1$

$<0.1$

$<0.1$

$<0.1$

$<0.1$

$<0.1$

$<0.1$

$<0.1$

$<0.1$

$<0.1$

$<0.1$

$<0.1$

$<0.1$

$<0.1$

$<0.1$

$<0.1$

$<0.1$

$<0.1$

$<0.1$
Cumulative

Percentage of

Total Catch

Silver lamprey (Ichthyomyzon unicuspis)

Ghost shiner (Notropis buchanani)

Pirate perch (Aphredoderus sayanus)

Spotted sucker (Minytrema melanops)

Striped shiner (Luxilus chrysocephalus)

White perch (Morone americana)

Yellow perch (Perca flavescens)

Total: 


\section{Introduction}

Long-term monitoring of fish populations in large rivers is important so that adverse trends can be detected before they lead to negative impacts on recreation, the local economy, or the ecosystem. Because fish are a primary biological resource targeted by recreational and commercial users of the Upper Mississippi River System (UMRS), it is worthwhile from an economic standpoint to monitor fish in the UMRS. A study of the economic importance of recreation in the UMRS estimated that over 12 million daily visits by recreationists took place during 1986, generating over $\$ 1.2$ billion (in 1990 dollars) in revenue (USACE 1994). Fishing was one of the top three most popular recreational activities in this study. In the portion of the Mississippi River bordered by Illinois and Missouri, commercial fishers harvested over 1.8 million $\mathrm{kg}$ of fish and caviar in 2003, worth over \$1 million (Maher 2005; R.J. Maher, Illinois Department of Natural Resources, pers. comm.; V.H. Travnichek, Missouri Department of Conservation, pers. comm.).

Fishes play a critical role in aquatic food webs and may have effects on other biota and water quality. For example, the feeding and spawning behaviors of common carp can cause several water quality problems including increased nutrient recycling, turbidity, and reduced macrophyte growth (Berstein and Olson 2001, Laird and Page 1996). Foraging by piscivorous fishes can lead to indirect interactions that cascade through the aquatic food web (Carpenter and Kitchell 1996). Fish communities are important indicators of ecological health in large-river ecosystems because of their diversity and response to environmental variation at multiple scales (Gammon and Simon 2000, Schiemer 2000, Schmutz et al. 2000).

Pool 26 supports important commercial and recreational fisheries, as well as a diverse fish community. Over 100 fish species, including the federally endangered pallid sturgeon (Scaphirynchus albus), the Missouri and Illinois-listed endangered lake sturgeon (Acipenser fulvescens), and Illinois-listed endangered species such as western sand darter (Ammocrypta clara) and bigeye shiner (Notropis boops) have been reported from Pool 26 (Pitlo et al. 1995, Bartels et al. 2004a, Bartels et al. 2004b, Ickes et al. 2005a). However, habitat alterations, navigation impacts, and invasive species may also be negatively impacting the important fisheries and the fish community of Pool 26.

Fishes use contiguous backwaters as habitats for spawning, feeding, nurseries, and overwintering. However, these areas have become less accessible in the UMRS because of excessive sedimentation, isolation by levees, and alteration of the flood regime (Holland 1986, Sheaffer and Nickum 1986, Sparks 1992). As a consequence of dam operating procedures in Pool 26, the lower end of the pool has an inverted flood regime: backwaters become very shallow or dry up during moderate spring floods (the time when many fish species use them for spawning), and become deeper during summer as water is held back to maintain depths adequate for navigation (Sparks et al. 1998). Some Habitat Rehabilitation and Enhancement Projects (HREP's) on Pool 26 have addressed sedimentation problems with levees to keep sediment laden water out of backwaters (Sparks 1995). These and other managed areas often sequester floodplain habitat behind levees, restricting the lateral movements of fishes between the main channel and these managed backwaters (Ickes et al. 2005b).

Invasive fish species have become an important issue in Pool 26, and both the number of non-native species introductions, as well as the population size of invasive species, has continued to increase. Invasive species can have negative impacts on water quality, aquatic vegetation, aquatic food webs, recreational and commercial fishing, and ultimately the economy (Summerfelt et al. 1970, Lubinski et al. 1986, Laird and Page 1996, Berstein and Olson 2001). When populations of invasive fishes become very abundant, they can have adverse effects on native species if their prey resources overlap. For example, Sampson (2005), found a strong similarity in the diet of Asian carp (bighead and silver carp) and native gizzard shad, and some dietary overlap between Asian carp and native bigmouth buffalo in Pool 26. 
This chapter presents fish population trends from 10 years of LTRMP data collected in Pool 26 of the Mississippi River from 1994 to 2003 by the INHS Great Rivers Field Station. We focus on 19 fish species for which LTRMP data are sufficient to investigate trends and are of interest to river managers because of recreational, commercial, or ecological concerns. The species chosen for analysis were divided into three categories: game species, nongame species, and invasive species. We included bluegill (Lepomis macrochirus), black crappie (Pomoxis nigromaculatus), white crappie (Pomoxis annularis), largemouth bass (Micropterus salmoides), channel catfish (Ictalurus punctatus), blue catfish (Ictalurus furcatus), flathead catfish (Pylodictis olivaris), freshwater drum (Aplodinotus grunniens), white bass (Morone chrysops), and sauger (Sander canadensis) in the game species category because they are commonly targeted by local anglers and were relatively abundant in our catch. Several nongame species including gizzard shad (Dorosoma cepedianum), emerald shiner (Notropis atherinoides), smallmouth buffalo (Ictiobus bubalus), shortnose gar (Lepisosteus platostomus), and orangespotted sunfish (Lepomis humilis) were chosen for analysis because they were abundant in our catch and could have important direct and indirect interactions with other species. We included the four most common invasive fishes in Pool 26-common carp (Cyprinus carpio), bighead carp (Hypophthalmichthys nobilis), silver carp (Hypophthalmichthys molitrix), and grass carp (Ctenopharyngodon idella) - in our invasive species category. Commercially harvested species are examined intensively in Chapter 3. In this chapter we present total catch of each species collected during the 10-year study period, and for each of the 19 focus species we present either mean catch-per-unit-effort (CPUE) by year, or annual total catch by all gears. In addition, CPUE or annual total catch are presented for YOY of some species.

\section{Methods}

Beginning in 1993, the LTRMP fisheries component began sampling Pool 26 using a stratified random sampling design, with several major aquatic areas chosen as sampling strata based on their enduring geomorphic features (Wilcox 1993). Gutreuter et al. 1995, provides detailed description on the LTRMP sampling design and methodology, so only basic descriptions will be provided here. Six main strata types including main channel border, side channel border, contiguous backwateroffshore, contiguous backwater-shoreline, impounded-offshore, and impounded-shoreline were sampled as part of the stratified random sampling design, while a seventh strata (tailwater) was sampled only with a fixed site (Table 2). Annual sampling was conducted during the three time periods June 15-July 31, August 1September 15, and September 16-October 31, using a multi-gear approach. Because sampling began on June 15 each year, spring flooding had usually ended, which helped reduce the effects of high-water levels and high-water velocities on catch rates. Furthermore, data were flagged when environmental conditions were believed likely to affect results, and sampling was usually postponed when surface velocity was greater than $1 \mathrm{~m} / \mathrm{second}$.

Pulsed-DC electrofishing, fyke nets, mini fyke nets, bottom trawls, small hoop nets, large hoop nets, tandem fyke nets, tandem mini fyke nets, and seines were all used until 2002. After re-evaluating the effectiveness of the LTRMP sampling gears, a programmatic decision was made to drop tandem fyke, tandem mini fyke, and seine nets from the program (Ickes and

Table 2. Area in hectares (ha) of strata used for stratified random fish sampling in Pool 26 of the Mississippi River, for the Long Term Resources Monitoring Program, 1994-2003.

\section{Sampling strata}

Main Channel Border

Area (ha)

Side Channel Border

Backwater Contiguous-Offshore

3308

1418

90

Backwater Contiguous-Shoreline

Impounded-Offshore

147

Impounded-Shoreline 
Burkhardt 2002). The decision to drop these gears resulted in the elimination of the contiguous backwater-offshore and impounded-offshore strata because at that time, tandem fyke nets and tandem mini fyke nets were the only gears being fished in these strata.

Each of the LTRMP gears catches a different assemblage of fish because they are all constructed and fished differently (Gutreuter et al. 1995). Mini fyke nets are especially effective at catching YOY and juvenile fishes. Fyke nets are effective for sampling certain centrarchids (black and white crappie, bluegill) and shortnose gar (Lubinski et al. 2001). Large hoop nets are effective at sampling channel areas for benthic fishes such as channel catfish, smallmouth buffalo, and common carp (Lubinski et al. 2001), while small hoop nets are effective for juveniles of these species. Small and large hoop nets are always fished as a paired set, and for this study their data were combined into one sample per site. Of all of the gears used for LTRMP sampling, electrofishing is the gear with the highest effectiveness for the most species and size classes of fish (Lubinski et al. 2001). The LTRMP uses standardized electrofishing power settings that account for changes in temperature and conductivity to deliver a constant power drop across a fixed length of fish tissue (Gutreuter et al. 1995).

For all analyses except our total catch summary (Table 1), we included only data from gears (electrofishing, fyke nets, mini fyke nets, small hoop nets, and large hoop nets) and strata (main channel border, side channel border, contiguous backwater-shoreline, and impounded-shoreline) that were consistently fished throughout the 1994 to 2003 study period. Annual gear allocations were: 72 electrofishing runs (15 minutes each); 24 fyke net sets (24 hours each), 39 mini fyke net sets (24 hours each); and 51 paired small and large hoop net sets (48 hours each). Our total catch summary (Table 1) includes all LTRMP fish collections made during the study period, from all strata and gears, to give the reader an accurate representation of our catch during the sample period.

We calculated mean CPUE and standard error for each species from the gear with either the greatest statistical power (Lubinski et al. 2001), or the lowest variance to mean ratio. Where variance to mean ratios was too great to produce meaningful CPUE estimates, we presented total catch by all gears combined to provide some information on catch variation among years. All CPUE calculations in this chapter are annual pool-wide means of catchper-unit-effort, weighted by strata, calculated using the proc surveymeans procedure in version 8.02 of SAS for Windows (See Appendix D). To examine trends in the production of YOY fishes, we derived a YOY cut-off length using the Von Bertalanffy Growth Equation with parameter estimates reported on Fishbase (www.fishbase.org) to estimate length at Age-1, and refined this estimate by examining LTRMP length data (See Appendix D). All fishes less than the YOY cut-off length were classified as YOY. To examine the production of YOY fishes during the 1993 flood, we had to estimate CPUE for Age-1 fishes because standard LTRMP sampling was not possible during the flood. Age-1 fishes were defined as all fishes greater than or equal to the YOY cut-off length but less than the Age-2 estimate from the Von Bertalanffy growth. To compare CPUE of Age-1 fishes among years, we looked for overlap among $95 \%$ confidence intervals. To test for trends through time, we conducted linear regression of annual CPUE values using a log transformation ( $\log 10 \mathrm{CPUE}+1)$ to conform to the linearity assumption. Regression lines were only plotted when significant $(\mathrm{P}<0.05)$, and we plotted untransformed CPUE on a log scale for easier graph interpretation (Figs. 1-12).

\section{Results and Discussion}

\section{Total Catch Information}

For all gears and strata (including those that were discontinued), a total of 284,515 fish were collected between 1994 and 2003, including 87 species representing 20 families (Table 1). The cyprinids had the most species of any fish family in Pool 26, with 27 species collected. Other dominant families were the centrarchids, ictalurids, and catostomids, each with 9 species collected. Gizzard shad was the most com- 
monly caught species, comprising $38 \%$ of the total catch. When combined with emerald shiner (the second most abundant species), the two comprised approximately $50 \%$ of the total catch. The third most abundant fish was common carp, followed by channel shiner, channel catfish, freshwater drum, and bluegill. These seven species account for $75 \%$ of the total catch, and the top 14 species account for approximately $90 \%$ of the total catch. The total catch also included four hybrids and a minimal number of fish identified to the family or higher taxonomic level.

\section{Game Species}

The four centrarchids commonly harvested by recreational fishers (bluegill, largemouth bass, white crappie, and black crappie) all had 1-2 major peaks in CPUE during the study period. Catch-per-unit-effort for both bluegill and largemouth bass peaked in 1994 and 2001. Electrofishing CPUE of bluegill peaked near $3.7 \mathrm{fish} / 15 \mathrm{~min}$ in 1994 and 2001, but reached lows of 0.6 in 1996 and 2.4 in 2003 (Fig. 1A). Largemouth bass reached 2 fish/15 minutes in 1994 and 2001, but declined to 0.1 in 1998 and 0.6 in 2003 (Fig. 1B). There was no significant trend in largemouth bass or bluegill CPUE during the study period, which is consistent with data for 1993-2002 from the other LTRMP study reaches, with the exception of Pool 8 (Ickes et al. 2005a). Young-of-the-year bluegill CPUE reached its highest level in 2000, and its lowest level in 2001, but there was no significant trend in YOY bluegill CPUE during the study period (Fig. 2A). Young-of-the-year largemouth bass CPUE increased significantly during the study period $\left(\mathrm{F}_{1},{ }_{8}=6.07, \mathrm{R}^{2}=0.43\right.$, $\mathrm{P}<0.039$ ), with CPUE near zero through 1996 then increasing to maximum values $(0.34$ and $0.42 \mathrm{fish} / 15$ minutes of electrofishing) in 2001 and 2003 (Fig. 2B). Future studies could examine whether this increase in YOY fish is recruiting into the adult largemouth bass population.

White and black crappie showed similar patterns relative to bluegill and largemouth bass. White crappie had no overall trend through the time period, with peak abundance occurring in 2001 (4.15 fish/24 hours; Fyke nets; Fig. $3 \mathrm{~A})$. Black crappie CPUE by electrofishing declined significantly $\left(\mathrm{F}_{1},{ }_{8}=6.75, \mathrm{R}^{2}=0.46\right.$, $\mathrm{P}<0.032$ ) during this time period, from 0.54 fish/15 minutes electrofishing in 1994, to a low of $0.02 \mathrm{fish} / 15$ minutes electrofishing in 1998 (Fig. 3B). Catch-Per-Unit-Effort of YOY white crappie from mini fyke nets increased significantly $\left(\mathrm{F}_{1},_{8}=7.76, \mathrm{R}^{2}=0.49, \mathrm{P}<0.024\right)$ from 1994-2003, suggesting that reproduction is increasing (Fig. 4A). Indeed, the two years with the highest CPUE of YOY white crappie (1.10 and 0.67 fish/24 hours) were 2001 and 2003, while the lowest catches occurred in 1994 and 1997 (<0.02 fish/24 hours). Catch-per-uniteffort of YOY black crappie from mini fyke nets peaked in 1995, 1998/1999, and 2002, suggesting that good reproduction occurred every three to four years (Fig. 4B). Although we saw a significant population decline in black crappie of all ages combined, there was no similar significant trend in YOY black crappie (Fig. 4B). It will be interesting to follow population trends for black crappie in Pool 26 to see if years with good YOY production result in recruitment to the adult population.

We observed different dynamics for all three major catfishes targeted by commercial and recreational fishers: channel catfish, flathead catfish, and blue catfish (Figs. 5 and 6). Mean CPUE peaked in 1999 and 2002 for both YOY channel catfish (2.38 and 1.65 fish/15 minutes) and channel catfish of all ages (5.48 and 3.46 fish/15 minutes); however, mean electrofishing CPUE for channel catfish does not show a strong upward or downward trend, suggesting that their population has been relatively stable throughout the study period (Figs. 5A and 5B). Flathead catfish CPUE generally declined from 1994-1998, and then remained fairly stable until 2003 (Fig. 5C). Throughout the 1990s we collected fewer than 20 blue catfish per year in all gears combined, but beginning in 2000 the total catch rose by an order of magnitude or more (Fig. 6A). We primarily collect blue catfish by hoop netting and trawling, and our blue catfish catch from each of these gears has been consistently higher since 2000. Hoop netting CPUE showed a significant increas- 

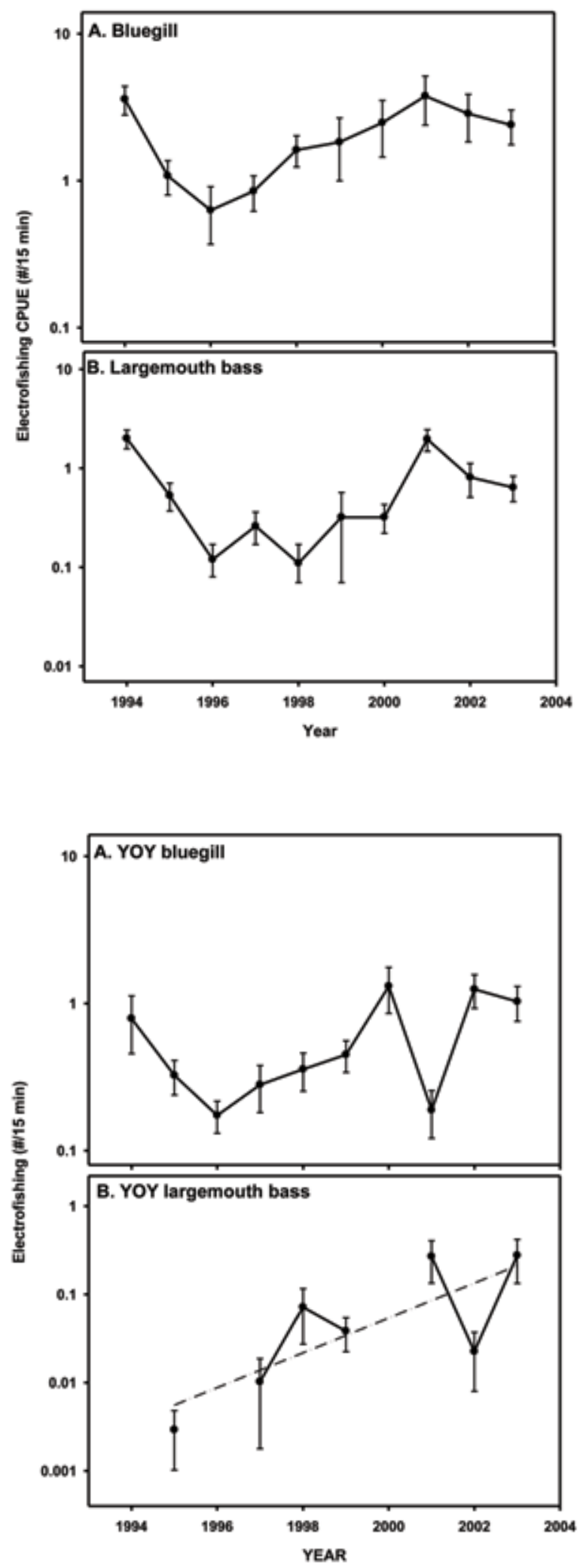

Figure 1. Catch-per-unit-effort values (pool wide mean and standard error) for (A) bluegill, and (B) largemouth bass, for electrofishing, from Pool 26 of the Mississippi River, for the Long Term Resource Monitoring Program, 1994-2003.

Note that catch-per-unit-effort values are graphed on a $\log$ scale.

Figure 2. Catch-per-unit-effort values (pool wide mean and standard error) for (A) young-of-the-year bluegill, and (B) young-of-the-year largemouth bass, for electrofishing, from Pool 26 of the Mississippi River, for the Long Term Resource Monitoring Program, 1994-2003. In B (young-of-the-year largemouth bass), catch-per-unit-effort was 0 in 1994, 1996, and 2000 but is not shown because the graph is on a log scale. Note that catch-per-uniteffort values are graphed on a log scale. 

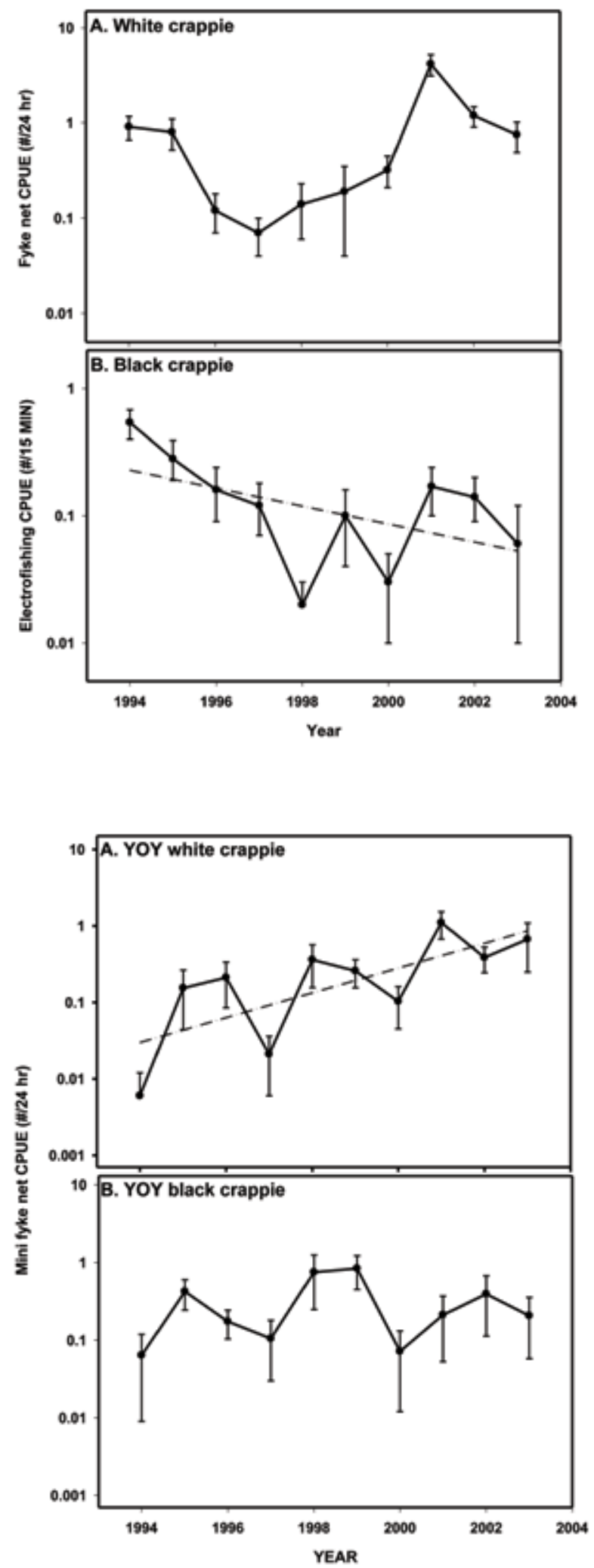

Figure 3. Catch-per-unit-effort values (pool wide mean and standard error) for (A) white crappie (fyke nets), and (B) black crappie (electrofishing), from Pool 26 of the Mississippi River, for the Long Term Resource Monitoring Program, 1994-2003. Note that catch-per-unit-effort values are graphed on a log scale.
Figure 4. Catch-per-unit-effort values (pool wide mean and standard error) for (A) young-of-the-year white crappie, and (B) young-ofthe-year black crappie, for mini fyke nets, from Pool 26 of the Mississippi River, for the Long Term Resource Monitoring Program, 1994-2003. Note that catch-perunit-effort values are graphed on a log scale. 


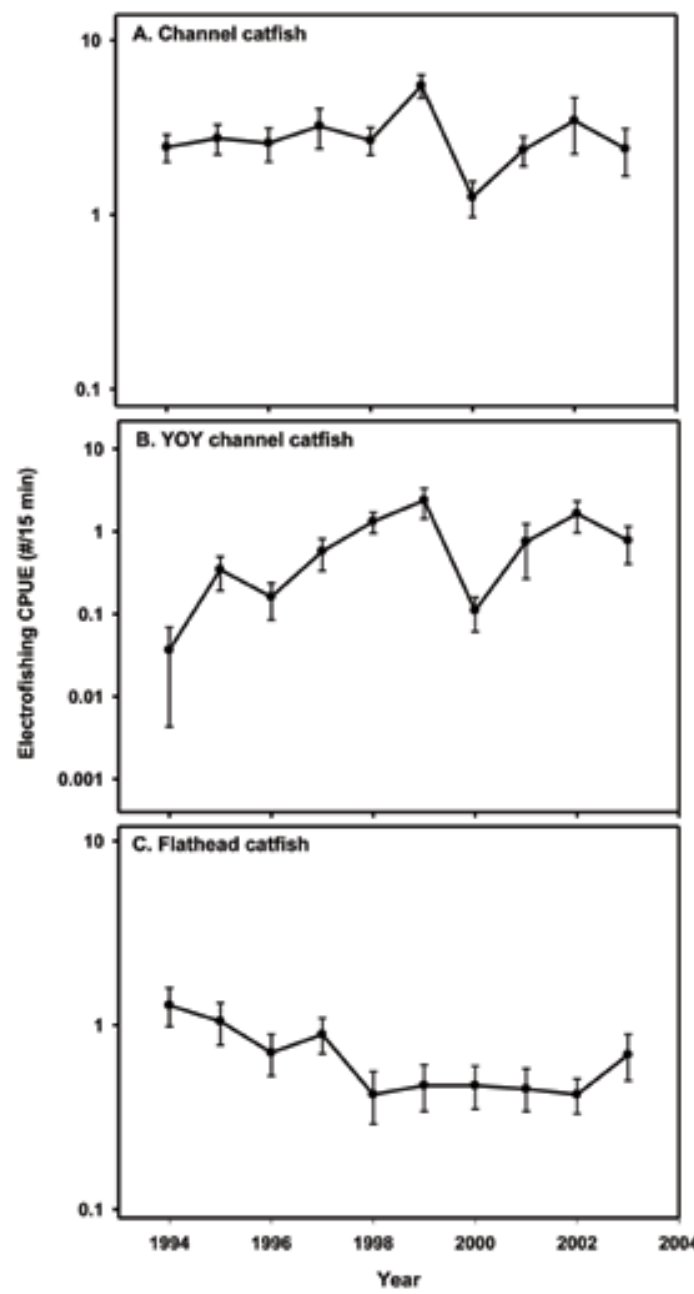

Figure 5. Catch-per-unit-effort values (pool wide mean and standard error) for (A) channel catfish, (B) young-of-the-year channel catfish, and (C) flathead catfish, for electrofishing, from Pool 26 of the Mississippi River, for the Long Term Resource Monitoring Program, 1994-2003. Note that catch-per-uniteffort values are graphed on a log scale.
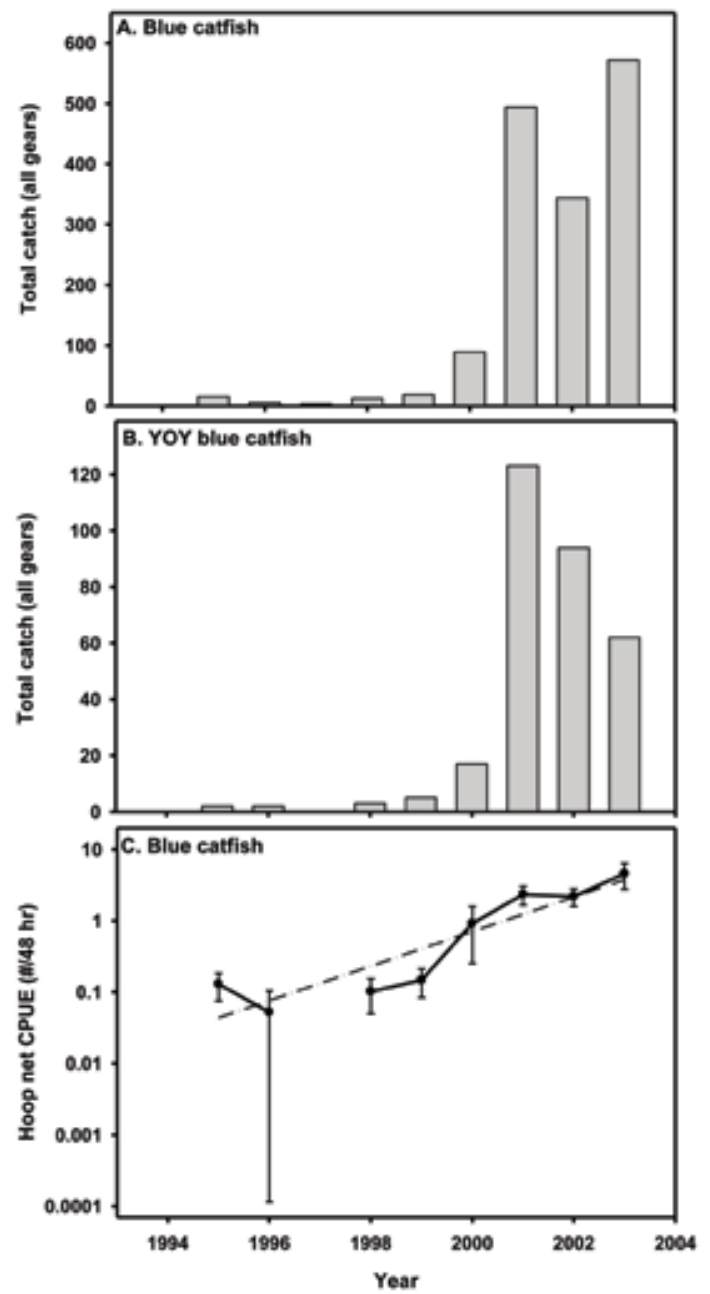

Figure 6. Annual total catch by all gears for (A) blue catfish, (B) young-of-theyear blue catfish, and, catchper-unit-effort values (pool wide mean and standard error) for (C) blue catfish (paired 2-ft and 4-ft hoop nets), from Pool 26 of the Mississippi River, for the Long Term Resource Monitoring Program, 1994-2003. Note that catch-per-unit-effort values are graphed on a $\log$ scale. 
ing trend $\left(\mathrm{F}_{1},{ }_{8}=30.02, \mathrm{R}^{2}=0.79, \mathrm{P}<0.001\right)$, where catch/48 hours remained close to zero until 2000-2003 when it ranged from about 1 to 4.5 fish/48 hours (Fig. 6C). There was a similar increase in total catch of YOY blue catfish (Fig. $6 \mathrm{~B})$ suggesting that reproduction was occurring in Pool 26 and/or in the lower Illinois River.

In addition to the centrarchid and ictalurid fisheries in Pool 26, recreational fisheries also exist for sauger, freshwater drum, and white bass. We caught 667 sauger during the study period, which was a minor portion $(0.23 \%)$ of our total catch (Table 1). Sauger CPUE peaked in 1994 at 1.49 fish/15 minutes, but was lower for the remainder of the study period, ranging from 0.01 to $0.59 \mathrm{fish} / 15$ minutes (Fig. 7A). Freshwater drum and white bass were the 6th and 9th most frequently collected species, respectively, during the study period (Table 1). There were no significant trends for either species during the study period (Figs. 7B and 7C).

\section{Nongame Species}

Gizzard shad, orangespotted sunfish, shortnose gar, emerald shiner, and smallmouth buffalo are the most common native nongame species in our catch. Gizzard shad is numerically the most common fish in our collections, accounting for over a third of our total catch (Table 1). Although annual variation in mean CPUE was great, ranging from approximately 20 to $100 \mathrm{fish} / 15$ minutes of electrofishing, there was no significant trend in gizzard shad abundance during the study period (Fig. 8A). Young-ofthe-year gizzard shad mean annual CPUE also varied greatly (4.1 to 75.0 fish/15 minutes), but did not show a significant trend (Fig. 8B). Orangespotted sunfish appear to be fairly stable aside from a decrease in CPUE in 1995 and a small peak in 1998 (Fig. 9A). Shortnose gar from fyke nets showed a significant increase $\left(\mathrm{F}_{1},{ }_{8}=7.94, \mathrm{R}^{2}=0.50, \mathrm{P}<0.023\right)$ during the study period, with the three highest catch rates (4.7-9.3 fish/24 hours) occurring from 2001-2003 (Fig. 9B). Emerald shiner CPUE increased significantly $\left(\mathrm{F}_{1},{ }_{8}=14.80, \mathrm{R}^{2}=0.65\right.$, $\mathrm{P}<0.005$ ) from less than 2 fish $/ 15$ minutes of electrofishing in 1994, to over 9 fish/15 minutes in 2003 (Fig. 9C). It may be wise for future studies to examine what might be driving this increasing trend in emerald shiners because, in general, emerald shiners are more abundant in the upper three LTRMP regional trend areas (RTA), but gizzard shad are more abundant in the lower three RTA, including Pool 26 (Chick et al. 2005). Smallmouth buffalo mean CPUE by electrofishing declined significantly $\left(\mathrm{F}_{1}\right.$, $\left.{ }_{8}=11.85, \mathrm{R}^{2}=0.60, \mathrm{P}<0.009\right)$, from over 3 fish/15 minutes in 1995, to less than 1 fish/15 minutes in 2002 (Fig. 10A). Young-of-the-year smallmouth buffalo CPUE from electrofishing generally declined during the first half of the study period, then reproduction appears to have become inconsistent, with the three highest and the three lowest YOY CPUE occurring during 1998-2003 (Fig. 10B). Chapter 3 further explores the dynamics of smallmouth buffalo in Pool 26 by dividing buffalo into size categories.

\section{Invasive Species}

Six of the 87 fish species collected during the study period were invasive, accounting for $6.7 \%$ of the total catch. With the exception of one white perch (Morone americana), all 19,147 individuals were Cyprinids native to Asia. Common carp accounted for $6.5 \%$ of the total catch, while bighead carp, grass carp, silver carp, and goldfish combined accounted for $0.2 \%$ of the total catch (Table 1). Common carp mean CPUE from electrofishing reached its lowest level in 2003, while bighead carp, silver carp, and grass carp total catches all reached their highest levels in 2003. There was a significant decline in common carp mean $\operatorname{CPUE}\left(\mathrm{F}_{1},{ }_{8}=13.37, \mathrm{R}^{2}=0.63, \mathrm{P}<0.006\right)$ throughout the study period, from a high of over 20 fish/15 minutes of electrofishing during 1996-1997, to less than 8 fish/15minutes in 2003 (Fig. 11A). This decrease in common carp CPUE was also seen at most of the other LTRMP study reaches, indicating that there was a system-wide decline in common carp during the period (Ickes et al. 2005a). Young-of-theyear common carp CPUE ranged from 0.08 fish/15 minutes in 2001, to 3.6 fish/15 minutes in 2003, but there was no significant trend in YOY common carp abundance over the study period (Fig. 11B). Since 1991 when bighead 


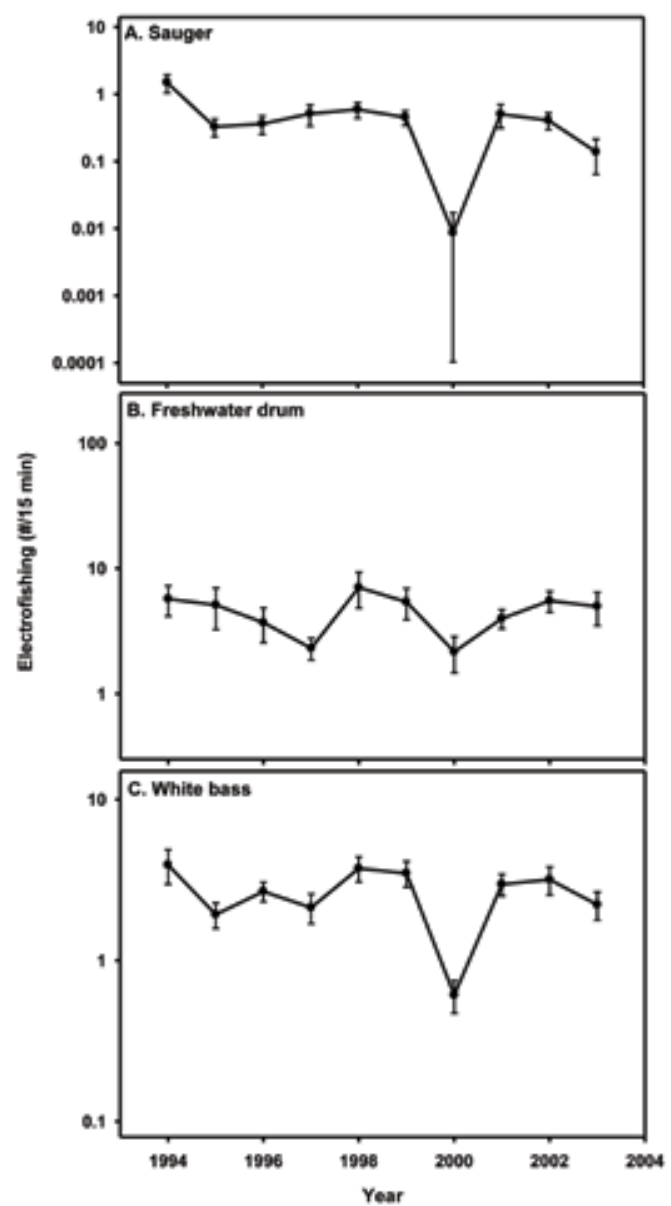

Figure 7. Catch-per-unit-effort values (pool wide mean and standard error) for (A) sauger, (B) freshwater drum, and (C) white bass, for electrofishing, from Pool 26 of the Mississippi River, for the Long Term Resource Monitoring Program, 1994-2003. Note that catch-perunit-effort values are graphed on a $\log$ scale.

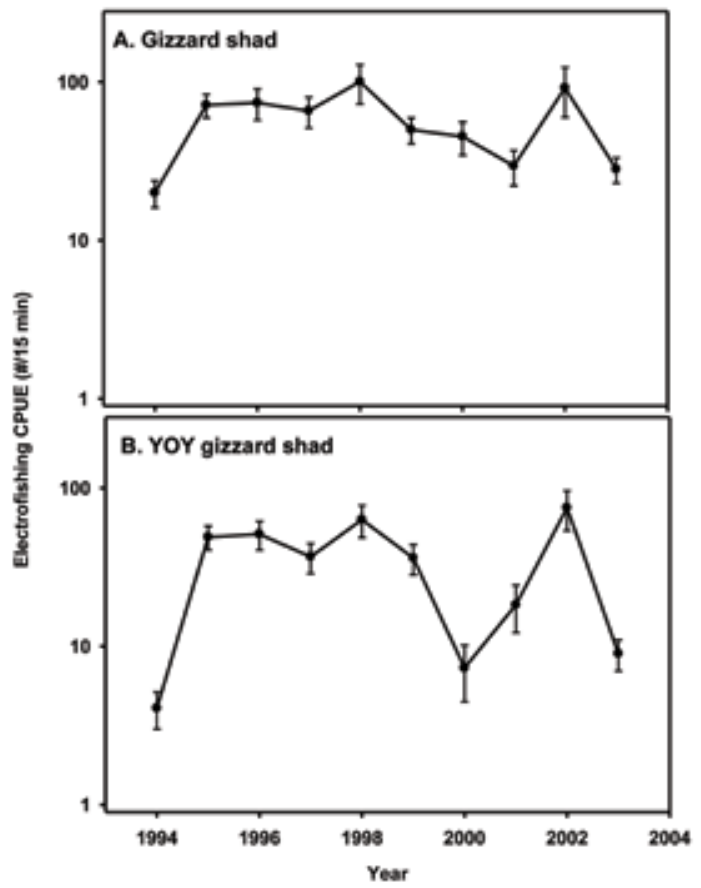

Figure 8. Catch-per-unit-effort values (pool wide mean and standard error) for (A) gizzard shad, and (B) young-of-the-year gizzard shad, for electrofishing, from Pool 26 of the Mississippi River, for the Long Term Resource Monitoring Program, 1994-2003. Note that catch-per-unit-effort values are graphed on a log scale. 


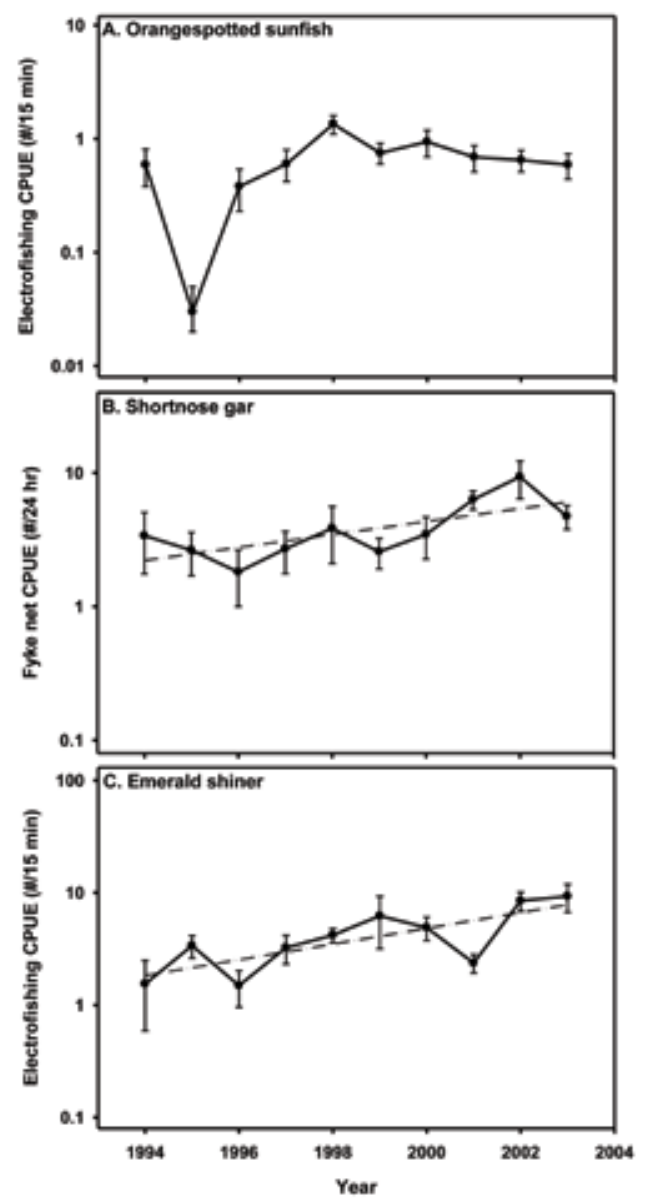

Figure 9. Catch-per-unit-effort values (pool wide mean and standard error) for (A) orangespotted sunfish, for electrofishing, (B) shortnose gar, for fyke nets, and (C) emerald shiner for electrofishing, from Pool 26 of the Mississippi River, for the Long Term Resource Monitoring Program, 1994-2003. Note that catch-per-unit-effort values are graphed on a log scale.

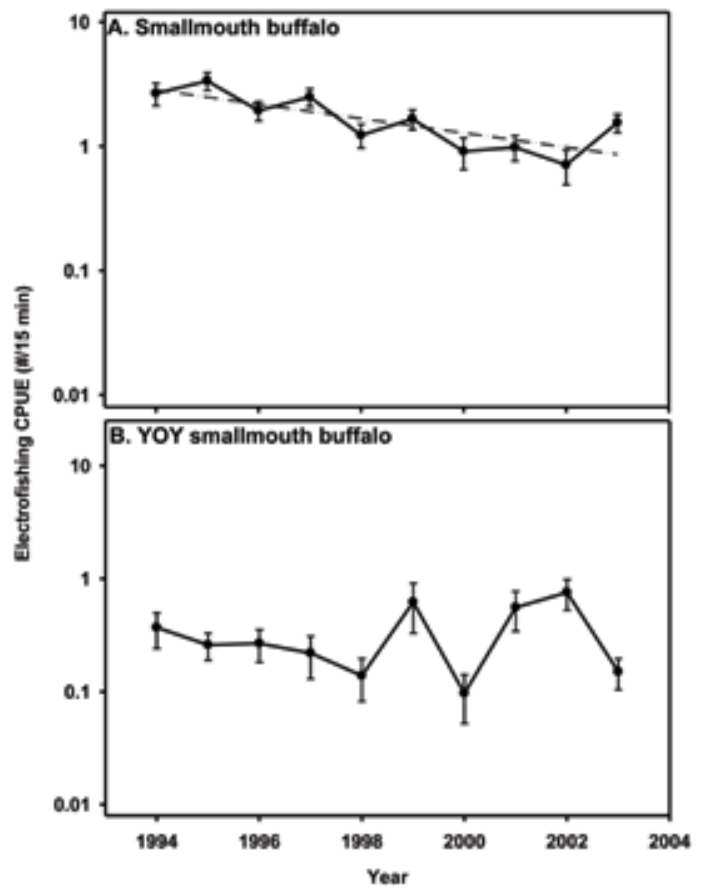

Figure 10. Catch-per-unit-effort values (pool wide mean and standard error) for (A) smallmouth buffalo, and (B) young-of-the-year smallmouth buffalo, for electrofishing, from Pool 26 of the Mississippi River, for the Long Term Resource Monitoring Program, 1994-2003. Note that catch-per-unit-effort values are graphed on a log scale. 
carp were first collected in Pool 26, and 1998 when silver carp were first collected, their populations have increased greatly. Because Asian carp are adept at avoiding most of the gear types used by the LTRMP, our catch data provide a crude index of abundance for these species. Nevertheless, our data do suggest a substantial increase in abundance. Total catch of bighead carp increased from 4 fish in 1995 to 97 fish in 2003, and total catch of silver carp increased from 2 fish in 1998 to 14 fish in 2003 (Figs. 12A and 12B). Grass carp total catch also increased during the study period, with the largest catch of 41 fish occurring in 2003 (Fig. 12C).

\section{Reproduction during the $\mathbf{1 9 9 3}$ Flood}

The 1993 flood of the Upper Mississippi River was extreme in both magnitude and duration, reaching $6.1 \mathrm{~m}$ above flood stage at Grafton, IL and remaining above flood stage for 203 days (Ratcliff and Theiling 1994). Several species appear to have produced exceptionally strong year classes, likely by using the expansive spawning and nursery areas created by the flood. Although we observed production of YOY fish in 1993, our dataset was incomplete because river traffic restrictions kept us from sampling Pool 26 during the flood. We were, however, able to approximate reproduction in 1993 by looking at the abundance of fish in length classes in 1994 that should correspond to Age-1. The trend we saw for largemouth bass, black crappie, white bass, and common carp was a higher CPUE of Age-1 fish in 1994 than in any other year during the study, indicating a very successful spawn in 1993. The $95 \%$ confidence interval for 1994 only overlapped with one other year for largemouth bass, white bass, and common carp, and with two other years for black crappie (Figs. 13A-13 D). These approximations of 1993 reproductive success in Pool 26 are consistent with fish collections we were able to make on the lower Illinois River during the 1993 flood. In this LTRMP focused study of three sites near the Illinois River's confluence with Pool 26, YOY largemouth bass, black crappie, and white bass were abundant at all three sites (Maher 1994).
Through analysis of length frequency data in annual LTRMP reports, it is clear that the 1993 year class has declined through time (Bartels et al. 2004a, Bartels et al. 2004b; Burkhardt et al. 1997, Burkhardt et al. 1998, Burkhardt et al. 2000, Burkhardt et al. 2001, Burkhardt et al. 2004a, Burkhardt et al. 2004b; Gutreuter et al. 1997a, Gutreuter et al. 1997b). Similarly, although catch of largemouth bass, black crappie, and white bass increased after the 1993 flood, there is little evidence of a sustained population increase.

\section{Conclusions}

The fish community of Pool 26 is a mix of game, nongame, and invasive species, as can be seen in the total catch for the study period; gizzard shad, emerald shiner, common carp, channel shiner, channel catfish, freshwater drum and bluegill were the most commonly collected species, accounting for $75 \%$ of our total catch. The LTRMP fish sampling design is primarily aimed at community assessment (Ickes et al. 2005a), but Pool 26 monitoring data have been sufficient to show significant population trends in several species (most notably blue catfish and common carp) and in YOY largemouth bass and white crappie (increasing trends). We note that our length cut-offs for YOY fishes should be verified by future length-at-age studies, nonetheless we are confident that our methods are likely to be accurate for major trends or substantial shifts in year-class strength (Appendix D).

The reasons for the dramatic increase in blue catfish in Pool 26 are not obvious. Similar, though not as dramatic, increases in blue catfish are apparent in the data collected from the Open River Reach (river mile 30 to 80; UMESC 2007) so we may be seeing effects from a regional pattern. Though purely speculative, blue catfish may have benefited from the significant increase in main channel water temperature detected by the LTRMP during this time period (see Chapter 1), because the Upper Mississippi River lies within the northern limits of their range. Additionally, blue catfish 


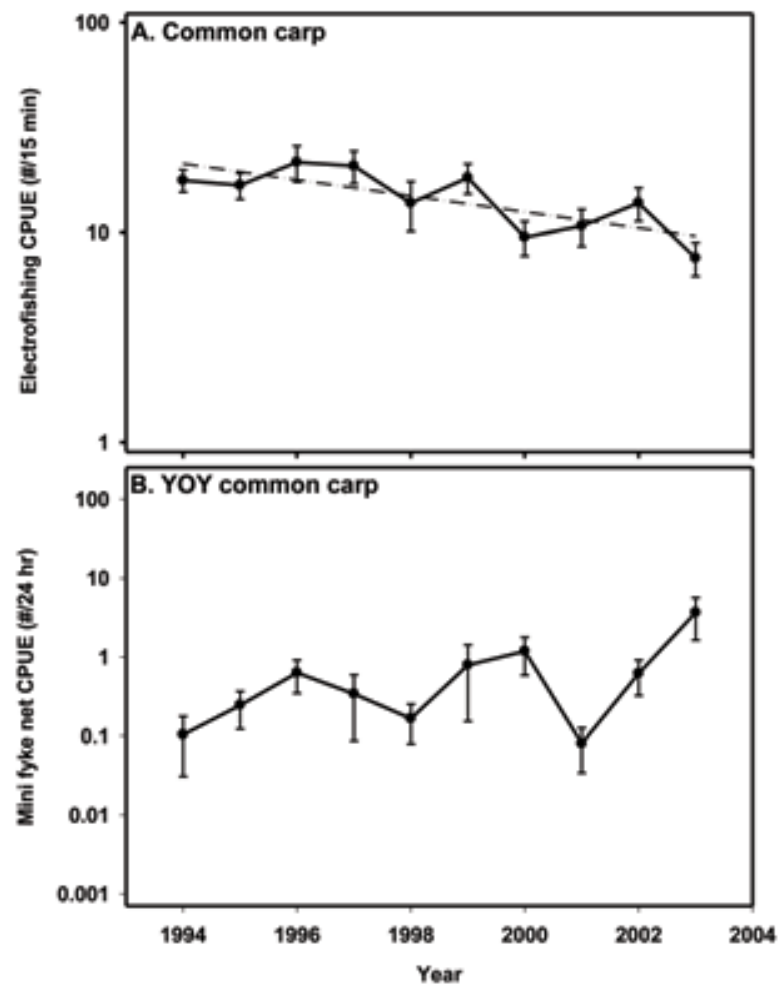

Figure 11. Catch-per-unit-effort values (pool wide mean and standard error) for (A) common carp (electrofishing), and (B) young-of-the-year common carp (mini fyke nets), from Pool 26 of the Mississippi River, for the Long Term Resource Monitoring Program, 1994-2003. Note that catch-per-uniteffort values are graphed on a log scale.

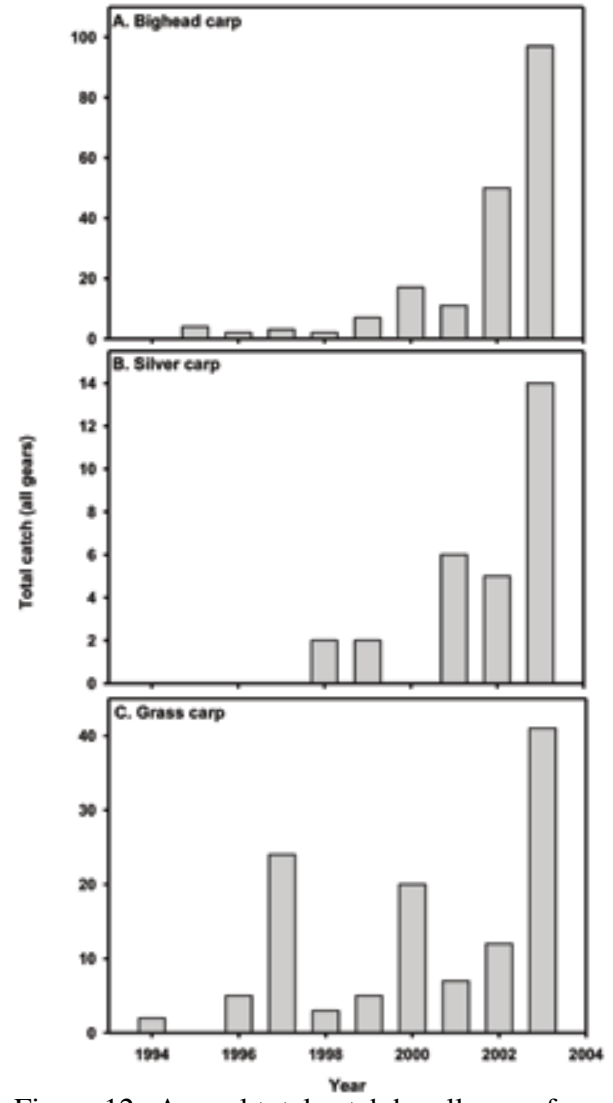

Figure 12. Annual total catch by all gears for (A) bighead carp, (B) silver carp, and (C) grass carp, for Pool 26 of the Mississippi River, for the Long Term Resource Monitoring Program, 1994-2003.

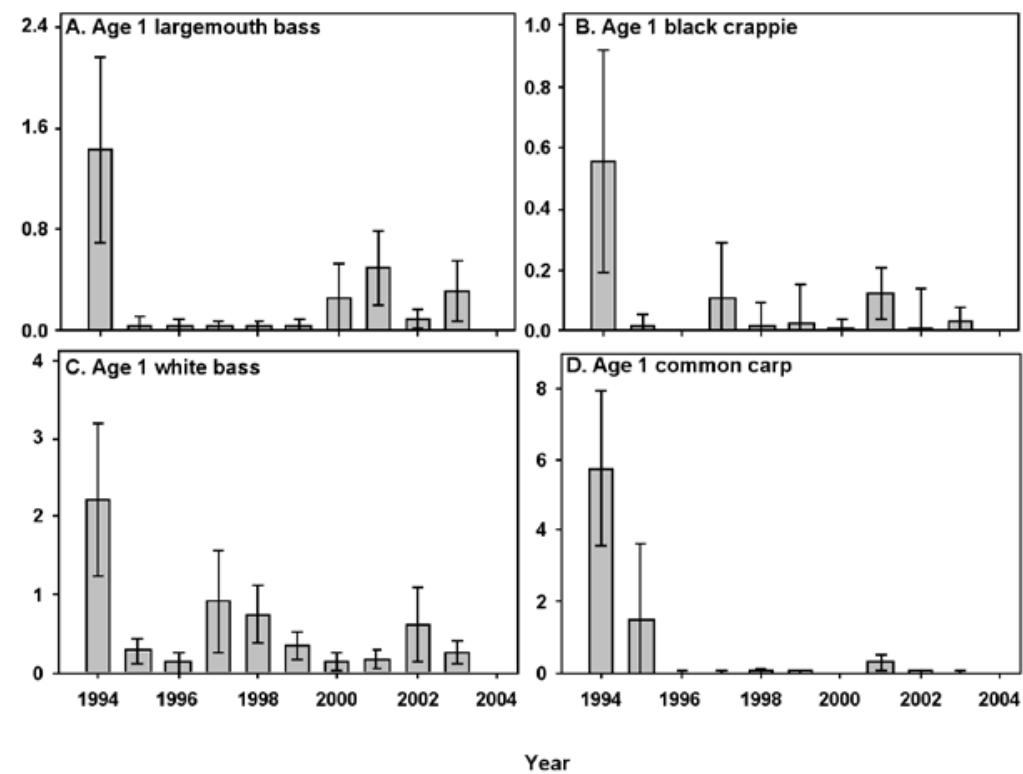

Figure 13. Catch-perunit-effort values (pool wide mean and $\pm 95 \%$ confidence interval) for age-1 (A) largemouth bass, (B) black crappie, (C) white bass, (D) common carp, for electrofishing, from Pool 26 of the Mississippi River, for the Long Term Resource Monitoring Program, 1994-2003. 
are known to move upstream in summer and downstream toward warmer water in winter (Pflieger 1997, Graham 1999). Catfishing tournaments increased during the time period of this study (pers. comm., Suzanne Halbrook, Alton Regional Convention and Visitors Bureau). During these tournaments, most of the reproductively mature blue catfish are caught below Lock and Dam 26 and are then usually released upstream of Lock and Dam 26 due to the weigh-in location. Locks and dams on the Mississippi River do not prevent, but do impede the movements of blue catfish (Coker 1929, Graham 1999), so an increase in catfish tournaments during this period could be influencing the observed increased CPUE of blue catfish in Pool 26.

In addition to detecting several statistically significant trends, LTRMP sampling detected the spread of previously undocumented exotic species in Pool 26 (bighead carp, silver carp, white perch), as well as the continued presence of three other previously established invasive species (common carp, grass carp, goldfish). There was a population explosion of bighead and silver carp in Pool 26 during the study period, and although the standard LTRMP sampling gears are not especially efficient at capturing bighead and silver carp, we were still able to document the spread of these species into Pool 26 and to witness an increase in their catch rates.

The apparent decline in common carp abundance seen during the study period may be linked to the Great Flood of 1993. Like several other species, common carp appear to have had a very successful spawn in 1993, and it is quite possible that their overall abundance has declined as the result of this large cohort of common carp gradually disappearing from the population. Because the LTRMP Pool 26 data were sufficient to show significant trends for both YOY and all ages of several species, it looks promising that further analyses of LTRMP data could yield insight into factors influencing recruitment and reproductive success of fishes in Pool 26. Very successful spawns by largemouth bass, black crappie, and white bass also appeared to have occurred during the Great
Flood of 1993, but there was little evidence of recruitment or sustained population increases for these species. It is logical to assume that the reason several species had especially successful spawns during 1993 was because more flooded terrestrial areas were available for reproduction than in recent history; however, it is difficult to determine whether the apparent peaks in abundance of several species immediately after 1993 were a result of the flood or other factors, because we do not have a comparable dataset for the period prior to the 1993 flood. This illustrates the value of long-term monitoring data. Had data, consistent with the methodology used from 1994 to the present, been available for three to five years prior to the 1993 flood, the LTRMP program would be in a unique position to make inferences about the effects of major floods on the ecology of great rivers. As we continue to strengthen our dataset with annual LTRMP fish collections, we will be better able to explain this and other long-term population trends in the fishes of Pool 26. 


\section{Literature Cited}

Bartels, A., M.C. Bowler, S. DeLain, E.J. Gittinger, D.P. Herzog, K.S. Irons, K. Mauel, T.M. O'Hara, and E. Ratcliff. 2004a. 2002 annual status report: a summary of fish data in six reaches of the Upper Mississippi River system. U.S. Geological Survey, Upper Midwest Environmental Sciences Center, La Crosse, Wisconsin. Web-based report LTRMPP 2004-W001 available online at: http://www.umesc.usgs.gov/reports_publications/LTRMPp/fish/ 2002/fish-srs.html.

Bartels, A., S. DeLain, K. Mauel, M.C. Bowler, E.J. Gittinger, E. Ratcliff, D. Herzog, K. Irons, T.M. O'Hara, and D. Ostendorf. 2004b. 2003 annual status report: a summary of fish data in six reaches of the Upper Mississippi River system. U.S. Geological Survey, Upper Midwest Environmental Sciences Center, La Crosse, Wisconsin. Web-based report LTRMPP 2004-W004 available online at: http://www.umesc.usgs.gov/reports_ publications/LTRMPp/fish/2003/fish-srs. html.

Bernstein, N.P., and J.R. Olson 2001. Ecological problems with Iowa's invasive and introduced fishes. Journal of the Iowa Academy of Science 108(4):185-209.

Burkhardt, R.W., S. Gutreuter, M. Stopyro, A. Bartels, E. Kramer, M.C. Bowler, F.A. Cronin, D.W. Soergel, M.D. Petersen, D.P. Herzog, K.S. Irons, T.M. O'Hara, K.D. Blodgett, and P.T. Raibley. 1997. 1996 annual status report: a summary of fish data in six reaches of the Upper Mississippi River system. U.S. Geological Survey, Environmental Management Technical Center, Onalaska, Wisconsin, August 1997. LTRMPP 97-P011. 15 pp. + Chapters 1-6. (NTIS PB97-206387)

Burkhardt, R.W., M. Stopyro, E. Kramer, A. Bartels, M.C. Bowler, F.A. Cronin, D.W. Soergel, M.D. Petersen, D.P. Herzog, T.M. O'Hara, and K.S. Irons. 1998. 1997 annual status report: a summary of fish data in six reaches of the Upper Mississippi River system. U.S. Geological Survey, Environmental Management Technical Center, Onalaska, Wisconsin, June 1998. LTRMPP 98-P008. 15 pp. + Chapters 1-6. (NTIS PB98-159155)
Burkhardt, R.W., S. DeLain, E. Kramer, A. Bartels, M.C. Bowler, F.A. Cronin, M.D. Petersen, D.P. Herzog, T.M. O'Hara, and K.S. Irons. 2000. 1998 annual status report: a summary of fish data in six reaches of the Upper Mississippi River system. U.S. Geological Survey, Upper Midwest Environmental Sciences Center, La Crosse, Wisconsin. LTRMPP 2000-P004. 14 pp. + Chapters 1-6. (NTIS PB2000-106952)

Burkhardt, R.W., S. DeLain, E. Kramer, A. Bartels, M.C. Bowler, E. Ratcliff, D.P. Herzog, K.S. Irons, and T.M. O'Hara. 2001. 1999 annual status report: a summary of fish data in six reaches of the Upper Mississippi River system. U.S. Geological Survey, Upper Midwest Environmental Sciences Center, La Crosse, Wisconsin. LTRMPP 2001-P002. 14 pp. + Chapters 1-6 (NTIS PB2001-107630).

Burkhardt, R.W., S. DeLain, A. Bartels, M.C. Bowler, E. Ratcliff, D.P. Herzog, K.S. Irons, and T.M. O'Hara. 2004a. 2000 annual status report: a summary of fish data in six reaches of the Upper Mississippi River system. U.S. Geological Survey, Upper Midwest Environmental Sciences Center, La Crosse, Wisconsin. Web-based report LTRMPP 2004-W003 available online at: http://www.umesc.usgs. gov/reports_publications/LTRMPp/fish/ 2000/fish-srs.html

Burkhardt, R.W., S. DeLain, A. Bartels, M.C. Bowler, E.J. Gittinger, E. Ratcliff, D.P. Herzog, K.S. Irons, and T.M. O'Hara. 2004b. 2001 annual status report: a summary of fish data in six reaches of the Upper Mississippi River system. U.S. Geological Survey, Upper Midwest Environmental Sciences Center, La Crosse, Wisconsin. Web-based report LTRMPP 2004-W002 available online at: http://www.umesc.usgs.gov/reports_publications/LTRMPp/fish/2001/fish-srs.html.

Carpenter, S.R., and J.F. Kitchell. 1996. The trophic cascade in lakes. Cambridge University Press. New York, N.Y. 
Chick, J.H., B.S. Ickes, M.A. Pegg, V.A. Barko, R.A. Hrabik, and D.P. Herzog. 2005. Spatial structure and temporal variation of fish communities in the Upper Mississippi River System. U.S. Geological Survey, Upper Midwest Environmental Sciences Center, La Crosse, Wisconsin. LTRMPP Technical Report 2005T004. 15 pp. (NTIS PB2005-106535).

Coker, R. 1929. Studies of the common fishes of the Mississippi River at Keokuk. U.S. Department of Commerce Bureau of Fisheries. Fisheries Document No. 1072.

Gammon, J. R., and T. P. Simon. 2000. Variation in a great river index of biotic integrity over a 20 -year period. Hydrobiologia 422/423:291-304.

Graham, K. 1999. A review of the biology and management of blue catfish. American Fisheries Society Symposium 24:37-49.

Gutreuter, S., R. Burkhardt, and K. Lubinski. 1995. Long Term Resource Monitoring Program rocedures: fish monitoring. National Biological Service, Environmental Management Technical Center, Onalaska, Wisconsin. LTRMPP 95-P002-1. 42 pp. + Appendixes A-J.

Gutreuter, S., R.W. Burkhardt, M. Stopyro, A. Bartels, E. Kramer, M.C. Bowler, F.A. Cronin, D.W. Soergel, M.D. Petersen, D.P. Herzog, P.T. Raibley, K.S. Irons, and T.M. O'Hara. 1997a. 1994 annual status report: a summary of fish data in six reaches of the Upper Mississippi River system. U.S. Geological Survey, Environmental Management Technical Center, Onalaska, Wisconsin. LTRMPP 97-P007. 15 pp. + Chapters 1-6. (NTIS PB97-198923).

Gutreuter, S., R.W. Burkhardt, M. Stopyro, A. Bartels, E. Kramer, M.C. Bowler, F.A. Cronin, D.W. Soergel, M.D. Petersen, D.P. Herzog, K.S. Irons, T.M. O'Hara, K.D. Blodgett, and P.T. Raibley. 1997b. 1995 annual status report: a summary of fish data in six reaches of the Upper Mississippi River system. U.S. Geological Survey, Environmental Management Technical Center, Onalaska, Wisconsin. LTRMPP97-P009. 15 pp. + Chapters 1-6. (NTIS PB97-205827).
Holland, L.E. 1986. Distribution and early life history of fishes in selected pools of the upper Mississippi River. Hydrobiologia 136:121-130.

Ickes, B.S., and R.W. Burkhardt. 2002. Evaluation and proposed refinement of the sampling design for the Long Term Resource Monitoring Program's fish component. U.S. Geological Survey, Upper Midwest Environmental Sciences Center, La Crosse, Wisconsin. LTRMPP 2002-T001. 17 pp. + Appendixes A-E. CD-ROM included. (NTIS \# PB2003500042).

Ickes, B.S., M.C. Bowler, A.D. Bartels, D.J. Kirby, S. DeLain, J.H. Chick, V.A. Barko, K.S. Irons, and M.A. Pegg. 2005a. Multiyear synthesis of the fish component from 1993 to 2002 for the Long Term Resource Monitoring Program. U.S. Geological Survey, Upper Midwest Environmental Sciences Center, La Crosse, Wisconsin. LTRMPP 2005-T005. 60 pp. + CD-ROM (Appendixes A-E). (NTIS PB2005-107572).

Ickes, B.S., J. Vallazza, J. Kalas, and B. Knights. 2005b. River floodplain connectivity and lateral fish passage: a literature review: U.S. Geological Survey, Upper Midwest Environmental Sciences Center, La Crosse, Wisconsin, June 2005, 25 pp.

Laird, C.A., and L.M. Page. 1996. Non-native fishes inhabiting the streams and lakes of Illinois. Illinois Natural History Survey Bulletin 35(1)1-51.

Lubinski, K.S., A. Van Vooren, G. Farabee, J. Janecek, and S.D. Jackson. 1986. Common carp in the Upper Mississippi River. Hydrobiologia 136:141-154.

Lubinski, K., R. Burkhardt, J. Sauer, D. Soballe, and Y. Yin. 2001. Initial analyses of change detection capabilities and data redundancies in the Long Term Resource Monitoring Program. U.S. Geological Survey, Upper Midwest Environmental Sciences Center, La Crosse, Wisconsin. LTRMPP 2001-T001. 
Maher, R. 1994. Observations of fish community structure and reproductive success in flooded terrestrial areas during an extreme flood on the Lower Illinois River. Pages 95-115 in National Biological Service, Illinois Natural History Survey, Iowa Department of Natural Resources, and Wisconsin Department of Natural Resources. LongTerm Resource Monitoring Program 1993 flood observations. National Biological Service, Environmental Management Technical Center, Onalaska, Wisconsin. LTRMPP 94-S011. 190 pp.

Maher, R. 2005. 2003 commercial catch report exclusive of Lake Michigan. Illinois Department of Natural Resources. 20 pp.

Pflieger, W.L. 1997. The fishes of Missouri. Missouri Department of Conservation, Jefferson City.

Pitlo, J. Jr., A. Van Vooren, and J. Rasmussen. 1995. Distribution and relative abundance of Upper Mississippi River fishes. Upper Mississippi River Conservation Committee, Rock Island, Illinois.

Ratcliff, E.N., and C.H. Theiling 1994. Water quality characteristics during and prior to an extreme flood on the Lower Illinois River. Pages 171-190 in National Biological Service, Illinois Natural History Survey, Iowa Department of Natural Resources, and Wisconsin Department of Natural Resources. Long-Term Resource Monitoring Program 1993 flood observations. National Biological Service, Environmental Management Technical Center, Onalaska, Wisconsin. LTRMPP 94-S011. 190 pp.

Robins, C.R., C.E. Bond, J.R. Brooker, E.A. Lachner, R.N. Lea, and W.B. Scott. 1991. Common and scientific names of fishes from the United States and Canada. 5th edition. Special Publication 20. American Fisheries Society, Bethesda, Maryland. 183 pp.

Sampson S.J. 2005. Dietary overlap between two Asian carp and three native filter feeding fishes of the Illinois and Mississippi rivers. Master's Thesis, Department of Natural Resources and Environmental Sciences, University of Illinois, Champaign-Urbana.
Schiemer, F. 2000. Fish as indicators for the assessment of ecological integrity of large rivers. Hydrobiologia 422/423:271-278.

Schmutz, S., M. Kaufmann, B. Vogel, M. Jungwirth, and S. Muhar. 2000. A multi-level concept for fish-based, river-type-specific assessment of ecological integrity. Hydrobiologia 422/423:279-289.

Sheaffer, W.A., and J. G. Nickum. 1986. Backwaters as nursery habitats for fishes in Pool 13 of the Upper Mississippi River. Hydrobiologia 136:131-140.

Sparks, R.E. 1992. Risks of altering the hydrologic regime of large rivers. Pages 119-152 in J. Cairns, Jr., B.R. Niederlehner, and D.R. Orvos, eds. Predicting ecosystem risk: advances in modern environmental toxicology, Volume 20. Princeton Scientific Publishing, Princeton, New Jersey.

Sparks, R.E. 1995. Maintaining and restoring the ecological integrity of the Mississippi River: importance of floodplains and floodpulses. Transactions of the 60th North American Wildlife and Natural Resources Conference.

Sparks, R.E., J.C. Nelson, and Y. Yin. 1998. Naturalization of the flood regime in regulated rivers: the case of the upper Mississippi River. Bioscience 48:706-720.

Summerfelt R.C., P.E. Mauck, and G. Mensinger, 1970. Food habits of carp, (Cyprinus carpio) in five Oklahoma reservoirs. Proceedings, Annual Conference of Southeastern Association of Game and Fish Commissioners 24:352-377.

U.S. Army Corps of Engineers, 1994. Executive summary, economic impacts of recreation on the Upper Mississippi River system. St. Paul District, St. Paul, Minnesota.

UMESC, 2007. Upper Midwest Environmental Sciences Center graphical fish database browser. Available online at: http://www. umesc.usgs.gov/data_library/fisheries/ graphical/randcpue.shtml.

Wilcox, D.B. 1993. An Aquatic habitat classification system for the Upper Mississippi River system. U.S. Fish and Wildlife Service, Environmental Management Technical Center, Onalaska, WI. EMTC 93-T003. 9 pp. + Appendix A. 
Chapter 3: Exploring Fishery Independent (LTRMP) Data as a Tool to Evaluate the Commercial Fishery in Pool 26 of the Mississippi River

Eric J. Gittinger, Rob Maher, Eric N. Ratcliff, and John H. Chick

\begin{abstract}
We used LTRMP fish data and reported commercial harvest data to assess the status of the commercial fishery in Pool 26. We found little evidence to suggest that commercial fishing is severely reducing fish populations in Pool 26 of the Mississippi River. Conversely, with the exception of common carp, which are declining throughout the Upper Mississippi River (UMR), we found that populations of stock-size fish (i.e., fish $\geq$ the approximate length of maturity or harvestable length) of most commercially harvested species have increased or maintained consistent numbers from 1994-2003. Most species we examined had increases in young-of-year (YOY) and/or substock numbers in the last two to three years of the time series, with buffalo and common carp being the notable exceptions. We found a significant increase in the catch-per-unit-effort of stock-size buffalo (three species combined) along with increased commercial harvest, but a significant decrease in the catch per unit effort (CPUE) of substock-size buffalo. Continued collection of LTRMP fish data will be especially useful for continued tracking of the buffalo fishery.
\end{abstract}




\section{Introduction}

Harvesting fish from rivers, lakes, and oceans for sale or trade is a profession that has existed for millennia around the world. The commercialization and modernization of fishing in the nineteenth and twentieth centuries turned a profession of old into billion dollar industries for many countries. Use of satellites, GPS, sonar, bigger and more effective gear and boats, and a greater knowledge of fish behavior has made it possible to more efficiently capture fish (Baelde 2001, Gunderson 1993, Pennington and Stromme 1998). Overfishing is a major challenge to the sustainable management of fisheries, and several commercially harvested fishes such as flatfish (e.g., halibut, sole, and flounder), Atlantic herring (Clupea harengus), Pacific herring (Clupea pallasii), cod (Gadus morhua), walleye (Sander vitreus), and lake trout (Salvelinus namaycush) are or have been driven to historically low population levels by overexploitation (Hilborn 1992, Horwood et al. 1998, Hutchings and Myers 1994, Myers et al. 1997, Radomski 1999, Trumble 1997). Of the 200 commercial fisheries monitored by the Food and Agriculture Organization of the United Nations, 25-33\% are reported as depleted or heavily overexploited (Weber 1995, Angermeier 2007).

Data from commercial catch reports can be a potentially useful tool for fisheries managers to regulate and monitor fish populations (Pennington and Stromme 1998); however, there are several inherent problems when using such data. When catch data from a commercial fishery are used to track abundance of exploited fishes, an increase in catch can be an indication that the population is increasing. All fishing gear, whether used in scientific studies or for commercial or recreational fishing, do not catch all size classes and/or species of fish equally well. Often, little information is known about how these biases affect the relationship between catch from the gear and the actual abundance of the populations of fishes in the environment. In addition to gear and methodological biases, commercial catch can be influenced by market forces (e.g., price of fishes) that in turn can influence fishing effort or intensity, along with the methodology (i.e., gear, habitats fished, etc.) used by commercial fishers (Gunderson 1993, Pennington and Stromme 1998). Because of these factors, catch rates can remain high and even increase as fish populations decrease, potentially leading to disastrous management decisions (Harley et al. 2001, Hilborn and Walters 1992, Hutchings and Myers 1994, Myers et al. 1997).

Other potential confounding factors that may influence catch over time trends are changes in regulations, accuracy of reported data (under reporting for tax/market value reasons, over reporting for regulatory concerns), and economic laws of supply and demand (Fox and Starr 1996). Market demand can lead to a new fishery or the cessation an established fishery (Fox and Starr 1996). A commercial fisherman's catch is driven by profits that are determined primarily by market prices, which can change rapidly with variation in supply and demand. For these reasons, changes in commercial catch may not be directly related to changes in fish abundance. Accurately managing a fishery without data that are free of all these confounding factors is usually a difficult task.

A solution to these problems is fisheryindependent data gathered by scientific surveys. Pennington and Stromme (1998) stated that although scientific surveys are often expensive, they are the most efficient way to monitor commercially valuable species and the anthropogenic impacts on the ecosystem by predicting recruitment, which is necessary to understand the temporal and spatial dynamics of the resource. Survey- or fishery-independent data can serve as a check on fishery catch data for formulating population status and trend indices, and can be valuable information for formulating responsible management strategies for many fisheries around the world (Gunderson 1993, Helser and Hayes 1995, Pennington and Stromme 1998, Peterman 2004). Ideally, scientists would provide stock assessment advice to fisheries managers (and stakeholders) to combine with their management objectives before recommending a particular action (i.e., harvest rate), which affects the entire ecosys- 
tem (R.M. Peterman 2004). Although detailed information on CPUE, length, weight, and age structure of fishes would be optimal, useful information can be gleaned simply from trends in fishery-independent CPUE.

The modernization of commercial fisheries and much of the focus on the management of commercial fisheries is based around marine systems. Aside from a few notable exceptions (e.g., Great Lakes fisheries), most freshwater commercial fisheries are still artisanal and are managed without fishery-independent data. Instead, managers often have to resort to anecdotal evidence or focused studies to evaluate their fisheries or respond to their constituents. Although using commercial harvest data to monitor the commercial fishery is problematic, these data are potentially very valuable for nontargeted species or by catch. Due to the sheer amount time commercial fishers have their nets in the water; they can be a great resource for detecting a new species or a significant increase in a nontargeted species. Good examples of this are commercial fisherman catching the first black carp (Mylopharyngodon piceus) in the United States (Chick et al. 2003), detecting the presence and then dramatic increase of exotic species such as the grass and Asian carp throughout much of the Mississippi and Illinois rivers, and the increase of blue catfish in Pool 26 of the Mississippi River.

Commercial fisheries in the Mississippi River are an excellent example of the artisanal fisheries typical of many freshwater ecosystems. Although both Illinois and Missouri have commercial fisheries on the Mississippi River, annual harvest in Pool 26 by Missouri commercial fishes is only $2-3 \%$ of the harvest from Illinois commercial fishers (unpublished data provided by Missouri Department of Conservation, Vince Travnichek). Therefore, we only used commercial harvest data from the Illinois Department of Natural Resources for this study. The state of Illinois issues approximately 1,400 commercial fishing licenses annually. Of these, approximately 350 either sell fish for money or catch over 1,000 lbs and are defined as full or part-time commercial fishers (Williamson 1995, Williamson 2000; Maher 2001, Maher 2005).
The annual reported commercial harvest for the state is often around 6-7 million pounds of fish with an estimated wholesale value of $\$ 1.5-\$ 1.7$ million (Williamson 1995, Williamson 2000; Maher 2001, Maher 2005). The value of the industry is even greater once the fish flesh is sold a second time in stores and restaurants throughout the state. This value will only increase through time as the marine fisheries around the world become more depleted.

The 580 miles of the Mississippi River that border Illinois make a significant contribution to the commercial fishing industry in Illinois. Approximately $48 \%$ of the full and part-time commercial fishers in the state fish these waters and they typically account for approximately $65 \%$ of the annual sales in the state (Williamson 1995 - Williamson 2000; Maher 2001 Maher 2005). The 41 miles of the Mississippi River that comprise Pool 26 also contribute significantly to the state's commercial fishery. Pool 26 is a unique part of the Upper Mississippi River System (UMRS), housing the last in a series of 26 dams starting in Minnesota and ending in Alton, Illinois. The pool contains the confluence of the Illinois River and is just upstream from the Missouri River's confluence, where river dynamics change dramatically. Annually, in Pool 26 there are usually 8-10 full time commercial fishers who report the vast majority of the harvest, this pool accounts for almost $20 \%$ of the Mississippi River annual sales, or approximately $13 \%$ of the total annual sales for the state of Illinois (Williamson 1995 - Williamson 2000; Maher 2001 - Maher 2005).

The INHS Great Rivers Field Station has been monitoring fish populations in Pool 26 of the Mississippi River (MR) for the Long Term Resources Monitoring Program (LTRMP) since 1989 (see Chapter 2). Although the program wasn't designed specifically to monitor the commercial fishery or the specific species that are commercially harvested, it was designed to track general trends in populations and habitat use of species that are important to the ecosystem and/or of concern to resource managers (Bartels et al. 2004). Our primary objective was to see if 10 years (1994-2003) of LTRMP 
data from Pool 26 of the Mississippi River could be useful in assessing the health of the commercial fishery. This is just one demonstration of the data available and how managers could use these to help evaluate their commercial fisheries.

\section{Methods}

Commercial harvest data were taken from the annual (1994-2003) Commercial Catch Reports (exclusive of Lake Michigan) for the state of Illinois. These annual reports are an assimilation of harvest reports that each commercial fisher is required to submit to the state to maintain their commercial license. These reports show gear types that are fished, general locations, market prices, and the total harvest of fish flesh in pounds, with no measure of effort. The fish harvest is broken down by species in many cases; blue catfish (Ictalurus furcatus), bowfin (Amia calva), common carp (Cyprinus carpio), channel catfish (Ictalurus punctatus), eel (Anguilla rostrata), flathead catfish (Pylodictis olivaris), freshwater drum (Aplodinotus grunniens), grass carp (Ctenopharyngodom idella), paddlefish (Polyodon spathula) and shovelnose sturgeon (Scaphirhynchus platorynchus). Other harvested fishes are broken down into groups such as: Asian carp (Hypophthalmicthys spp.), buffalo (Ictiobus spp.), bullhead (Ameiurus spp.), carpsuckers (Carpiodes spp.), gar (Lepisosteidae), herring (Hiodontidae) and suckers (Catostomidae). For our study we looked at the following species/groups: channel catfish, blue catfish, flathead catfish, buffalo, common carp, Asian carp, and grass carp. Our primary focus was on the annual harvest (lbs) of fish on Pool 26 of the Mississippi River.

The LTRMP uses a multi-gear approach (six gear types) for monitoring, and a stratified random sampling design, with strata being broad habitat types (main channel, side channel, backwater, and impounded). Sampling occurs over three time periods (TP); TP1 is June 15-July 31 , TP2 is August $1-$ September 15, and TP3 is September 16-October 31. A detailed description of LTRMP protocol and methodology is documented in Gutreuter et al., 1995. For this study, we primarily used the two most effective gear types at capturing the species/groups of fish identified above, as well as results from a statistical power analysis of inter-annual changes in mean catch (Lubinski et al. 2001). The strongest design-based inferences that can be made from LTRMP data are derived from catch-per-unit-efffort (CPUE) data from single gears, where a measure of central tendency (i.e., mean) and variance (i.e., standard error) can be calculated. Electrofishing and hoop net data provided the best information for most of the species/group comparisons we investigated. We sampled 70-72 electrofishing sites per year (1994-2003). Hoop nets are set in pairs with one large and one small net set parallel to each other at each site. For this study we combined the two nets to give us one sample per site (3851 sites sampled per year from 1994-2003). For some species/size classes, no single gear provided adequate data for calculating mean and variance. In these cases, total catch from either a single or combination of all LTRMP gears that were fished consistently in all years and strata were used to make inferences about species trends (e.g., YOY blue catfish are only caught in trawls at a fixed site in the tailwaters of Lock and Dam 25). These data can provide some insight into population trends, but the inferences one can make are not as strong because there is no accounting for effort and no way to assess variance.

We used SAS to calculate annual total catch, mean CPUE, and standard error for each species/group, weighted by strata, from LTRMP data (see Appendix D). We did this for three different size classes: stock size (i.e., fish $\geq$ the approximate length of maturity or harvestable length), substock, and young of the year (YOY; Table 1). Because we are looking at different size classes readers should not expect identical trends for all size classes combined presented in Chapter 2. These size classes were determined from several sources. To determine stock size, we used the Illinois commercial legal size limit of 15 inch $(380 \mathrm{~mm})$ on catfishes, for the remaining species we used a "marketable size" (see Table 1) to determine at what size these fish were harvested (pers. comm., Robert 
Table 1. Specific fish lengths ( $\mathrm{mm}$ ) used to define the three size classes (young of the year (YOY), substock and stock) used for each species in our study. See Appendix D for details on how size criteria for YOY were developed.

\begin{tabular}{llll}
\hline Species/Group & YOY & Substock & Stock \\
\hline Channel Catfish & $<100$ & $100-379$ & $>379$ \\
Blue Catfish & $<140$ & $140-379$ & $>379$ \\
Flathead Catfish & $<140$ & $140-379$ & $>379$ \\
Buffalo & $<150$ & $150-329$ & $>330$ \\
Common Carp & $<140$ & $140-329$ & $>330$ \\
*Bighead Carp & $<230$ & $230-329$ & $>330$ \\
*Silver Carp & $<200$ & $200-329$ & $>330$ \\
Grass Carp & $<210$ & $210-329$ & $>330$ \\
\hline
\end{tabular}

* Grouped as Asian Carp

Maher, Commercial Fishery Program Director, Illinois Department of Natural Resources). YOY size groups were determined through the Von Bertalanffy growth equation and through examination of LTRMP data for length through time (see appendix D). Substock-size groups were fish that did not fit into either the stock or YOY size groups and likely includes several year classes from 1- to 4-year-old fish depending on the species of fish. Although we may have some outliers overlapping in our year class representations for YOY fish, our main purpose is to demonstrate potential stocks that could recruit into the next size class; i.e., YOY to substock, substock to stock-size fishes. To look for temporal trends, we used linear regressions with time as the independent variable (1994 = Time 1, $1995=$ Time 2, etc. $)$ on annual means of CPUE, log-transformed $(\log 10+1)$ to conform to the assumption of linearity and homoscedasticity of error. Regressions were plotted only when significant $(\mathrm{P}<0.05)$, and we plotted untransformed CPUE on a log scale for easier graph interpretation.

\section{Results and Discussion}

For both commercial and LTRMP data, there are a few things that must be considered when assessing potential trends. Although we plotted commercial and LTRMP data on the same graph, we do not necessarily expect the trends to follow one another. For commercially targeted species, a commercial fisher's effort can dramatically increase in response to the market value/demand for fish flesh; thus, population dynamics cannot be estimated using only commercial harvest data due to the lack of any measure of effort and control of the accuracy of reported data. We still find it valuable to plot the data side by side with LTRMP data in an effort to potentially detect dramatic changes in fish populations. For instance, if commercial catch steadily increased over time but was followed by a sharp reduction in harvest and the LTRMP data had been declining over time, we might suggest that the fish population declined to low levels where commercial fishers either could not harvest many fish or populations declined below a threshold where it wasn't profitable to fish for that species of fish.

We also need to consider that these data are a 10-year snap shot (1994-2003) of a much larger picture and the inferences one can make from these data only get better as more years are added. For example, in 1993 a large flood event influenced the whole Upper Mississippi River System, and the flood's influence appears evident in the LTRMP data for several fish species (see Chapter 2). Although we observe several trends that were likely caused by this flood the lack of comparable long-term data taken before the flood prevents us from making strong inferences about the flood's influence on the biotic community. Additionally, several commercially harvested species are long-lived, and 10 years is not sufficient to observe generational shifts or the full influence of strong or weak year classes on population dynamics. With a large, open, highly disturbed, and diverse ecosystem such as the Mississippi River, only long-term data maintained with consistency and precision over the course of decades can form a historical database where the effects of events such as the flood of 1993 can be effectively evaluated. 
Channel Catfish: The commercial harvest of channel catfish peaked at 82,000 and 80,000 lbs harvested in 1994 and 1998, respectively. Aside from those two years, the commercial harvest has steadily decreased from $66,000 \mathrm{lbs}$ in 1995 to a low of $50,000 \mathrm{lbs}$ in 2003 (Fig. 1A). LTRMP electrofishing CPUE (fish per $15 \mathrm{~min}$ ) of stock-size channel catfish peaked at 1.78 in 1994, and a reached a low of 0.73 in 1998, while all other year's CPUEs have fluctuated between 0.88 and 1.35 (Fig. 1A). Both commercial and LTRMP data show that stocksize channel catfish hit highs in 1994 and have shown a small decreasing trend since 1994. The variance around LTRMP means, however, suggests that inferences about declines in channel catfish populations are not strongly supported by these data.

LTRMP electrofishing CPUE of both YOY and substock channel catfish peaked in 1999, followed by low CPUEs of both size groups in 2000 (Fig. 1B). Both size groups again increased after 2000 with YOY appearing to have relatively good years from 2001-2003 (Fig.

1B). Given these data, there appears to be little evidence that the channel catfish population is declining even though commercial harvest has declined. This decline could be due to changes in commercial fishers effort, market value changes of various fish, or perhaps a shift in the commercial catch to other species such as blue catfish (which is sold as "catfish"). In the years 2004-2006, it will be interesting to see if these recent strong year classes recruit into the stocksize channel catfish population.

Blue Catfish: The commercial harvest of blue catfish has increased from 4,800 lbs in 1994 to approximately $21,000-26,000$ lbs by 20022003. In 2000, the blue catfish harvest increased substantially to almost $80,000 \mathrm{lbs}$ (Fig. 2A), almost 20,000 lbs higher than channel catfish that year. From the years 1994-2000, hoop net CPUEs (fish per 48 hours) ranged from 0.0-0.09; the CPUEs increased to 0.11, 0.12 , and 0.17 from 2001 to 2003 with an even larger increase to 0.63 in 2004 (not analyzed here). There was a significant positive trend $\left(\mathrm{F}_{1},{ }_{9}=8.31, \mathrm{R}^{2}=0.48, \mathrm{P}<0.020\right)$ of LTRMP hoop net CPUEs for stock-size blue catfish from 1994-2003 (Fig. 2A).

LTRMP total catch of YOY blue catfish in trawls was < 4 from 1994-1999 but increased to $17,123,94$, and 62 fish from 2000 to 2003

(Fig. 2B). We found a significant increase in substock-size blue catfish using LTRMP hoop net CPUEs, where a low of 0.0 in 1994 increased to a high of 8.8 in $2002\left(\mathrm{~F}_{1},{ }_{9}=41.29\right.$, $\mathrm{R}^{2}=0.82, \mathrm{P}<0.001$; Fig. 2B). LTRMP data, and to a lesser extent commercial harvest, suggest that large numbers of blue catfish have not only moved (likely upstream from open river) into Pool 26 but have also spawned in recent years, thus displaying significant increases in all size classes. It is possible that the increase of blue catfish has led to commercial fishers harvesting less channel and flathead catfish, since all three species are marketed as "catfish."

Flathead Catfish: The commercial harvest of flathead catfish remained relatively steady from 1994 to 2000 ranging from $21,000-28,000 \mathrm{lbs}$ harvested annually, before dramatically decreasing to $13,700 \mathrm{lbs}$ (2001), $7800 \mathrm{lbs}$ (2002), and 11,700 lbs (2003) (Fig. 3A). A regression of stock-size flathead catfish captured in LTRMP hoop nets (CPUE) was not significant. The graph shows stock-size flathead catfish decreasing from 1994-2000 before increasing in the following years (2001-2003), however the 10 -year trend line appears to be relatively flat suggesting the population is relatively constant (Fig. 3A).

Substock flathead catfish CPUE in hoop nets showed a significant $\left(\mathrm{F}_{1},{ }_{9}=4.92, \mathrm{R}^{2}=0.35, \mathrm{P}\right.$ $<0.050$ ) increasing trend from 1994-2003 (Fig. $3 \mathrm{~B})$. YOY flathead catfish do not appear to be well sampled by LTRMP methods, with total catch ranging from 1-4 fish annually. Recent declines in the commercial catch of flathead catfish may be related to the increased availability of blue catfish to commercial fishers rather than a population decline. Given the increase of substock flathead catfish, there should be fish recruiting into the stock-size class in the near future.

(continued on page 379) 
A. Stock size channel catfish

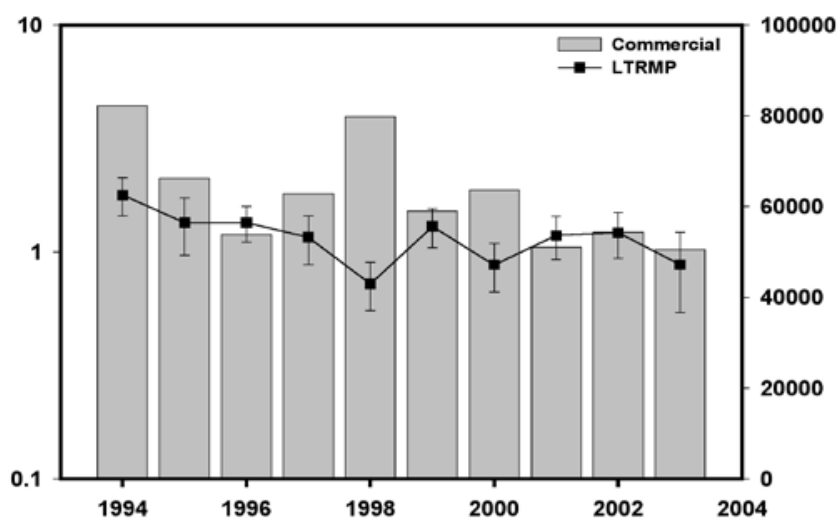

B. LTRMP catch of YoY \& substock channel catfish

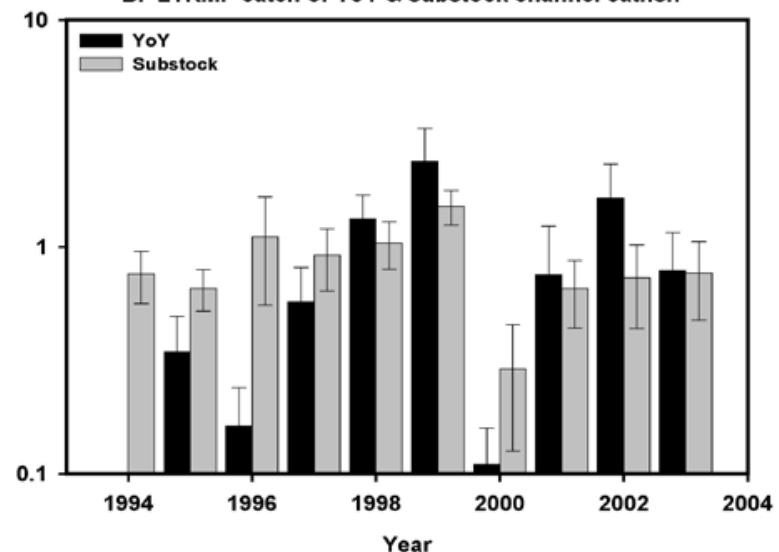

Figure 1. A) Bar graph displaying the total pounds of channel catfish harvested by commercial fishers in Pool 26 on the right axis and a scatter plot (with standard error bars) of LTRMP electrofishing CPUE (fish per $15 \mathrm{~min}$ ) of stock-size channel catfish $(>380 \mathrm{~mm}$ ) in Pool 26 of the Mississippi River from 1994-2003 plotted on a log scale on the left axis. B) Bar graphs (with standard error bars) of LTRMP electrofishing CPUEs of substock (100-379 mm) and YOY $(<100 \mathrm{~mm})$ channel catfish in Pool 26 of the Mississippi River from 1994-2003 plotted on a log scale. 

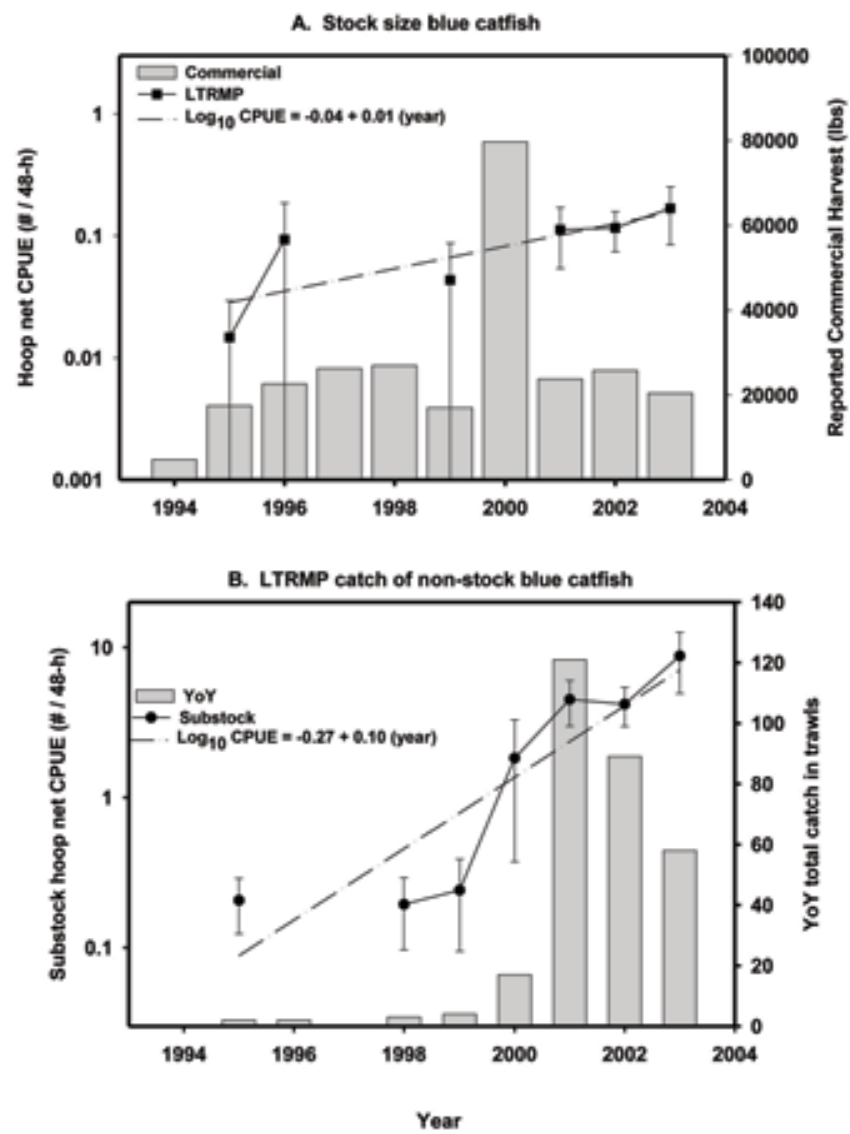

Figure 2. A) Bar graph displaying the total pounds of blue catfish harvested by commercial fishers in Pool 26 on the right axis and a scatter plot (with standard error bars) of LTRMP hoop net CPUE (fish per $48 \mathrm{~h}$ ) of stock-size blue catfish (>380 mm) in Pool 26 of the Mississippi River from 1994-2003 plotted on a log scale on the left axis. Dashed line is a significant regression of the LTRMP data. B) Bar graph displaying total catch of YOY $(<140 \mathrm{~mm})$ blue catfish in LTRMP trawls on the right axis and a scatter plot (with standard error bars) of LTRMP hoop net CPUE (fish per $48 \mathrm{~h}$ ) of substock (140-379 mm) blue catfish in Pool 26 of the Mississippi River from 1994-2003 plotted on a log scale on the left axis. Dashed line is a significant regression of the LTRMP data. 
A. Stock size flathead catfish

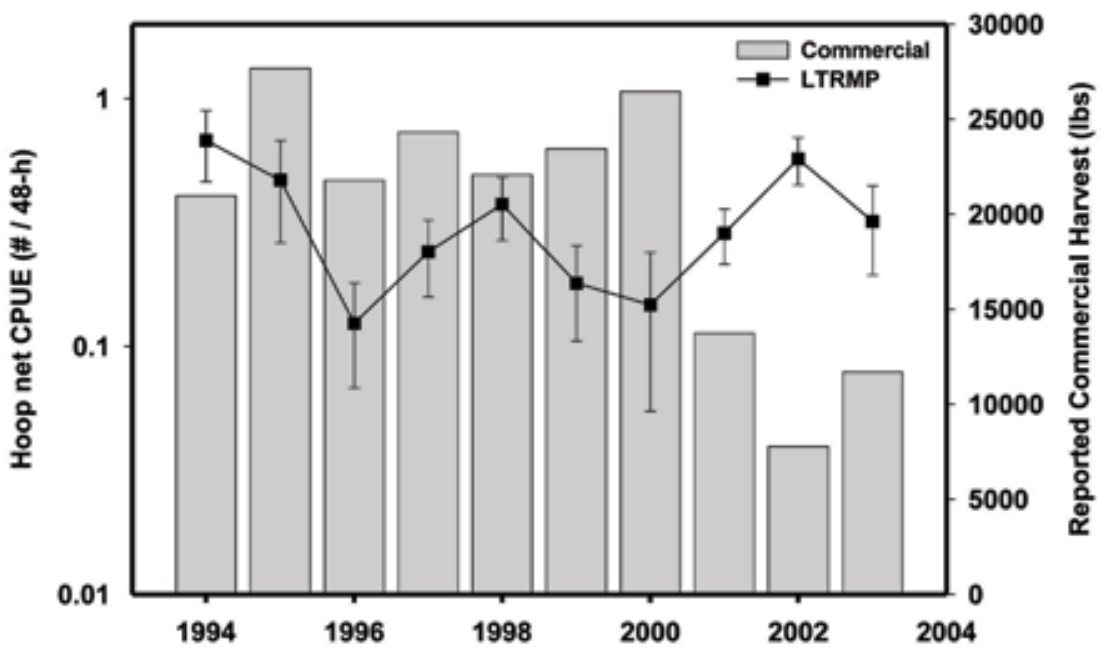

B. LTRMP catch of substock flathead catfish

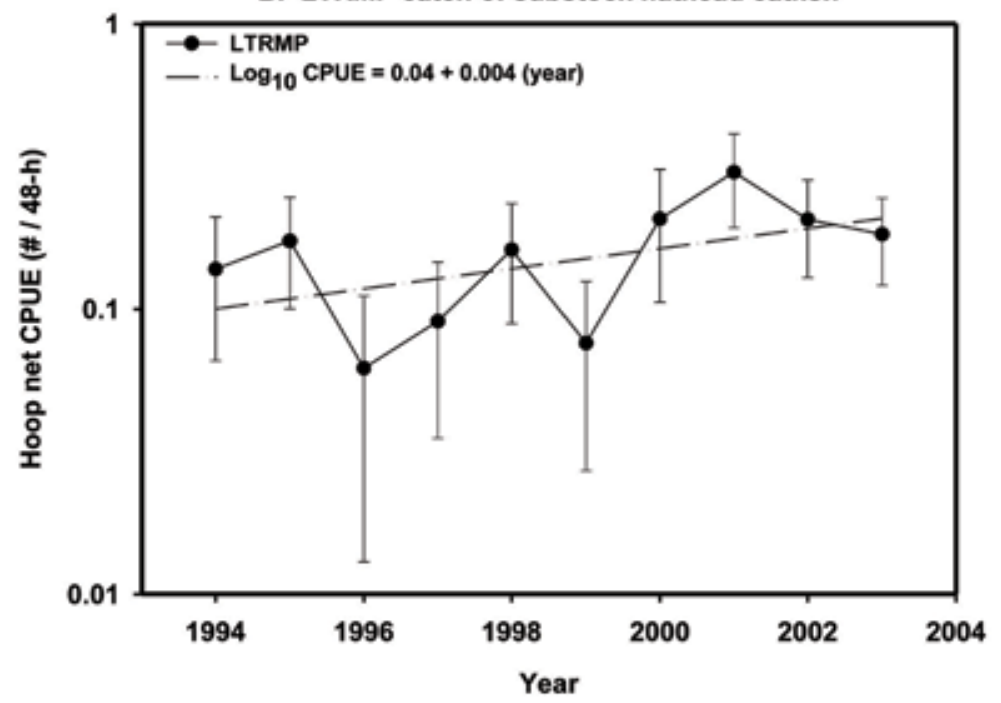

Figure 3. A) Bar graph displaying the total pounds of flathead catfish harvested by commercial fishers in Pool 26 on the right axis and a scatter plot (with standard error bars) of LTRMP hoop net CPUE (fish per $48 \mathrm{~h}$ ) of stock-size flathead catfish (>380 $\mathrm{mm}$ ) in Pool 26 of the Mississippi River from 1994-2003 plotted on a log scale on the left axis. B) Scatter plot (with standard error bars) of LTRMP hoop net CPUE (fish per 48 h) of substock (140-379 mm) flathead catfish in Pool 26 of the Mississippi River from 1994-2003 plotted on a log scale. Dashed line is a significant regression of the LTRMP data. 
Buffalo: The commercial harvest of buffalo doubled from $250,000 \mathrm{lbs}$ harvested in 1994 to a high of $520,000 \mathrm{lbs}$ in 2001 (Fig. 4A). For this study LTRMP data for the three species of buffalo are grouped as one (smallmouth, bigmouth, and black buffalo); however, a quick breakdown of buffalo CPUEs by species shows that smallmouth buffalo were over an order of magnitude higher than bigmouth and black buffalo. LTRMP electrofishing CPUE for stock-size buffalo showed a significant $\left(\mathrm{F}_{1}\right.$, $\left.{ }_{8}=6.41, \mathrm{R}^{2}=0.44, \mathrm{P}<0.030\right)$ increasing trend during the same time that commercial catch was doubling (Fig. 4A). Conversely, substock buffalo electrofishing CPUE substantially decreased from 2.71 and 3.13 in 1994 and 1995 to a low of 0.18 in 2001, showing small increases to 0.42 and 0.83 in 2002 and 2003 (Fig. 4B). Across the 1994 to 2003 time series, there was a significant $\left(\mathrm{F}_{1},{ }_{8}=25.472, \mathrm{R}^{2}=0.76, \mathrm{P}<\right.$ 0.001) negative trend for electrofishing CPUE for substock buffalo (Fig. 4B).

Electrofishing CPUEs for YOY buffalo have been between 0.15 and 0.37 for all years except 1999 (0.62), 2001 (0.57), and 2002 (0.76) (Fig. 4B). It appears the high numbers of substock buffalo present from 1994-1997 recruited into the stock-size population, driving the increasing trend of stock-size buffalo and the increases in commercial harvest. Small decreases in the number of stock-size buffalo from 1998-2003 likely explain the recent declines in the commercial harvest of stock buffalo. Substantially larger YOY buffalo numbers in 1999, 2001, and 2002 appear to be recruiting into substock-size populations during 2002-2003.

Common Carp: Commercial harvest of common carp peaked in 1996 with approximately 90,000 lbs harvested but has since declined to $9,000 \mathrm{lbs}$ in 2003 (Fig. 5A). LTRMP hoop net CPUE data of stock-size common carp significantly $\left(\mathrm{F}_{1},{ }_{9}=11.48, \mathrm{R}^{2}=0.56, \mathrm{P}<\right.$ 0.008 ) declined from a high of approximately 13 fish per $48 \mathrm{hr}$ net set in 1994 to lows < 2 in 1999 and 2001 (Fig. 5A). Other than a small increase in 2000, CPUE has remained low $(\sim 2)$ from 1998-2003. In both the commercial and LTRMP data, it appears that a strong year class was produced during the 1993 flood (see Chapter 2), but stock-sizes of common carp numbers have declined since the mid-nineties.

Electrofishing CPUE for substock common carp also significantly $\left(\mathrm{F}_{1},{ }_{8}=22.32, \mathrm{R}^{2}=0.74\right.$, $\mathrm{P}<0.001$ ) declined from a high 8.5 in 1994 to less than 1.5 from 1996-2003 (Fig. 5B). YOY common carp production appears low from 1994-2000 with electrofishing CPUEs ranging from 0.0 to 0.03 , before increasing to $0.1-0.2$ during 2001-2003 (Fig. 5B). Carp numbers appear to have declined due to poor spawns and recruitment from 1994-2000. Data from 2004-2006 will reveal if the apparent increased production of YOY carp during 2001-2003 will increase populations of substock and stock-size common carp.

Asian Carp: The commercial harvest of stocksize Asian carp was zero in 1994, but harvest increased to 5,000-8,000 lbs from 1995-1999 before jumping to approximately $70,000 \mathrm{lbs}$ harvested in 2000 and 22,000 lbs in 2003 (Fig. 6A). LTRMP electrofishing CPUEs for stocksize Asian carp increased from 0.0 in 1994 to 0.14 in 2001, with an overall significant $\left(\mathrm{F}_{1},{ }_{8}=\right.$ $\left.6.84, \mathrm{R}^{2}=0.46, \mathrm{P}<0.030\right)$ increase across the whole time series (Fig. 6A). Asian carp are not well sampled by LTRMP sampling protocols, and counting silver carp that jump into our boats may be the most effective method for this species. LTRMP sampling collected 18 and 7 stock-size Asian carp in 2002 and 2003, respectively; in those same years, 119 and 106 fish (nearly all silver carp) jumped into our boats hitting people 24 and 41 times. YOY Asian carp total captures in all gears have increased from zero in 1994-1996 to 86 in 2003 (Fig. 6B). Captures of substock Asian carp were zero from 1994-1998 then increased to a high of 5 in 2000; however, this size group appears to be exceptional at avoiding LTRMP sampling gears. LTRMP sampling suggests exponential population growth of Asian carp populations, with our two largest spawning events (2002 and 2003) yet to recruit into the stock-size population.

(continued on page 383) 
A. Stock size buffalo
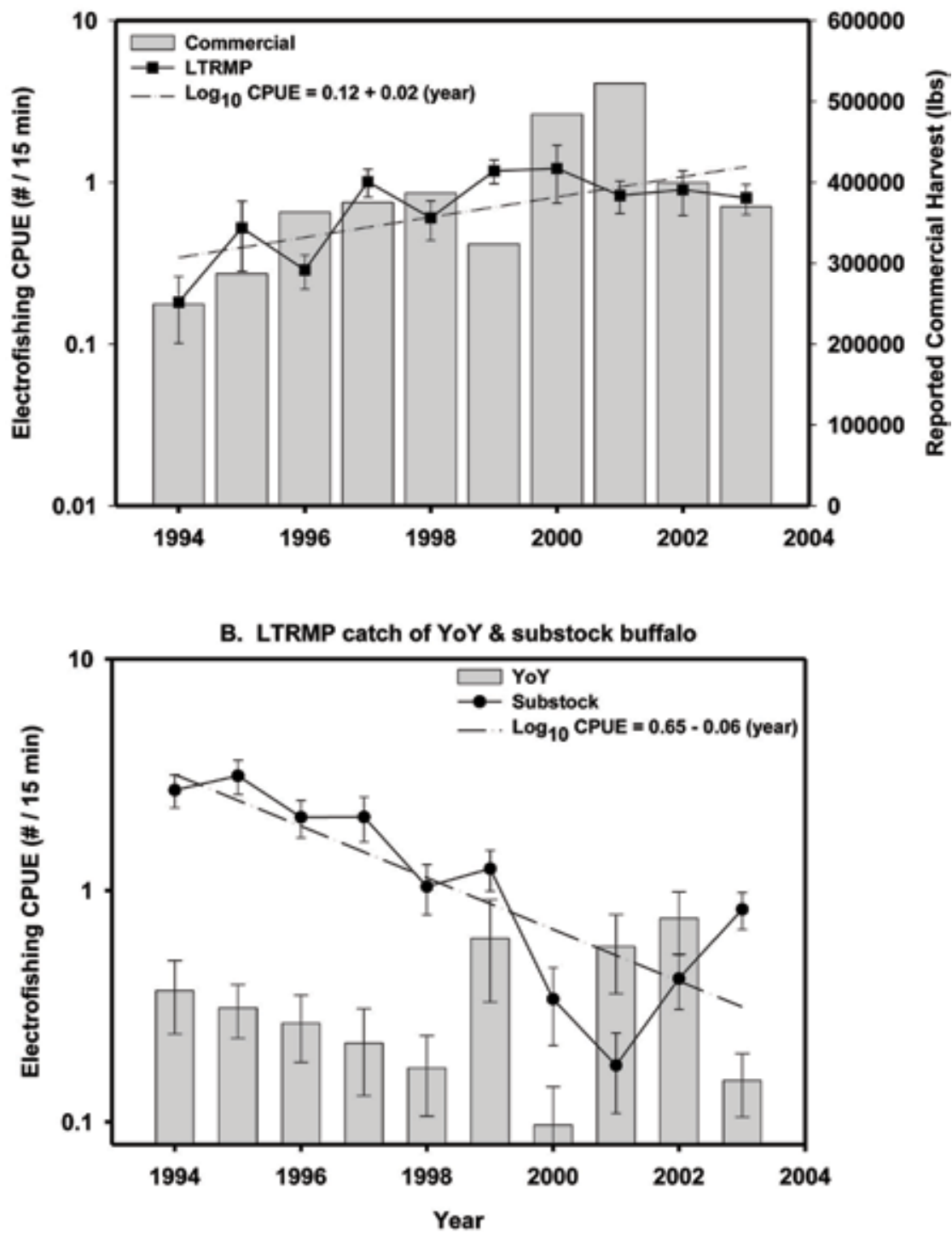

Figure 4. A) Bar graph displaying the total pounds of buffalo harvested by commercial fishers in Pool 26 on the right axis and a scatter plot (with standard error bars) of LTRMP electrofishing CPUE (fish per $15 \mathrm{~min}$ ) of stock-size buffalo $(>330 \mathrm{~mm}$ ) in Pool 26 of the Mississippi River from 1994-2003 plotted on a log scale on the left axis. Dashed line is a significant regression of the LTRMP data. B) Bar graph (with standard error bars) displaying LTRMP electrofishing CPUE (fish per $15 \mathrm{~min}$ ) of YOY (< $150 \mathrm{~mm}$ ) buffalo and a scatter plot (with standard error bars) of LTRMP electrofishing CPUE (fish per $15 \mathrm{~min}$ ) of substock (150-329 mm) buffalo in Pool 26 of the Mississippi River from 1994-2003 plotted on a log scale on the left axis. Dashed line is a significant regression of the LTRMP data. 


\section{A. Stock size common carp}
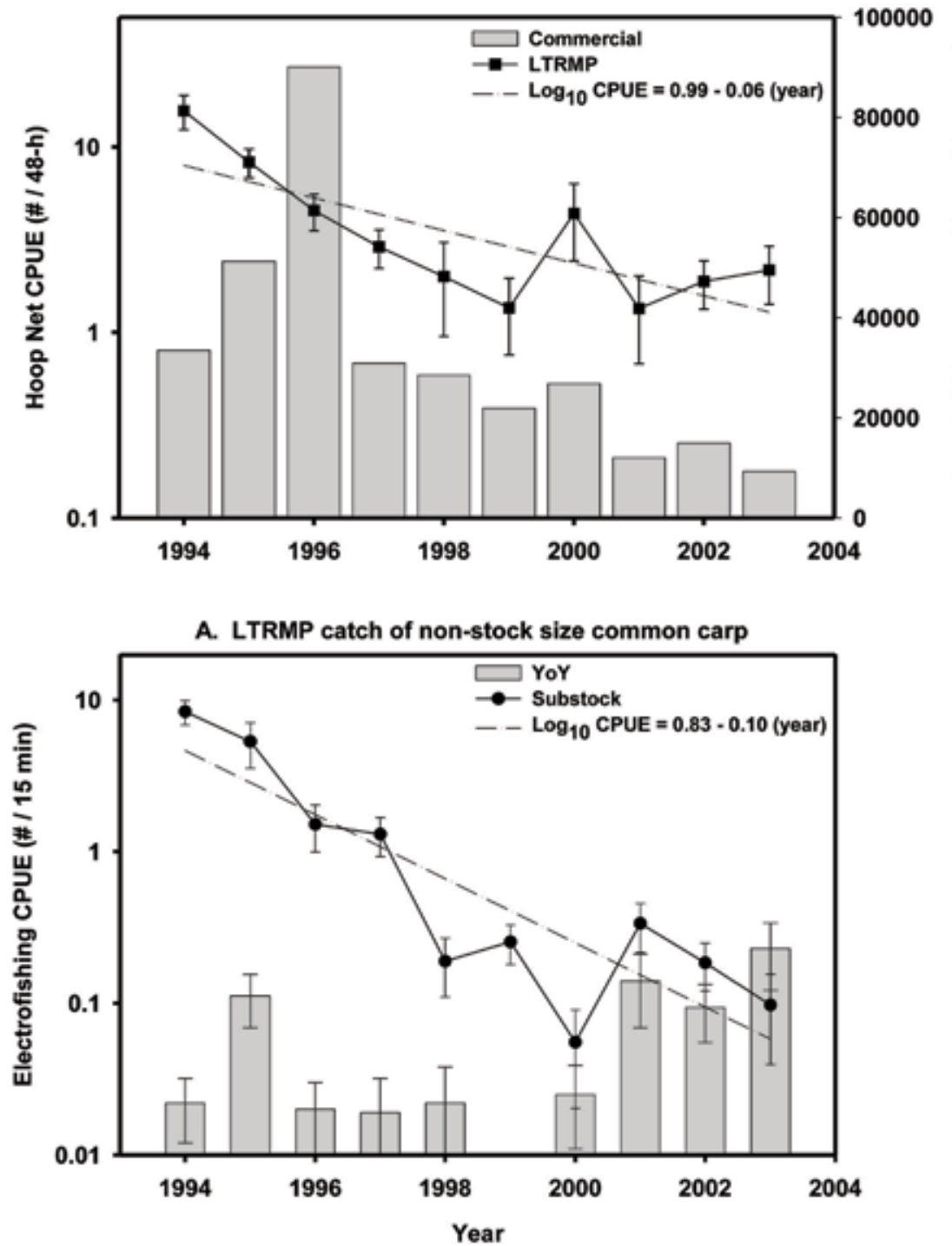

Figure 5. A) Bar graph displaying the total pounds of common carp harvested by commercial fishers in Pool 26 on the right axis and a scatter plot (with standard error bars) of LTRMP hoop net CPUE (fish per $48 \mathrm{~h}$ ) of stock-size common carp (>330 mm) in Pool 26 of the Mississippi River from 1994-2003 plotted on a log scale on the left axis. Dashed line is a significant regression of the LTRMP data. B) Bar graph (with standard error bars) displaying LTRMP electrofishing CPUE (fish per $15 \mathrm{~min}$ ) of YOY $(<140$ $\mathrm{mm}$ ) common carp and a scatter plot (with standard error bars) of LTRMP electrofishing CPUE (fish per $15 \mathrm{~min}$ ) of substock (140-329 mm) common carp in Pool 26 of the Mississippi River from 1994-2003 plotted on a log scale on the left axis. Dashed line is a significant regression of the LTRMP data. 


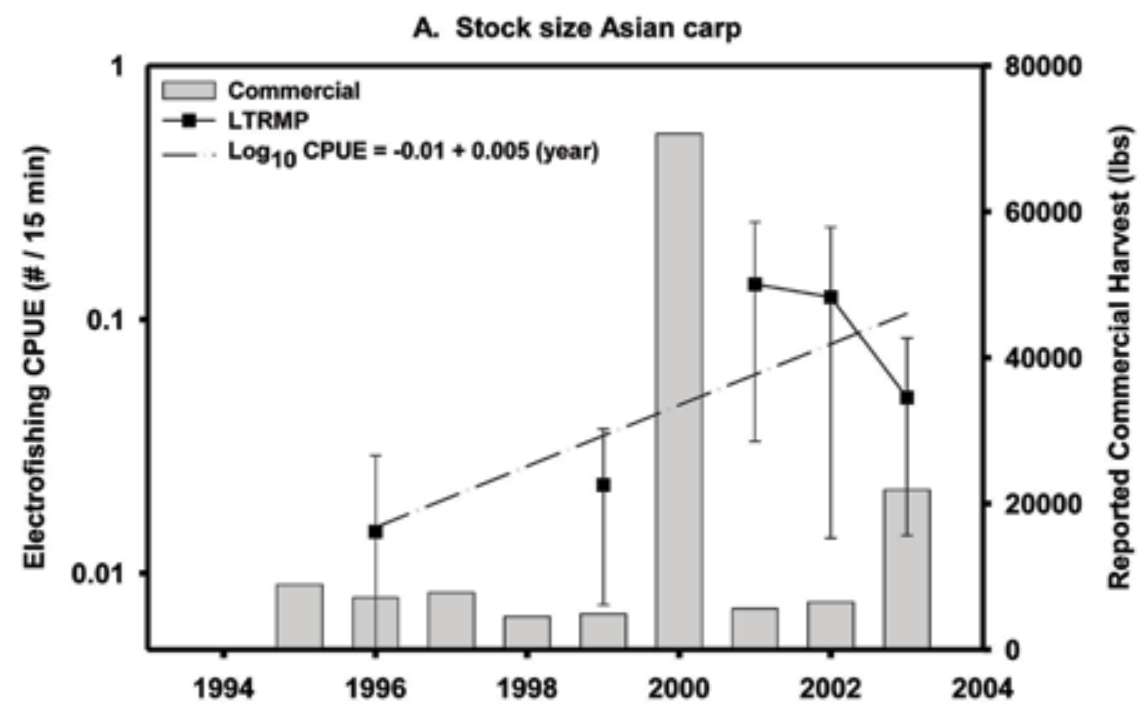

B. LTRMP catch of YoY Asian carp

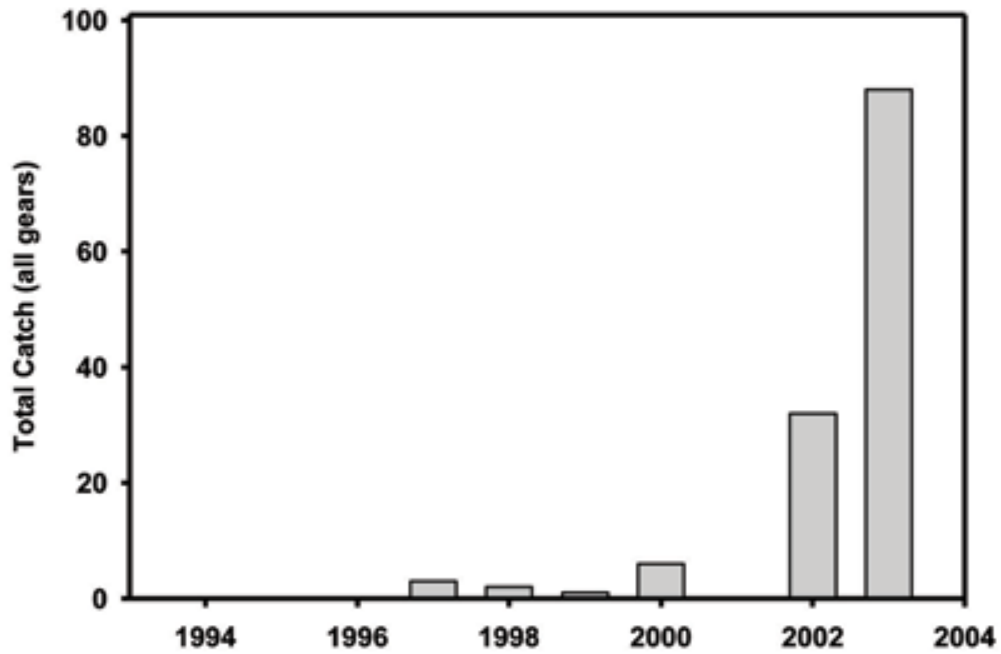

Figure 6. A) Bar graph displaying the total pounds of Asian carp harvested by commercial fishers in Pool 26 on the right axis and a scatter plot (with standard error bars) of LTRMP electrofishing CPUE (fish per $15 \mathrm{~min}$ ) of stock-size Asian carp (>330 mm) in Pool 26 of the Mississippi River from 1994-2003 plotted on a log scale on the left axis. Dashed line is a significant regression of the LTRMP data. B) Bar graph displaying total catch of YOY Asian carp $(<230 \mathrm{~mm}$ bighead carp and $<200 \mathrm{~mm}$ silver carp $)$ in all LTRMP gears in Pool 26 of the Mississippi River from 1994-2003. 
Grass Carp: The commercial harvest of stocksize grass carp has steadily increased from zero fish harvested in 1994 to a high of over 18,000 lbs in 2003 (Fig. 7A). A regression of LTRMP electrofishing CPUE data shows an increase in stock-size grass carp from zero in 1994 and 1995 to a high of 0.11 in $2002\left(\mathrm{~F}_{1},{ }_{8}=6.06, \mathrm{R}^{2}\right.$
$=0.43, \mathrm{P}<0.040)$. YOY grass carp had three peak years with 22 (1997), 14 (2000), and 30 (2003) total fish captured in all gears. All other years had a total YOY catch of 0-2 fish (Fig. 7B). Substock grass carp were rarely captured, ranging from $0-1$ fish/yr. These data suggest grass carp numbers appear to be increasing in Pool 26.

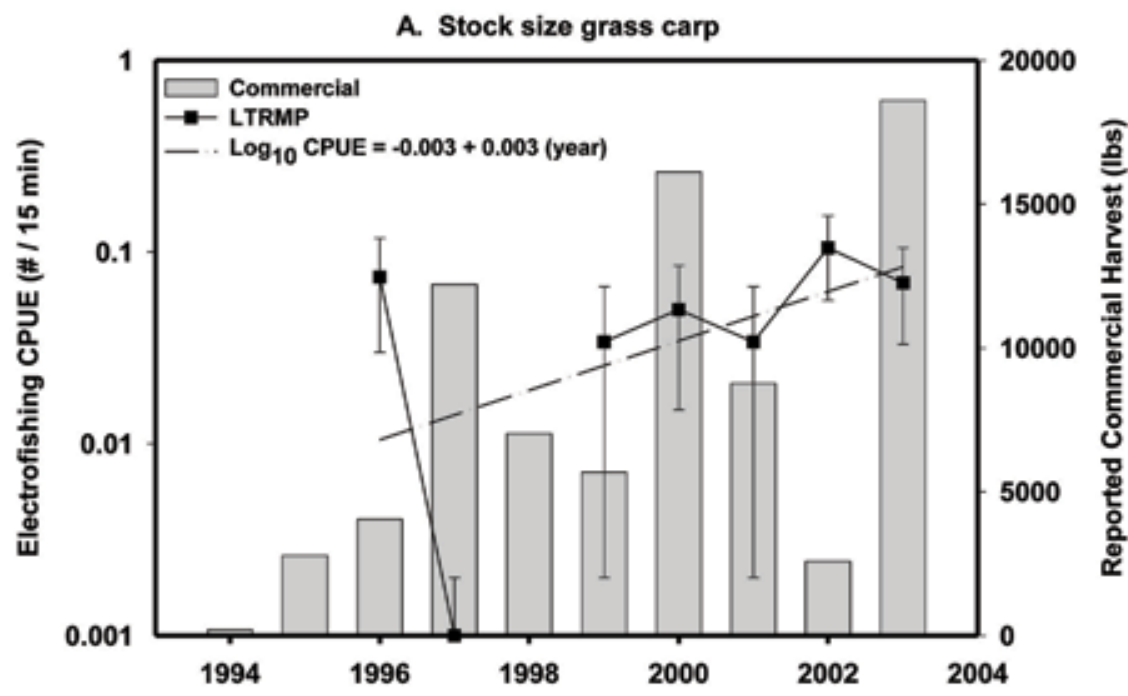

B. LTRMP catch of YoY grass carp

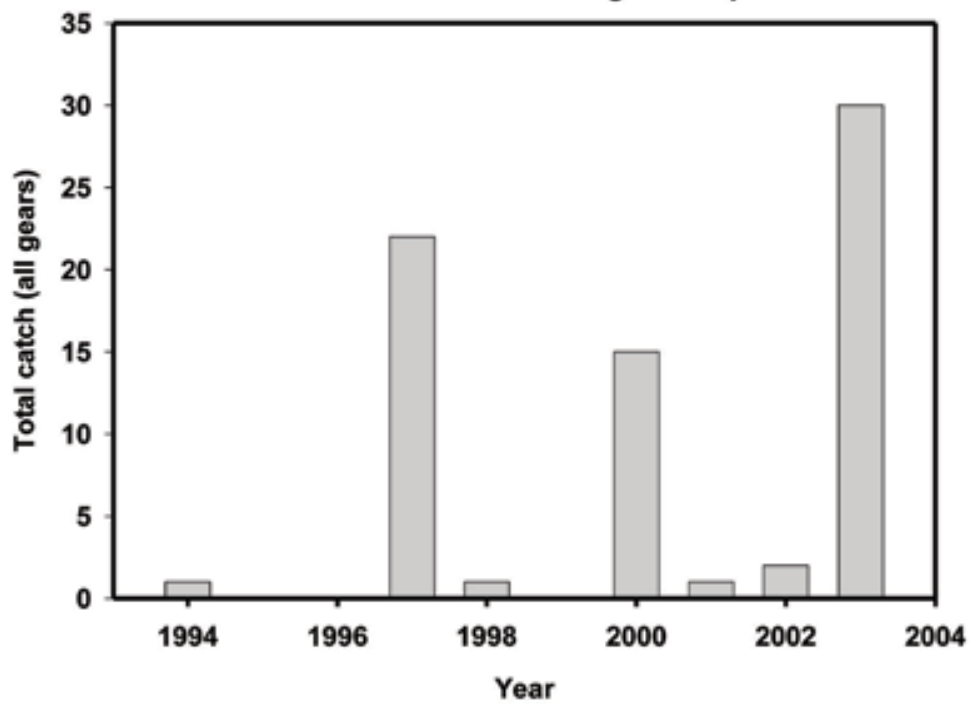

Figure 7. A) Bar graph displaying the total pounds of grass carp harvested by commercial fishers in Pool 26 on the right axis and a scatter plot (with standard error bars) of LTRMP electrofishing CPUE (fish per $15 \mathrm{~min}$ ) of stock-size grass carp (>330 mm) in Pool 26 of the Mississippi River from 1994-2003 plotted on a log scale on the left axis. Dashed line is a significant regression of the LTRMP data. B) Bar graph displaying total catch of YOY grass carp $(<210 \mathrm{~mm})$ in all LTRMP gears in Pool 26 of the Mississippi River from 1994-2003. 


\section{Conclusions}

We found little evidence to suggest that commercial fishing is severely reducing fish populations in Pool 26 of the Mississippi River. Conversely, with the exception of common carp (more on carp below), we find that populations of stock-size fish have increased or maintained relatively consistent numbers from 1994-2003. In the case of buffalo, we find the number of stock-size fish increasing, which has supported a dramatic increase in commercial harvest.

As a whole, we found little evidence that commercially harvested species in Pool 26 were being over exploited, and reproductive patterns for several species suggest they could experience increased numbers of stock-size fish in the near future. Almost all of the species we looked at in this study have shown increases in YOY and/or substock numbers from 2000-2003, with buffalo and common carp being the notable exceptions. Continued sampling will be required over several more years to determine if these year classes recruit to the stock-sized populations of Pool 26. Buffalo substock numbers steadily declined from 1994-2001 with an apparent small rebound during 2002-2003. This trend raises potential concerns if buffalo substock numbers continued to decline while commercial harvest of stocksize buffalo continued to increase. However, Pool 26 is not a closed system and fish like buffalo can migrate in and out of the pool through the locks and dams or up the Illinois River. Looking at the LTRMP CPUE trend (Fig. 4A) for stock-size fish we see the curve flatten from 2001-2003. This could be a result of reduced recruitment from the declining substock population in addition to an increase in commercial harvest during the same time period. Continued monitoring of buffalo numbers is needed to ensure that their populations are sustainable.

We conducted this exploration of data to demonstrate the usefulness of LTRMP data to the management of commercial fisheries, and in detecting recruitment of different size classes of fish to the next level (i.e. YOY > substock $>$ stock). For example, buffalo electrofishing CPUEs for YOY steadily decline from 1994-1998, substock follows suit with a 1-year lag; YOY was lowest in 2000 before significant increases in 2001 and 2002, where substock lagged a year and was lowest in 2001 with sig- nificant increases in 2002 and 2003 (Fig. 4A). From such data we could predict that buffalo substock numbers will decline in 2004 following a poor year of YOY in 2003. We have no sure explanation why the number of stock-size fish has continued to increase while substock numbers have decreased. It is likely a combination of new fish migrating into the pool and a very large year class of substock fish coming out of the 1993 flood with populations not yet reaching equilibrium. We were also able to document apparent substantial increases in the abundance of blue catfish and non-native Asian and grass carp populations.

As was already discussed, predicting population trends based only on commercial harvest data can be misleading because of market and other extrinsic factors that can influence harvest; however, commercial harvest data can be very helpful in detecting large scale events such as migrations or extirpation of species in an area. This is primarily due to the sheer number of hours fished as well as selection of location and gear type that are best to harvest fish. Blue catfish, Asian carp, grass carp, and black carp are an excellent example of the value of commercial harvest data. In all three cases, commercial fishers captured these species in high numbers a year or more before LTRMP data detected them (Figs. 2A, 6A, and 7A). Both the blue catfish and Asian carp commercial harvest jumped significantly in the year 2000 , indicating a new population of adult or stock-size fish (Figs. 2A and 6A). LTRMP data for these same species also detected the apparent migration of these fishes into Pool 26, only lagging by one year. LTRMP data also displays a significant increase in reproduction (YOY fish) of these two species starting after the adult migration in 2000. Only future sampling will determine if these populations will be sustainable in Pool 26.

Our study demonstrates one of the many uses of long-term monitoring data. The sampling design of the LTRMP gives a broad spectrum of data that was useful in assessing population status. Although the focus of the program is to allow for the tracking of populations with CPUE data (e.g., Lubinski et al. 2001), we feel that other uses of LTRMP data, such as tracking size (year) classes within species and migrations of new species into an area, can also be valuable to managers. 


\section{Literature Cited}

Angermeier, P. 2007. The role of fish biologists in helping society build ecological sustainability. Fisheries 32(1):9-20.

Bartels, A., S. DeLain, K. Mauel, M.C. Bowler, E.J. Gittinger, E. Ratcliff, D. Herzog, K. Irons, T.M. O'Hara, and D. Ostendorf. 2004. 2003 annual status report: a summary of fish data in six reaches of the Upper Mississippi River System. U.S. Geological Survey, Upper Midwest Environmental Sciences Center, La Crosse, Wisconsin. Web-based report LTRMP 2004-W004 available online at: http://www.umesc.usgs.gov/reports_publications/ltrmp/fish/2003/fish-srs.html.

Baelde, P. 2001. Fishers's description of changes in fishing gear and fishing practices in the Australian South East trawl fishery. Marine and Freshwater Research 52:411417.

Bednarek, A.T. 2001. Undamming rivers: a review of the ecological impacts of dam removal. Environmental Management 27:803-814.

Chick, J.H., R.J. Maher, B.M. Brooks, and M.R. Thomas. 2003. First black carp captured in the U.S. Science 300:1876-1877.

Dudgeon, D. 1992. Endangered ecosystems: a review of the conservation status of tropical Asian rivers. Hydrobiologia 248:167-191.

Dufford, D.W. 1994. 1993 Commercial catch report, exclusive of Lake Michigan. Commercial Fishing Program, Illinois Department of Natural Resources, Brighton, Illinois.

Fox, D.S., and R.M. Starr. 1996. Comparison of commercial fishery and research catch data. Canadian Journal of Fisheries and Aquatic Sciences 53:2681-2694.

Gunderson, D.R. 1993. Surveys of fisheries resources. Wiley, New York, New York. 248 pp.

Gutreuter, S., R. Burkhardt, and K. Lubinski. 1995. Long Term Resource Monitoring Program procedures: fish monitoring. National Biological Service, Environmental Management Technical Center, Onalaska, Wisconsin. LTRMPP 95-P002-1. 42 pp. + Appendixes A-J.
Harley, S.J., R.A. Myers, and A. Dunn. 2001. Is catch-per-unit-effort proportional to abundance? Canadian Journal of Fisheries and Aquatic Sciences 58:1760-1772.

Helser, T.E., and D.B. Hayes. 1995. Providing quantitative management advice from stock abundance indices based on research surveys. Fisheries Bulletin 93:290-298.

Hilborn, R. 1992. Current and future trends in fisheries stock assessment and management. South African Journal of Marine Sciences 12:975-988.

Hilborn, R., and C.J. Walters. 1992. Quantitative fisheries stock assessment: choice, dynamics, and uncertainty. Chapman \& Hall, New York, New York.

Horwood, J.W., J.H. Nichols, and S. Milligan. 1998. Evaluation of closed areas for fish stock conservation. Journal of Applied Ecology 35:893-903.

Hutchings, J.A., and R.A. Myers. 1994. What can be learned from the collapse of a renewable resource? Atlantic cod, Gadus morhua, of Newfoundland and Labrador. Canadian Journal of Fisheries and Aquatic Sciences 51:2126-2146.

Lubinski, K., R. Burkhardt, J. Sauer, D. Soballe, and Y. Yin. 2001. Initial analyses of change detection capabilities and data redundancies in the Long Term Resource Monitoring Program. U.S. Geological Survey, Upper Midwest Environmental Sciences Center, La Crosse, Wisconsin. LTRMPP 2001-T001.

Maher, R. 2005. 2003 commercial catch report, exclusive of Lake Michigan. Commercial Fishing Program, Illinois Department of Natural Resources, Brighton, Illinois.

Maher, R. 2003. 2002 commercial catch report, exclusive of Lake Michigan. Commercial Fishing Program, Illinois Department of Natural Resources, Brighton, Illinois.

Maher, R. 2002. 2001 commercial catch report, exclusive of Lake Michigan. Commercial Fishing Program, Illinois Department of Natural Resources, Brighton, Illinois..

Maher, R. 2001. 2000 commercial catch report, exclusive of Lake Michigan. Commercial Fishing Program, Illinois Department of Natural Resources, Brighton, Illinois. 
Myers, R.A., J.A. Hutchings, and N.J. Barrowman. 1997. Why do fish stocks collapse? The example of cod in Atlantic Canada. Ecological Applications 7(1):91-106.

Pennington, M., and T. Stromme. 1998. Surveys as a research tool for managing dynamic stocks. Fisheries Research 37:97-106.

Peterman, R.M. 2004. Possible solutions to some challenges facing fisheries scientists and managers. ICES Journal of Marine Science 61:1331-1343.

Radomski, P.J. 1999. Commercial overfishing and property rights. Fisheries 24(6):22-29.

Sparks, R.E. 1995. Large rivers and their floodplains. Bioscience 45:168-182.

Trumble, R.J. 1997. Northeast Pacific flatfish management. Journal of SEA Research 39:167-181.

Weber, P. 1995. Protecting oceanic fisheries and jobs. Pages 41-60 in L.R. Brown, ed. State of the world 1995, a Worldwatch Institute report on progress toward a sustainable society. W.W. Norton \& Company, New York.

Williamson, B. 2000. 1999 commercial catch report, exclusive of Lake Michigan. Commercial Fishing Program, Illinois Department of Natural Resources, Brighton, Illinois.

Williamson, B. 1999. 1998 commercial catch report, exclusive of Lake Michigan. Commercial Fishing Program, Illinois Department of Natural Resources, Brighton, Illinois.

Williamson, B. 1998. 1997 commercial catch report, exclusive of Lake Michigan. Commercial Fishing Program, Illinois Department of Natural Resources, Brighton, Illinois.

Williamson, B. 1997. 1996 commercial catch report, exclusive of Lake Michigan. Commercial Fishing Program, Illinois Department of Natural Resources, Brighton, Illinois.

Williamson, B. 1996. 1995 commercial catch report, exclusive of Lake Michigan. Commercial Fishing Program, Illinois Department of Natural Resources, Brighton, Illinois.

Williamson, B. 1995. 1994 commercial catch report, exclusive of Lake Michigan. Commercial Fishing Program, Illinois Department of Natural Resources, Brighton, Illinois. 
Chapter 4: Evaluating Relationships between Environmental Factors and the Fish Community in Pool 26 of the Mississippi River

John H. Chick, Lori A. Soeken-Gittinger, Eric N. Ratcliff, Eric J. Gittinger, and Benjamin J. Lubinski

\begin{abstract}
We used data from the Long Term Resource Monitoring Program (LTRMP) to examine environmental parameters correlated with trends in fish community structure and abundance. Patterns of fish community structure for all size classes did not correlate with LTRMP water quality data or riverine discharge, but patterns of young-of-the-year (YOY) community structure were significantly correlated with spring chlorophyll-a (Chl-a), spring discharge, and summer temperature. Significant positive relationships were found between catch-per-unit-effort (CPUE) of YOY black crappie, sauger, and smallmouth buffalo with discharge. We found multiple regression models with $\mathrm{R}^{2}>0.50$ for YOY black and white crappie, channel catfish, largemouth bass, sauger, and common carp with combinations of these environmental factors and the abundance of stock-sized fishes (i.e., an index of parental abundance). Multivariate correlations for Age-1 fishes with environmental factors during the spring and summer of the previous year support our findings for YOY fishes. The value of these analyses lies primarily in generating hypotheses that can be addressed with additional monitoring data and focused research projects. Our analyses suggest that LTRMP data can provide important information on the status and trends of critical natural resources in the Pool 26 reach of the Upper Mississippi River System (UMRS). The full value of these data will only be achieved through the continuation of this monitoring program into future years and decades, combined with focused research projects developed in response to the patterns observed in the monitoring data.
\end{abstract}




\section{Introduction}

Long-term ecological monitoring wouldn't be necessary if ecosystems were simple and inhabited by only a small number of species with population dynamics governed by a few key environmental factors and biotic interactions. Under these circumstances, theoretical and empirical research could yield models capable of accurately predicting the ecosystem and population responses to the majority of natural and anthropogenic perturbations. Unfortunately, ecosystems are usually not so simple. Most ecosystems are inhabited by hundreds or thousands of species with complex direct and indirect interactions that form reticulate connection webs rather than simple chains (Polis 1991, Polis and Strong 1996). Many species exhibit complex life histories so their population dynamics are governed by conditions in multiple habitats and/or ecosystems (Benard 2004). Furthermore, the environmental factors affecting population and community dynamics are numerous and interact with species across a hierarchical array of spatial and temporal scales (Allen and Hoekstra 1992), often through complex and nonlinear modes (Rhodes et al. 1996). As a result, ecosystem and resource dynamics are frequently complex and difficult to predict, exhibiting threshold behavior and multiple stable states (Carpenter et al. 1999, Gunderson 2000, Scheffer et al. 2001). Attempting to model or even track the myriad of complex linkages among the various components of ecosystems, however, is not practical. Therefore, management often relies on monitoring data as a feedback tool, because the large number of variables capable of affecting the natural resources they are managing makes it impractical to rely only on models.

Ideally, sound management of ecosystems require an adaptive approach (Walters 1986) where management is conducted as an experiment, modeling is used for prediction and hypothesis generation, and ecological monitoring is used to assess management success, ground truth models, and ultimately feedback to refine management planning. This ideal is rarely achieved, but managers frequently rely on monitoring data to track trends in the natural resources they are concerned with and will adjust management practices based on these trends. In doing so, managers are acting in an adaptive manner, though with a less formalized (and possibly effective) protocol than would occur under the ideal model of adaptive management.

Although long-term ecological monitoring is usually associated with assessing the status and trends of natural resources, evaluating management actions and testing model predictions, analysis of long-term monitoring data also has yielded unique and important information about ecological dynamics. Long-term catch data from commercial fisheries has provided important insights into the population dynamics of fishes (Hjort 1914, 1926; Le Cren 1987; Cushing 1996; see Chapter 3). Long-term ecological data collected in Oneida Lake (New York) provides an excellent example of the insights researchers can gain from long-term data. Analysis of this data set has provided insight into fish population dynamics (Forney 1971, Hall and Rudstam 1999), trophic interactions (McQueen et al. 1992), and the effects of invasive species (Mayer et al. 2000). A search of the scientific literature (using Current Contents) from 1993 to 2005 yields 120 publications with Oneida Lake as a keyword; testament to the value of long-term data for developing a successful ecological research program. There are other examples of long-term data collection and analysis throughout the world. For example, the National Science Foundation in the United States invests in long-term research and monitoring through the Long Term Ecological Research (LTER) and National Ecological Observation Network (NEON) programs.

The Long Term Resource Monitoring Program (LTRMP) for the Upper Mississippi River System (UMRS) is also an excellent example of the value of long-term ecological data. A component of the Upper Mississippi River Restoration - Environmental Management Program, this partnership has provided important information on the status and trends of key natural resources in the UMRS (USGS 1999). Numerous reports and publications have been produced by the LTRMP (http://www.umesc. 
usgs.gov/reports_publications/LTRMPp_rep_ list.html) assessing management activities and questions about ecological dynamics of the UMRS. Many of these publications report on additional research that was a "spin-off" of LTRMP monitoring. In recent years, with over 10 years of consistent data collection for most LTRMP components, several analysis projects have been initiated to comprehensively review LTRMP monitoring findings. This bulletin is part of this effort. Our objectives for this chapter are to use LTRMP water quality and fish monitoring data in a cross-component analysis to determine key water quality parameters that correspond with temporal variation in the populations of fishes in navigation Pool 26.

\section{Methods}

The previous chapters summarized trends and other findings from LTRMP water quality and fish component data collected in Pool 26. Here, we conduct a cross-component analysis to gain insight into the function of the Upper Mississippi River ecosystem. Our basic approach is to ascertain which water quality parameters are associated with variation in fish populations. We adopted a rather unique approach for these analyses, starting with identifying fish community patterns, then conducting multivariate correlations of those patterns with environmental factors. This work was used to identify environmental factors with the greatest association with YOY fish community structure. We then conducted univariate regression and multiple regression analyses to further assess relations among YOY fishes and these environmental factors. Finally, we conducted similar community analyses for Age-1 fishes and water quality parameters from the previous year, as a check on our analysis for YOY fishes.

\section{Data Selection}

The two main water quality data sets available are from stratified random sampling and fixed site sampling (see Chapter 1). Stratified random sampling (SRS) is designed to provide pool-wide means across all major strata (e.g., main channel, backwaters, etc.). Whereas this is a spatially intense sampling design, the temporal extent is limited to four, two-week sampling periods throughout the year. Fixed site sampling has the opposite characteristics. This data set is temporally rigorous (weekly to bi-weekly sampling), with limited spatial coverage. We used annual means from the SRS data set to correlate to annual means of fishes from all size classes, and fixed site data from main channel sites to correlate with YOY fishes and Age-1 fishes. Fixed site data were further divided into three-month seasons (e.g., winter $=$ January - March, Spring = April-June, Summer $=$ Jul-September, Fall $=$ October-December).

We chose a limited set of water quality variables for our analysis (Table 1). From the basic parameters measured, we included water temperature, turbidity, and chlorophyll-a (Chl-a). We did not include conductivity or dissolved oxygen, because the range of variation for these parameters in Pool 26 is limited and unlikely to be correlated with variation in fish abundance. Because variables related to water clarity (e.g., Secchi depth, suspended solids, and turbidity) are highly correlated in Pool 26 (Chapter 1 ), we chose to include only turbidity in our analyses. We included Chl-a because it is the most direct indicator of primary production measured by LTRMP. Finally, we also included annual means of river discharge because flood and drought conditions should have important influences on fish populations and communities. In addition to the annual means for these variables, we also included the standard error for discharge, as interannual variation of this factor may influence fish reproduction, growth, and survival.

We used the Lubinski et al. (2001) power analysis to determine the fish species used in our analysis of all size classes. Species included were limited to those with power $>0.5$ to detect a $20 \%$ inter-annual change in CPUE in at least one stratum for at least one of the gears included in the analysis (Table 2). The size criteria used to determine YOY and Age-1 fishes were identical to those in Chapters 2 and 3. We chose the species included in the YOY and Age-1 analyses based on our results in Chapters 2 and 3 (see Appendix D). Species were cho- 
Table 1. Water quality parameters used in the cross-component analyses for fishes of all size classes (A), for YOY fishes (B) and for Age-1 fishes (C). Win = Winter, Spr = Spring, Sum = summer.

\begin{tabular}{lll} 
A. All Size Classes & B. YOY Fishes & C. Age-1 Fishes \\
\hline Water Temperature & Spr Water Temperature & Win Water Temperature \\
Dissolved Oxygen & Spr Turbidity & Win Turbidity \\
Turbidity & Spr Chl-a & Win Chl-a \\
Chl-a & Spr River Discharge & Win River Discharge \\
River Discharge & Spr Discharge error & Win Discharge Error \\
Standard Error Temp & Sum Water Temperature & Spr Water Temperature \\
Standard Error Turbidity & Sum Turbidity & Spr Turbidity \\
Standard Error Chl-a & Sum Chl-a & Spr Chl-a \\
Standard Error discharge & Sum River Discharge & Spr River Discharge \\
& Sum Discharge error & Spr Discharge Error \\
& & Sum Water Temperature \\
& & Sum Turbidity \\
& & Sum Chl-a \\
& & Sum River Discharge \\
& & Sum Discharge Error \\
\hline
\end{tabular}

Table 2. List of fish species used in the cross-component analysis of fishes of all size classes, YOY fishes, and Age- 1 fishes.

\begin{tabular}{lllll}
\hline Common Name & Scientific Name & All Sizes & YOY & Age-1 \\
\hline Black crappie & Pomoxis nigromaculatus & $\mathrm{X}$ & $\mathrm{X}$ & $\mathrm{X}$ \\
Bluegill & Lepomis macrochirus & $\mathrm{X}$ & $\mathrm{X}$ & $\mathrm{X}$ \\
Common carp & Cyprinus carpio & $\mathrm{X}$ & $\mathrm{X}$ & $\mathrm{X}$ \\
Channel catfish & Ictalurus punctatus & $\mathrm{X}$ & $\mathrm{X}$ & $\mathrm{X}$ \\
Emerald shiner & Notropis atherinoides & $\mathrm{X}$ & & \\
Flathead catfish & Pylodictis olivaris & $\mathrm{X}$ & $\mathrm{X}$ & $\mathrm{X}$ \\
Freshwater drum & Aplodinotus grunniens & $\mathrm{X}$ & $\mathrm{X}$ & $\mathrm{X}$ \\
Gizzard shad & Dorosoma cepedianum & $\mathrm{X}$ & $\mathrm{X}$ & $\mathrm{X}$ \\
Largemouth bass & Micropterus salmoides & $\mathrm{X}$ & & \\
Orangespotted sunfish & Lepomis humilis & $\mathrm{X}$ & $\mathrm{X}$ & $\mathrm{X}$ \\
Sauger & Sander canadensis & $\mathrm{X}$ & $\mathrm{X}$ & $\mathrm{X}$ \\
Smallmouth buffalo & Ictiobus bubalus & $\mathrm{X}$ & $\mathrm{X}$ & $\mathrm{X}$ \\
Shortnose gar & Lepisosteus platostomus & $\mathrm{X}$ & $\mathrm{X}$ & $\mathrm{X}$ \\
White bass & Morone chrysops & & & \\
White crappie & Pomoxis annularis & & & \\
\hline & & & &
\end{tabular}


sen that appeared to have the greatest promise for detecting temporal trends in CPUE with regard to variation around the annual means (Table 2). For consistency, the same species used in the YOY analysis were also included in the Age- 1 analysis.

The flood of 1993 severely restricted the amount of standardized sampling that could be completed, therefore we only included data from 1994 through 2004. Additionally, no SRS water quality data was collected in 2003 due to funding cuts. A reduced set of fixed sites was monitored in 2003, and we chose to include these data, rather than to further restrict the number of years used in these analyses.

\section{Analyses}

We used a multi-gear approach in putting together the fish data sets, following the methods described in Chick et al. (2005). For our analysis of all size classes of fishes, we combined data from day electrofishing, fyke nets, mini fyke nets, and large and small hoop nets. Data were transformed prior to standardization to reduce the influence of dominant species on multivariate analyses, and to conform to assumptions of normality and homoscedasticity for univariate analyses. Dominance diversity graphs and variance to means ratios were examined to determine appropriate transformations. Day electrofishing, fyke net, and large and small hoop nets data were square-root transformed, whereas mini-fyke net data were logarithmically transformed. Data for each gear were standardized by dividing the transformed mean CPUE for each species and year by the grand mean of total CPUE for each gear. The data sets for each gear were then combined by summing the standardized means for each species and year (Chick et al. 2005). For YOY fishes, we used data from day electrofishing, small hoop nets, and mini-fyke nets, using the square-root transformation for all gear before standardizing and combining the data sets. Data for Age-1 fishes were derived from day electrofishing, fyke nets, large hoop nets, and small hoop nets, using the square-root transformation for all gear before standardizing and combining the data sets.
Nonmetric multidimensional scaling (NMDS) was used to examine patterns in the community structure of fishes (all size classes and YOY) and in water quality data, based on the Bray-Curtis similarity matrix. All analyses were conducted using the SAS (SAS Institute 2001) and Primer (Primer-E Ltd. 2001) software packages. Water quality data were standardized by dividing the annual means of each parameter by the greatest annual mean of that parameter. This standardization places each parameter on an identical scale (from 0 to 1), allowing for unbiased multivariate analysis. Multivariate correlations were conducted using a nonparametric Mantel correlation (Relate procedure in Primer), and a canonical version of this test (Bioenv procedure in Primer) was used to identify the subset of environmental variables most strongly correlated with community structure.

Univariate regression analysis was performed using SAS (proc reg). Simple linear regressions (i.e., one independent variable) were conducted for YOY fish species and water quality variables identified in the canonical Mantel correlation. Regressions that were overly influenced by one or more outliers (identified by manually removing outliers) are not reported. We then conducted multiple regression analyses using backward selection $(a=0.05)$ to identify the model for each YOY species that yielded the greatest $R^{2}$ from the water quality variables identified in the canonical Mantel correlation and the CPUE of stock-sized fish for the corresponding YOY species. In these analyses, CPUE of stock-sized fishes is an index of the abundance of spawning fishes, and stock size was determined as in Chapter 3. These analyses are more of an exercise in pattern detection and hypothesis generation, rather than hypothesis testing. We did not adjust P-values (e.g., a Bonferroni technique) to protect experiment wide error, however; we only report multiple regression models where $R^{2} \geq 0.50$ to reduce the likelihood of reporting spurious or anomalous regressions. 


\section{Results and Discussion}

Patterns among years were apparent in the NMDS analysis of fish (all sizes) community structure, but we found little evidence of a correlation of these patterns with environmental factors. The fish community for the year 1994 was distinct from all other years, and to a lesser extent, the years 1995, 1996, 2001, and 2002 were also separated from the central grouping of years (Fig. 1). There were also groupings evident in the NMDS of SRS water quality parameters, with the years 1994 and 2000 distinct from other years (Fig. 2). Multivariate correlations for the fish and water quality data, however, were not significant $(\mathrm{R}=0.064 ; \mathrm{P}=$ 0.352 ). Because of the extremely low $R$ statistic, further attempts to correlate environmental data were not attempted.

The lack of a correlation between annual means in LTRMP fish data for all sizes, and annual means in LTRMP SRS water quality data is not surprising. Annual means of fish populations as a whole would be unlikely to be related to water quality conditions within the same year unless conditions were extreme (e.g., anoxic conditions, extreme winter temperature, catastrophic floods, etc.). For most fishes, population size within a given year will be related to environmental conditions from previous years that influenced year-class strength and subsequent recruitment of offspring. Furthermore, in the case of this data set, the most striking pattern in the fish community data, the distinctness of 1994 is likely to be a product of the 1993 flood. As documented in Chapters 2 and 3, the 1993 flood appeared to produce strong year classes for several species, which appear to have dominated the populations of several fishes for multiple years. The lack of LTRMP water quality sampling throughout most of 1993 restricts analyses of the 1993 flood. It may be possible to conduct lagged-correlations with environmental factors in the future when a longer time series will be available.

Limiting our analyses to YOY fishes allowed us to identify several environmental factors that correlate with annual variation of YOY fishes. Spawning and survival of YOY fishes are directly influenced by environmental variation within the same year. This will be especially true during the spring and summer, when fish spawning and YOY growth occur. Data from LTRMP fixed sites provide an appropriate time series to correlate with YOY fish data. For this analysis, it is desirable to have a finer time series (i.e., weekly or bi-weekly) because variability in climatic conditions can be important to YOY growth and survival. Data from LTRMP SRS water quality sampling is more spatially rigorous, but these data are only a snapshot of seasonal variation.

For YOY fishes, patterns among years were apparent in our NMDS analysis, and similarity in YOY fish community structure among years correlated with similarity in environmental factors among years. The years 1994, 2000, and 2002 stood out from all other years in our NMDS (Fig. 3). Multivariate correlations between YOY fish community structure and environmental factors was not significant $(\mathrm{R}$ $=0.226 ; \mathrm{P}=0.097$ ), but the $\mathrm{R}$ value was great enough to merit canonical analyses. Canonical correlations revealed that the greatest association of fish community structure occurred for an environmental data set comprised of spring Chl-a, spring discharge, and summer temperature ( $\mathrm{R}=0.715$; Figs. 4-6). Therefore, we used univariate regression to further explore YOY fish associations with these factors.

We found significant regressions between YOY and single environmental factors for black and white crappie, channel catfish, smallmouth buffalo and sauger. The positive relationship between smallmouth buffalo and discharge may explain the low numbers of substock buffalo mentioned in Chapter 3 . There have been fewer spring floods in Pool 26 in recent years. Catch per unit effort of YOY black crappie, smallmouth buffalo, and sauger was positively related to spring discharge (Fig. 7). Catch per unit effort of YOY channel catfish and white crappie were positively related to summer temperature (Fig. 8). We found multiple regression models where $\mathrm{R}^{2}>0.50$ for various combinations of stock-size CPUE and environmental factors for black and white crappie, channel catfish, largemouth bass, sauger, and freshwater drum (Table 3).

(continued on page 398) 


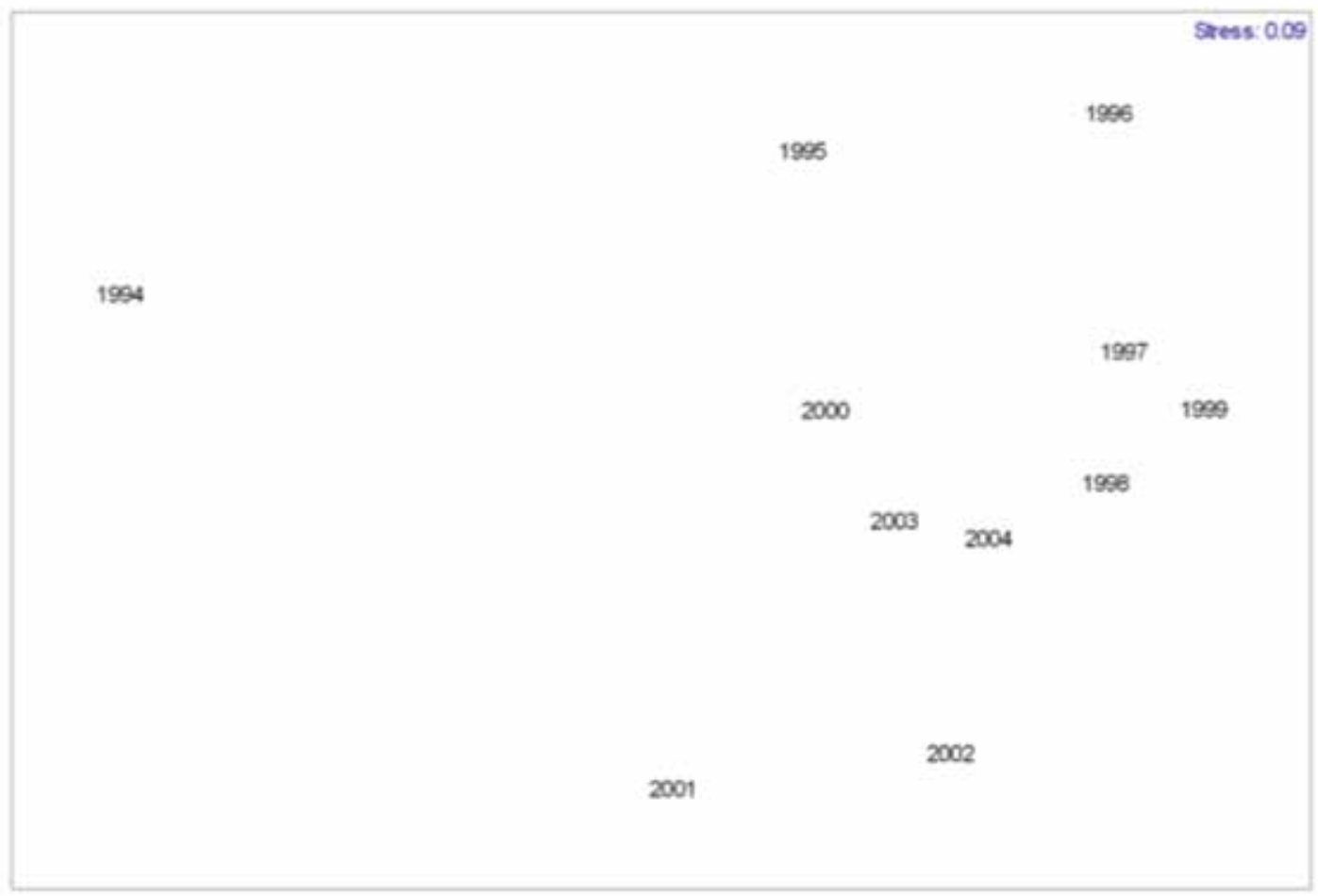

Figure 1. Nonmetric multidimensional scaling plot for fish community structure in Pool 26. Data were collected through the Long Term Resource Monitoring Program from 1994 to 2004.

1997

\section{5}

1996

1999

1998

2004

Figure 2. Nonmetric multidimensional scaling plot for water quality data in Pool 26. Data were collected through the Long Term Resource Monitoring Program from 1994 to 2004. 


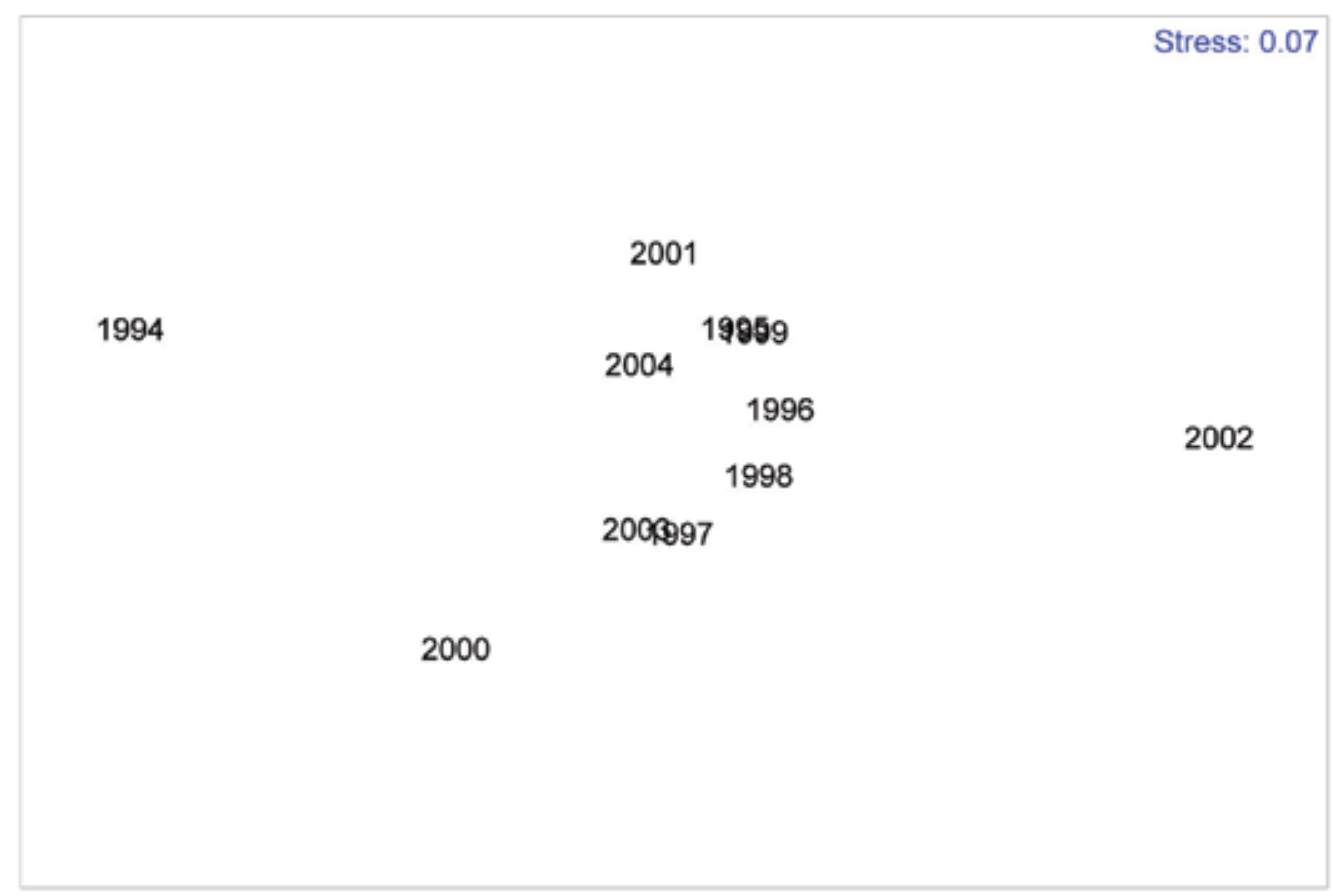

Figure 3. Nonmetric multidimensional scaling plot for YOY fish community structure in Pool 26. Data were collected through the Long Term Resource Monitoring Program from 1994 to 2004.

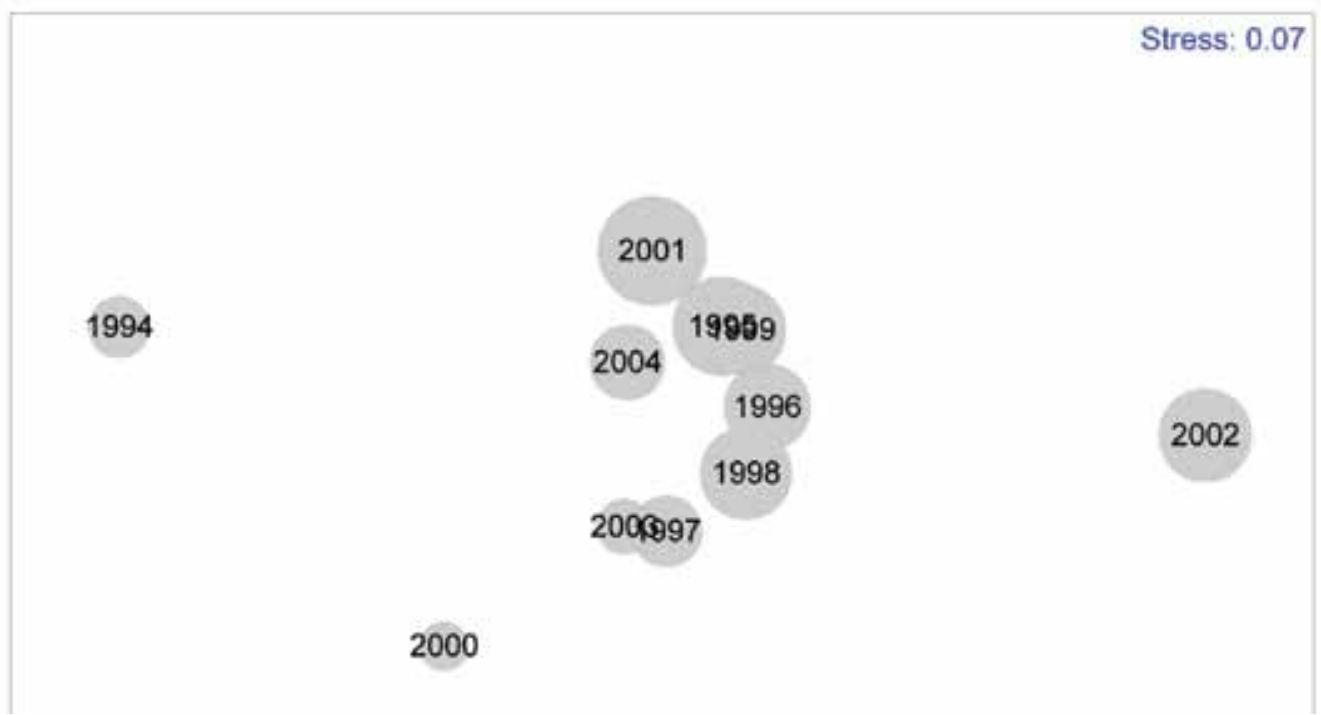

Figure 4. Nonmetric multidimensional scaling plot for YOY fish community structure in Pool 26. Bubble size corresponds to increasing spring discharge. Data were collected through the Long Term Resource Monitoring Program from 1994 to 2004. 


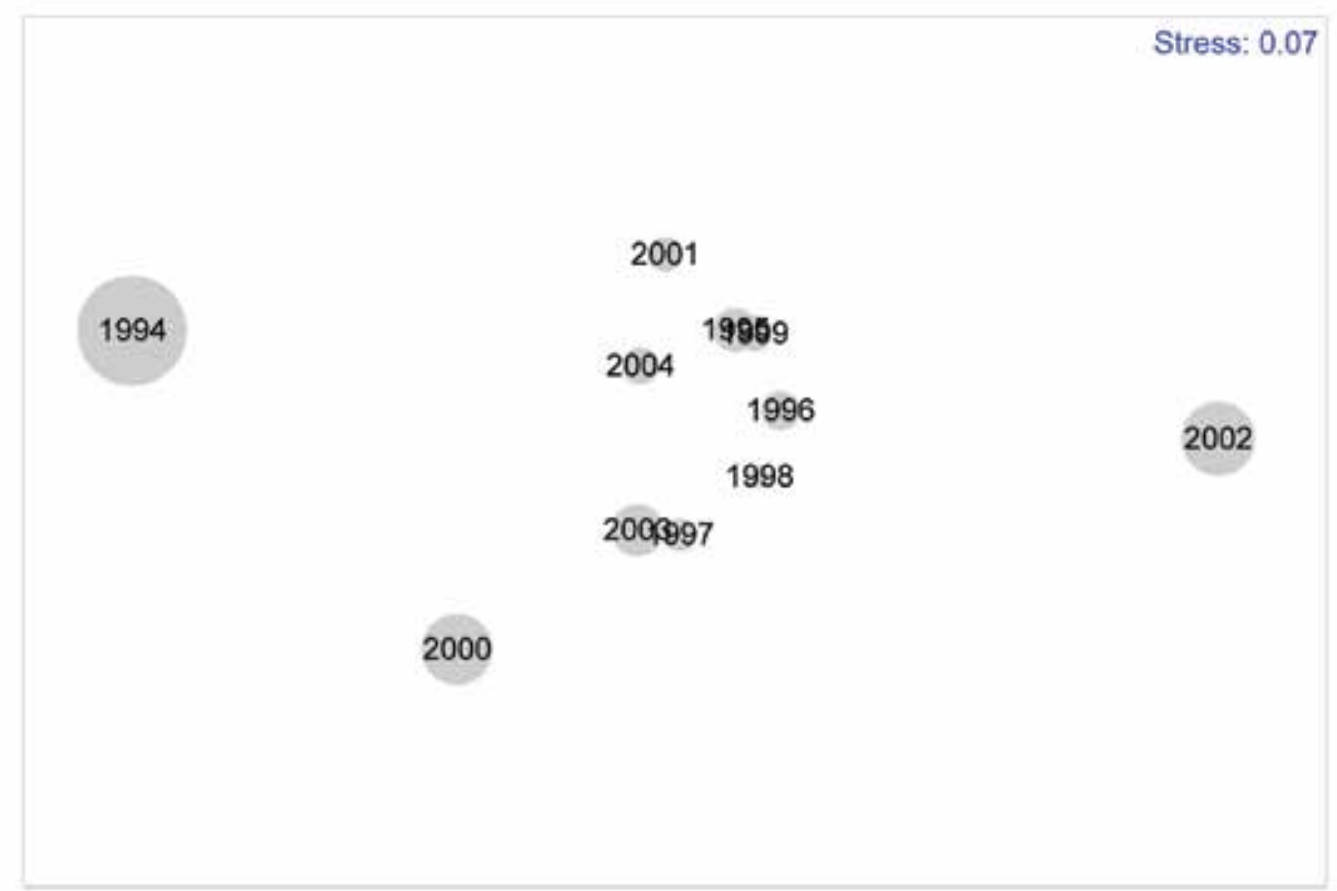

Figure 5. Nonmetric multidimensional scaling plot for YOY fish community structure in Pool 26. Bubble size corresponds to increasing springtime chlorophyll-a concentration. Data were collected through the Long Term Resource Monitoring Program from 1994 to 2004.

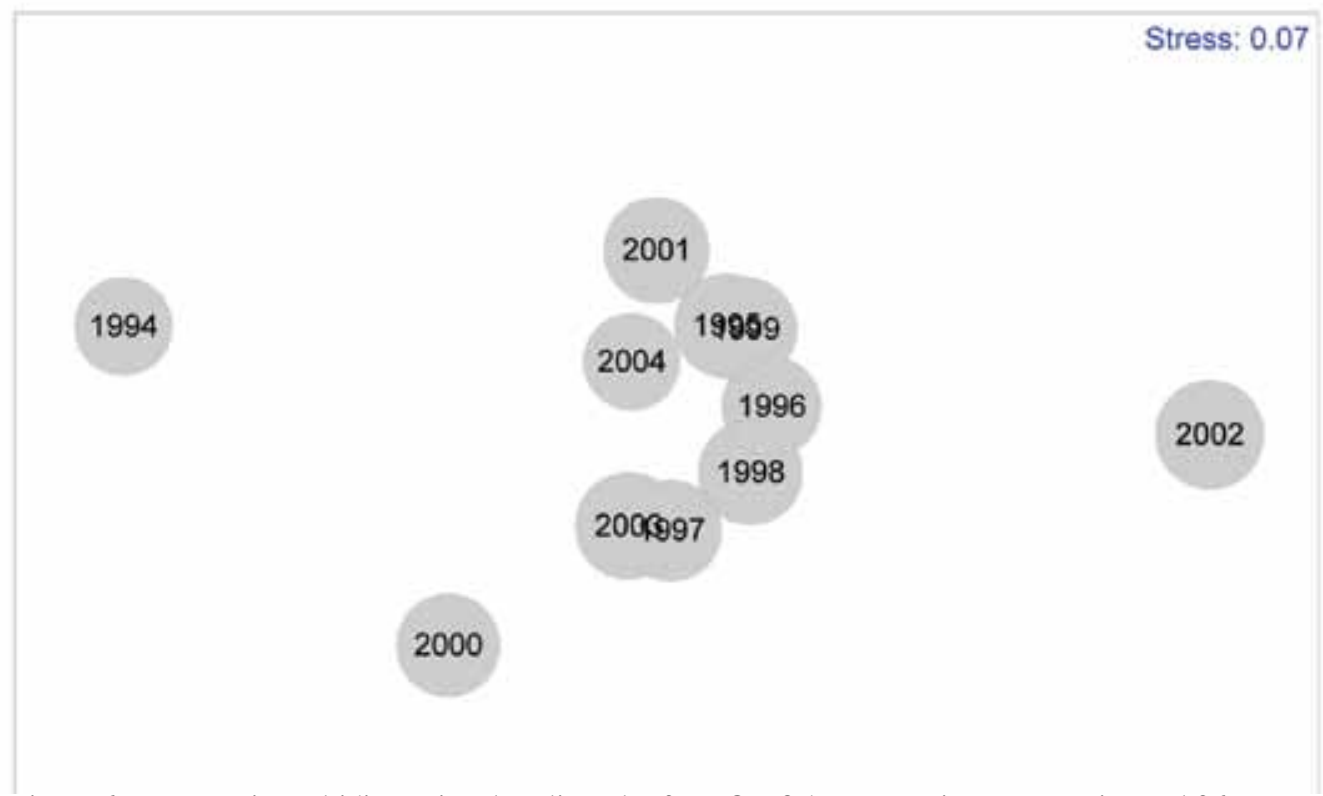

Figure 6. Nonmetric multidimensional scaling plot for YOY fish community structure in Pool 26. Bubble size corresponds to increasing summer temperature. Data were collected through the Long Term Resource Monitoring Program from 1994 to 2004. 


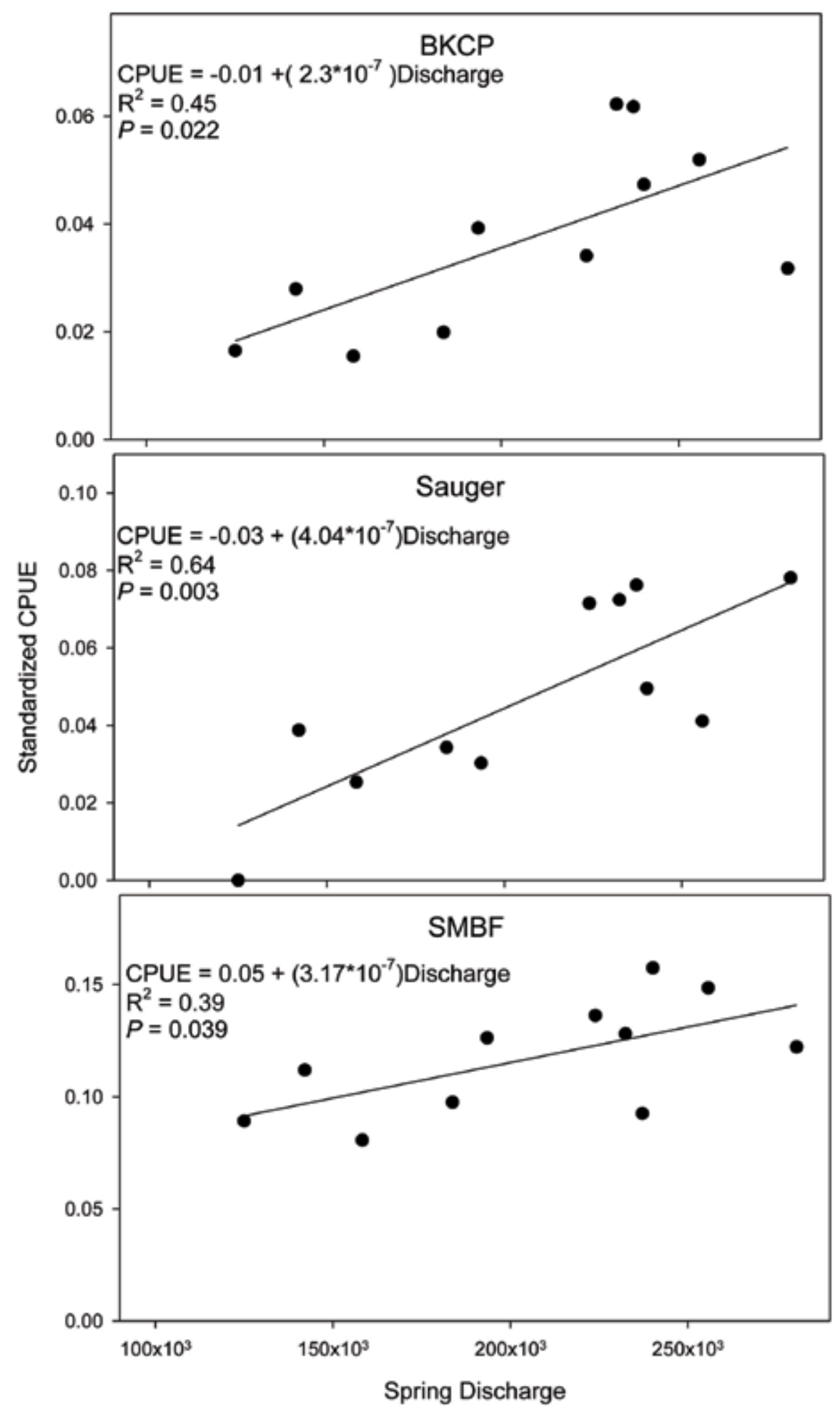

Figure 7. Linear regressions of YOY black crappie, sauger, and smallmouth buffalo with spring discharge. Data were collected through the Long Term Resource Monitoring Program from 1994 to 2004. 


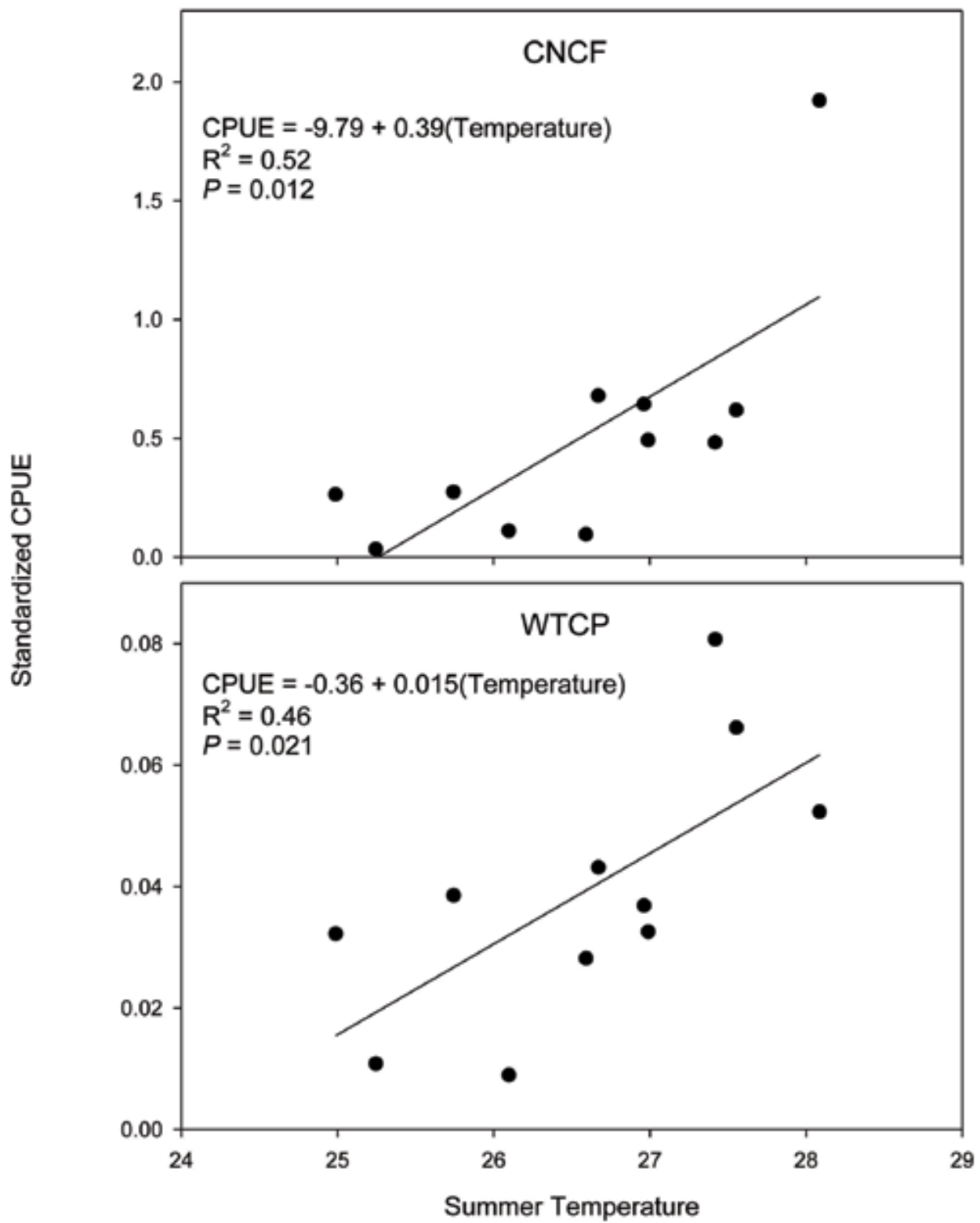

Figure 8. Linear regressions of YOY channel catfish and white crappie with summer temperature. Data were collected through the Long Term Resource Monitoring Program from 1994 to 2004. 
Table 3. Summary of multiple regression results for CPUE of YOY fishes versus stock abundance (stock size) and environmental parameters. Values for stock size and environmental variable are the model parameter estimates. Xs are placed for parameters not selected in the final model.

\begin{tabular}{lccccc}
\hline Dependent Var (Y) & Stock Size & Spring Chl-a & Spring Discharge & Summer Temp & $\mathrm{R}^{2}$ \\
\hline YOY Bluegill & $\mathrm{X}$ & $\mathrm{X}$ & $\mathrm{X}$ & $\mathrm{X}$ & \\
YOY Black crappie & -0.049 & $\mathrm{X}$ & 0.069 & 0.057 & 0.5 \\
YOY Common carp & $\mathrm{X}$ & $\mathrm{X}$ & $\mathrm{X}$ & $\mathrm{X}$ & \\
YOY Channel catfish & $\mathrm{X}$ & 0.631 & 1.02 & 9.652 & 0.62 \\
YOY Freshwater drum & $\mathrm{X}$ & -0.862 & -1.582 & 5.319 & 0.93 \\
YOY Gizzard shad & $\mathrm{X}$ & $\mathrm{X}$ & $\mathrm{X}$ & $\mathrm{X}$ & \\
YOY Largemouth bass & 0.376 & -0.072 & $\mathrm{X}$ & 0.354 & 0.66 \\
YOY Sauger & 0.189 & -0.067 & 0.076 & $\mathrm{X}$ & 0.7 \\
YOY Smallmouth buffalo & $\mathrm{X}$ & $\mathrm{X}$ & $\mathrm{X}$ & $\mathrm{X}$ & \\
YOY White Bass & $\mathrm{X}$ & $\mathrm{X}$ & $\mathrm{X}$ & $\mathrm{X}$ & \\
YOY White Crappie & 0.205 & -0.042 & $\mathrm{X}$ & 0.262 & 0.72 \\
\hline
\end{tabular}

Environmental conditions during the winter and the overall growth and condition of larvae before the onset of winter are thought to critically influence survival of YOY fishes to Age 1. Our canonical multivariate correlations of Age-1 fish revealed the strongest correlations $(\mathrm{R}=0.605)$ with a combination of the previous year's spring discharge, spring discharge error, summer temperature, and summer discharge error, supporting our YOY analysis. Given that several studies (Johnson and Evans 1996, Garvey et al. 1998a, 1998b, Pangle et al. 2004) have pointed to the importance of over-winter conditions to the survival of YOY fishes, it is somewhat surprising that no winter variables correlated with the abundance of Age-1 fishes. In Pool 26, the overall growth and condition of larvae before the onset of winter, which are influenced by environmental factors such as spring discharge and summer temperature, may be more important to survival of fishes to Age 1 then conditions during the winter itself.

From research on the factors controlling year class strength and recruitment of fishes, it is possible to devise ecological explanations for our regression results. Many riverine fishes use floodplain habitats for spawning, and increased flooding increases the availability of floodplain spawning and nursery habitat, so we should expect positive associations with YOY abundance and spring discharge (Welcomme 1985). For fishes spawning in open water (e.g., freshwater drum), negative associations with discharge might be expected because floods can wash eggs and larval fish out of the system or into undesirable habitats. We might expect positive associations of YOY abundance with summer temperature, because increased temperature should increase YOY growth, which is thought to be a critical factor for survival (Houde 1987). The consistent negative associations of YOY abundance with springtime Chl-a (Fig. 9; Table 1) is a bit more puzzling. Zooplankton, an important prey item for YOY fishes, may influence this relationship because greater populations of zooplankton could reduce algae populations (lower Chl-a) through grazing and simultaneously increase the growth of YOY fishes. Increased levels of Chl-a also might adversely affect the ability of YOY fishes to see prey items, but turbidity should be a better indicator of water clarity. Hypoxic conditions from algal blooms also is an unlikely explanation because we rarely detect hypoxic conditions in Pool 26 (see Chapter 1).

We do not suggest that the results of our analyses provide strong inferences into any cause and effect relationships. Instead, we see the value of our analyses in their use for hypothesis generation for future investigations. The next steps would be to include data from other LTRMP regional trend areas, and to look toward improving our criteria for categorizing fish as YOY by developing length at age keys through the analysis of otoliths or scales collected from fishes in these areas. Additionally, we feel the real value of these analyses will be realized 5, 10, or 20 years from now when they can be repeated with the additional LTRMP data. 


\section{Conclusions}

Patterns of fish community structure did not correlate with LTRMP water quality data or riverine discharge when all size classes of fishes were grouped together. Community structure of YOY fishes was significantly correlated with spring Chl-a, spring discharge, and summer temperature. We found multiple regression models with $\mathrm{R}^{2}>0.50$ for YOY black and white crappie, channel catfish, largemouth bass, sauger, and common carp with combinations of these environmental factors and the abundance of stock-sized fishes (i.e., an index of parental abundance). Multivariate correlations for Age-1 fishes with environmental factors during the spring and summer from the previous year support our findings for YOY fishes. The value of these analyses lies primarily in generating hypotheses that can be addressed by repeating these analyses with monitoring data from other reaches, monitoring data from future years, and through focused research projects. 


\section{Literature Cited}

Allen, T.F.H., and T.W. Hoekstra. 1992. Toward a unified theory of ecology. Columbia University Press, New York.

Benard, M.F. 2004. Predator-induced phenotypic plasticity in organisms with complex life histories. Annual Review of Ecology and Systematics 35:651-673.

Carpenter, S., W. Brock, and P. Hanson. 1999. Ecological and social dynamics in simple models of ecosystem management. Conservation Ecology 3:4 [online at www.consecol. org/vol3/iss2/art4].

Chick, J.H., B.S. Ickes, M.A. Pegg, V.A. Barko, R.A. Hrabik, and D.P. Herzog. 2005. Spatial structure and temporal variation of fish communities in the Upper Mississippi River system. U.S. Geological Survey, Upper Midwest Environmental Sciences Center, La Crosse, Wisconsin. LTRMPP Technical Report 2005T004. 15 pp. (NTIS PB2005-106535).

Cushing, D.H. 1996. Towards a science of recruitment in fish populations. O. Kinne, ed. Excellence in ecology. Volume 7. Ecology Institute. Olendorf/Luhe, Germany.

Forney, J.L. 1971. Development of dominant year classes in a yellow perch population. Transactions of the American Fisheries Society 101:739-749.

Garvey J.E., R.A. Wright, and R.A. Stein. 1998a. Overwinter growth and survival of Age-0 largemouth bass (Micropterus salmoides): revisiting the role of body size. Canadian Journal of Fisheries \& Aquatic Sciences. 55:2414-2424.

Garvey J.E., N.A. Dingledine, N.S. Donovan, and R.A. Stein. 1998b. Exploring spatial and temporal variation within reservoir food webs-predictions for fish assemblages. Ecological Applications. 8:104-120.

Gunderson, L.H. 2000. Ecological resilience: in theory and application. Annual Review of Ecology and Systematics 3:425-439.

Hall, S.R., and L.G. Rudstam. 1999. Habitat use and recruitment: a comparison of longterm recruitment patterns among fish species in a shallow eutrophic lake, Oneida Lake, NY, U.S.A. Hydrobiologia 408-409:101113.
Hjort, J. 1914. Fluctuations in the great fisheries of Northern Europe. Reports to the International Counseil Pour L'Exploration de la Mer 20:1-228.

Hjort, J. 1926. Fluctuations in the year-classes of important food fishes. Journal du Conseil, Counseil Permanent International Pour L'Exploration de la Mer 1:1-38.

Houde, E.D. 1987. Fish early life dynamics and recruitment variability. American Fisheries Society Symposium 2:17-29.

Johnson, T.B., and D.O. Evans. 1996. Temperature constraints on overwinter survival of Age- 0 white perch. Transactions of the American Fisheries Society. 125:466-471.

Le Cren, E.D. 1987. Perch (Perca fluviatilis) and pike (Esox lucius) in Windermere from 1940 to 1985: studies in population dynamics. Canadian Journal of Fisheries and Aquatic Sciences 44:216-228.

Lubinski, K., R. Burkhardt, J. Sauer, D. Soballe, and Y. Yin. 2001. Initial analyses of change detection capabilities and data redundancies in the Long Term Resource Monitoring Program. U.S. Geological Survey, Upper Midwest Environmental Sciences Center, La Crosse, Wisconsin. LTRMPP 2001-T001. 23 pp. + Appendixes A-E (NTIS \# PB2002100123).

Mayer, C.M., A.J. VanDeValk, J.L. Forney, L.G. Rudstam, and E.L. Mills. 2000. Response of yellow perch (Perca flavescens) in Oneida Lake, New York, to the establishment of zebra mussels (Dreissena polymorpha). Canadian Journal of Fisheries and Aquatic Sciences 57:742-754.

McQueen, D.J., E.L. Mills, J.L. Forney, M.R.S. Johannes, and J.R. Post. 1992. Trophic level relationships in pelagic food webs: comparisons derived from long-term data sets for Oneida Lake, New York (USA), and Lake St. George, Ontario (Canada). Canadian Journal of Fisheries and Aquatic Sciences 49:1588-1596.

Pangle K.L., T.M. Sutton, R.E. Kinnunen, and M.H. Hoff. 2004. Overwinter survival of juvenile lake herring in relation to body size, physiological condition, energy stores, and food ration. Transactions of the American Fisheries Society. 133:1235-1246. 
Polis, G.A. 1991. Complex trophic interactions in deserts: an empirical critique of food-web theory. American Naturalist 138:123-155.

Polis, G.A., and D.R. Strong. 1996. Foodweb complexity and community dynamics. American Naturalist 147:813-846.

Primer-E Ltd. 2001. Primer for Windows Version 5.2.4. Plymouth, United Kingdom.

Rhodes, O.E. Jr., R.K. Chesser, and M.H. Smith. 1996. Population dynamics in ecological space and time. University of Chicago Press, Chicago.

SAS Institute (2001) SAS System for Windows Ver 8.02. SAS Institute Inc., Cary, NC, USA

Scheffer, M., S. Carpenter, J. A. Foley, C. Folk and B. Walker. 2001. Catastrophic shifts in ecosystems. Nature 413:591-596.

USGS. 1999. Ecological status and trends of the Upper Mississippi River system 1998: a report of the Long Term Resource Monitoring Program. U.S. Geological Survey, Upper Midwest Environmental Sciences Center, La Crosse, Wisconsin. LTRMPP 99-T001. 236 pp.

Walters, C.J. 1986. Adaptive management of renewable resources. McGraw Hill, New York.

Welcomme, R.L. 1985. River fisheries. FAO Fisheries Technical Paper 262. United Nations Food and Agriculture Organization, Rome. 


\section{Key Findings from a Decade of Monitoring on Pool 26 of the Upper Mississippi River}

- We estimate that annual expenditures of $\$ 84$ and $\$ 55$ million are made for fishing and hunting, respectively, in the region surrounding Pool 26 based on license sales and state expenditure data from the U.S. Fish and Wildlife Service. (Chapter 1)

- Pool 26 is a highly productive river reach, with average chorophyll-a, total phosphorous, total nitrogen, and total inorganic solids that are comparable to levels in eutrophic to highly eutrophic lakes. (Chapter 1)

- The average current velocity in the main channel of the Mississippi River in Pool 26 range from 0.364-0.414 meters per second during the summer and fall; even during the lowest discharge levels in a year the reach has a residence time no longer than 2.7 days. (Chapter 1 )

- Discharge was significantly related to many water quality parameters, including Secchi depth, turbidity, total suspended solids, total nitrogen, nitrate-nitrite, and total phosphorus. (Chapter 1)

-We observed a significant linear increase in mean water temperature in the main channel from 1994 to 2004. When these data were analyzed by season, positive linear trends were found during the spring $\left(0.515^{\circ} \mathrm{C}\right.$ per year $)$ and fall $\left(0.646^{\circ} \mathrm{C}\right.$ per year $)$. (Chapter 1)

- Gizzard shad, emerald shiner, common carp, channel shiner, channel catfish, freshwater drum, and bluegill accounted for $75 \%$ of the numerical total catch. (Chapter 2)

- Cyprinids were the best represented family in Pool 26, with 27 species collected. (Chapter 2)

- Blue catfish CPUE has increased dramatically beginning in 2000 , possibly related to the increase in water temperature observed by the water quality component. (Chapter 2)

- Common carp decreased throughout the time series, which appears to be a systemic trend (i.e., across all LTRMP reaches). (Chapter 2)

- LTRMP data were also useful for detecting the spread of exotic species into Pool 26, such as the population explosion of bighead and silver carp during the study period. (Chapter 2)
- Several species, including largemouth bass, black crappie, white bass, and common carp, produced strong year classes during the flood of 1993. (Chapter 2)

-We found little evidence to suggest that commercial fishing is severely reducing fish populations in Pool 26 of the Mississippi River. (Chapter 3)

- Catch Per Unit Effort of stock-size fish of most commercially harvested species has increased or maintained relatively consistent numbers from 1994-2003. (Chapter 3)

- One potential point of concern was a significant decrease in the CPUE of substock-size buffalo. (Chapter 3)

- Patterns of fish community structure for all size classes did not correlate with LTRMP water quality data or riverine discharge, but patterns of YOY community structure were significantly correlated with spring Chl-a, spring discharge, and summer temperature. (Chapter 4)

- Significant positive relationships were found between CPUE of YOY black crappie, sauger, and smallmouth buffalo with discharge. (Chapter 4)

-We found multiple regression models with $\mathrm{R}^{2}>$ 0.50 for YOY black and white crappie, channel catfish, largemouth bass, sauger, and common carp with combinations of spring Chl-a, spring discharge, summer temperature, and the abundance of stocksized fishes (i.e., an index of parental abundance). (Chapter 4)

- Multivariate correlations for Age-1 fishes with environmental factors during the spring and summer from the previous year support our findings for YOY fishes. (Chapter 4)

- Our analyses suggest that LTRMP data can provide important information on the status and trends of critical natural resources in the Pool 26 reach of the UMRS. The full value of these data will only be achieved through the continuation of this monitoring program into future years and decades, combined with focused research projects developed in response to the patterns observed in the monitoring data. 
EPILOGUE: Is Long-term Ecological Montoring Possible?

\author{
John H. Chick
}

The U.S. Congress recognized the Upper Mississippi River System (UMRS) as a nationally significant ecosystem and transportation system in the 1986 Water Resources Development Act (WRDA). They showed proper stewardship for the resources of the UMRS by establishing the Upper Mississippi River Restoration Environmental Management Program (UMRR-EMP) to conduct habitat enhancement and rehabilitation projects, and in authorizing the Long Term Resource Monitoring Program (LTRMP) to track ecosystem health and serve as an early warning system. Unfortunately, the funding that is actually allocated to the UMRR-EMP each year does not appear to be in line with the goals and values put forth in the 1986 and 1999 WRDA bills. In fact, inadequate funding has seriously impaired construction of habitat projects by the UMRR-EMP and forced reductions in LTRMP monitoring and research. The partnership of state and federal managers and scientists that make up the LTRMP have responded to these challenges through strategic planning, improvements to efficiency, and by incorporating other funding sources into the program when possible. I am hopeful that we will continue to meet budgetary challenges into the future, but also recognize that budgetary constraints are the biggest obstacle to maintaining a viable long-term monitoring program of any sort.

Ten or 12 years of consistent monitoring are hardly long enough to truly be considered "long term." I sincerely hope that this bulletin will be useful in informing natural resource managers, decision makers, and the general public about the value of LTRMP data. The LTRMP stands as a testament to both the value of long-term data and the difficulties associated with maintaining support for gathering these data. By examining LTRMP trends in Pool 26, we may raise awareness and interest in the program from the local community. Chapter 1 presents economic and ecological information, such as the use of the Mississippi River as a source of drinking water and the estimated expenditures on recreational fishing and hunting that many in the region likely are unaware of. Additionally, the warming trend found for main channel water temperature in the spring and fall is informative and raises questions. Is this trend a short-term one, or are we seeing effects of global climate change? Even information as simple as the variety of fishes that live within Pool 26 will be new information for the general public. Therefore, we are hopeful that this bulletin will not only be useful for scientists and river managers, but also for increasing the awareness and visibility of the LTRMP among the general public in the Pool 26 region. 


\section{Appendix A: Sample Sizes for Yearly Graphs}

Sample sizes: Yearly means, temperature.

$\begin{array}{lcccc}\text { Year } & \text { Main Channel } & \text { Side Channel } & \begin{array}{c}\text { Backwater } \\ \text { Contiguous }\end{array} & \text { Impounded } \\ 1994 & 78 & 154 & 130 & 53 \\ 1995 & 80 & 166 & 155 & 60 \\ 1996 & 80 & 163 & 150 & 60 \\ 1997 & 80 & 148 & 161 & 60 \\ 1998 & 80 & 169 & 175 & 59 \\ 1999 & 80 & 169 & 140 & 60 \\ 2000 & 80 & 153 & 140 & 50 \\ 2001 & 79 & 169 & 161 & 56 \\ 2002 & 60 & 126 & 108 & 45 \\ 2003 * & 0 & 0 & 0 & 0 \\ 2004 & 65 & 130 & 149 & 54\end{array}$

*sampling not conducted in 2003

Sample sizes: Yearly means, dissolved oxygen.

$\begin{array}{lcccc}\text { Year } & \text { Main Channel } & \text { Side Channel } & \begin{array}{c}\text { Backwater } \\ \text { Contiguous }\end{array} & \text { Impounded } \\ 1994 & 78 & 154 & 129 & 53 \\ 1995 & 80 & 166 & 155 & 60 \\ 1996 & 75 & 156 & 148 & 60 \\ 1997 & 80 & 148 & 161 & 60 \\ 1998 & 80 & 169 & 175 & 59 \\ 1999 & 80 & 169 & 140 & 60 \\ 2000 & 80 & 153 & 140 & 50 \\ 2001 & 79 & 169 & 161 & 56 \\ 2002 & 60 & 126 & 108 & 45 \\ 2003 * & 0 & 0 & 0 & 0 \\ 2004 & 65 & 130 & 149 & 54 \\ *\end{array}$

Sample sizes: Yearly means, Secchi depth.

$\begin{array}{lcccc}\text { Year } & \text { Main Channel } & \text { Side Channel } & \begin{array}{c}\text { Backwater } \\ \text { Contiguous }\end{array} & \text { Impounded } \\ 1994 & 78 & 147 & 130 & 53 \\ 1995 & 80 & 166 & 154 & 50 \\ 1996 & 80 & 163 & 150 & 60 \\ 1997 & 80 & 48 & 161 & 60 \\ 1998 & 79 & 169 & 175 & 59 \\ 1999 & 77 & 162 & 139 & 60 \\ 2000 & 78 & 153 & 137 & 41 \\ 2001 & 79 & 169 & 156 & 56 \\ 2002 & 60 & 126 & 107 & 45 \\ 2003 * & 0 & 0 & 0 & 0 \\ 2004 & 65 & 130 & 149 & 54\end{array}$

*sampling not conducted in 2003 
Sample sizes: Yearly means, turbidity.

$\begin{array}{lcccc}\text { Year } & \text { Main Channel } & \text { Side Channel } & \begin{array}{c}\text { Backwater } \\ \text { Contiguous }\end{array} & \text { Impounded } \\ 1994 & 75 & 153 & 129 & 48 \\ 1995 & 80 & 166 & 155 & 60 \\ 1996 & 80 & 162 & 150 & 60 \\ 1997 & 80 & 148 & 161 & 60 \\ 1998 & 79 & 166 & 175 & 59 \\ 1999 & 79 & 168 & 140 & 60 \\ 2000 & 80 & 153 & 140 & 50 \\ 2001 & 79 & 169 & 160 & 56 \\ 2002 & 60 & 126 & 108 & 45 \\ 2003 * & 0 & 0 & 0 & 0 \\ 2004 & 65 & 130 & 149 & 54\end{array}$

*sampling not conducted in 2003

Sample sizes: Yearly means, suspended solids.

$\begin{array}{lcccc}\text { Year } & \text { Main Channel } & \text { Side Channel } & \begin{array}{l}\text { Backwater } \\ \text { Contiguous }\end{array} & \text { Impounded } \\ 1994 & 75 & 151 & 129 & 53 \\ 1995 & 71 & 147 & 138 & 53 \\ 1996 & 60 & 126 & 116 & 45 \\ 1997 & 80 & 148 & 161 & 59 \\ 1998 & 79 & 165 & 175 & 59 \\ 1999 & 80 & 169 & 140 & 60 \\ 2000 & 74 & 144 & 140 & 50 \\ 2001 & 79 & 169 & 160 & 56 \\ 2002 & 59 & 125 & 108 & 31 \\ 2003 * & 0 & 0 & 0 & 0 \\ 2004 & 65 & 129 & 149 & 54\end{array}$

*sampling not conducted in 2003

Sample sizes: Yearly means, total nitrogen.

$\begin{array}{lcccc}\text { Year } & \text { Main Channel } & \text { Side Channel } & \begin{array}{c}\text { BackwaterI } \\ \text { Contiguous }\end{array} & \text { mpounded } \\ 1994 & 43 & 77 & 70 & 28 \\ 1995 & 43 & 87 & 88 & 34 \\ 1996 & 44 & 88 & 82 & 32 \\ 1997 & 44 & 82 & 91 & 32 \\ 1998 & 48 & 94 & 102 & 31 \\ 1999 & 46 & 93 & 85 & 33 \\ 2000 & 28 & 52 & 52 & 17 \\ 2001 & 27 & 56 & 52 & 19 \\ 2002 & 21 & 41 & 41 & 15 \\ 2003 * & 0 & 0 & 0 & 0 \\ 2004 & 23 & 44 & 49 & 18\end{array}$

*sampling not conducted in 2003 
Sample sizes: Yearly means, nitrate-nitrite nitrogen.

$\begin{array}{lcccc}\text { Year } & \text { Main Channel } & \text { Side Channel } & \begin{array}{c}\text { Backwater } \\ \text { Contiguous }\end{array} & \text { Impounded } \\ 1994 & 43 & 77 & 41 & 28 \\ 1995 & 43 & 88 & 42 & 35 \\ 1996 & 44 & 88 & 49 & 32 \\ 1997 & 44 & 82 & 72 & 32 \\ 1998 & 48 & 94 & 88 & 31 \\ 1999 & 46 & 93 & 85 & 33 \\ 2000 & 29 & 50 & 20 & 17 \\ 2001 & 27 & 56 & 28 & 17 \\ 2002 & 21 & 40 & 23 & 15 \\ 2003 * & 0 & 0 & 0 & 0 \\ 2004 & 21 & 42 & 26 & 15\end{array}$

*sampling not conducted in 2003

Sample sizes: Yearly means, total phosphorous.

$\begin{array}{lrccc}\text { Year } & \text { Main Channel } & \text { Side Channel } & \begin{array}{c}\text { Backwater } \\ \text { Contiguous }\end{array} & \text { Impounded } \\ 1994 & 43 & 77 & 71 & 28 \\ 1995 & 43 & 88 & 88 & 35 \\ 1996 & 33 & 66 & 67 & 24 \\ 1997 & 44 & 82 & 91 & 32 \\ 1998 & 48 & 94 & 102 & 31 \\ 1999 & 48 & 93 & 86 & 33 \\ 2000 & 28 & 52 & 52 & 17 \\ 2001 & 27 & 56 & 56 & 19 \\ 2002 & 21 & 42 & 41 & 15 \\ 2003 * & 0 & 0 & 0 & 0 \\ 2004 & 23 & 44 & 47 & 18\end{array}$

*sampling not conducted in 2003

Sample sizes: Yearly means, soluble reactive phosphorous.

$\begin{array}{lcccc}\text { Year } & \text { Main Channel } & \text { Side Channel } & \begin{array}{c}\text { Backwater } \\ \text { Contiguous }\end{array} & \text { Impounded } \\ 1994 & 40 & 66 & 57 & 21 \\ 1995 & 43 & 83 & 69 & 25 \\ 1996 & 44 & 87 & 70 & 30 \\ 1997 & 39 & 68 & 67 & 17 \\ 1998 & 48 & 94 & 102 & 31 \\ 1999 & 36 & 70 & 60 & 24 \\ 2000 & 24 & 53 & 44 & 14 \\ 2001 & 27 & 38 & 49 & 13 \\ 2002 & 21 & 0 & 32 & 11 \\ 2003 * & 0 & 42 & 0 & 15 \\ 2004 & 21 & & 39 & \end{array}$


Sample sizes: Yearly means, chlorophyll-a.

$\begin{array}{lcccc}\text { Year } & \text { Main Channel } & \text { Side Channel } & \begin{array}{l}\text { Backwater } \\ \text { Contiguous }\end{array} & \text { Impounded } \\ 1994 & 75 & 155 & 129 & 53 \\ 1995 & 80 & 166 & 146 & 60 \\ 1996 & 78 & 162 & 149 & 60 \\ 1997 & 80 & 147 & 161 & 59 \\ 1998 & 79 & 166 & 175 & 59 \\ 1999 & 80 & 169 & 140 & 60 \\ 2000 & 80 & 152 & 140 & 50 \\ 2001 & 78 & 169 & 158 & 56 \\ 2002 & 60 & 125 & 108 & 45 \\ 2003^{*} & 0 & 0 & 0 & 0 \\ 2004 & 65 & 130 & 150 & 54\end{array}$

*sampling not conducted in 2003 


\section{Appendix B: Sample Sizes for Seasonal Graphs}

Sample Sizes - Seasonal means: temperature.

$\begin{array}{lrcrc}\text { Month/Episode } & \text { Main Channel } & \text { Side Channel* } & \text { Backwater Contiguous } & \text { Impounded } \\ \text { January } & 25 & & 25 & 26 \\ \text { Jan-Feb SRS } & 182 & 332 & 279 & 123 \\ \text { February } & 34 & & 33 & 33 \\ \text { March } & 39 & & 48 & 43 \\ \text { April } & 44 & & 60 & 47 \\ \text { Apr-May SRS } & 200 & 420 & 431 & 150 \\ \text { May } & 39 & & 55 & 47 \\ \text { June } & 51 & & 62 & 53 \\ \text { July } & 43 & 418 & 50 & 46 \\ \text { July-Aug SRS } & 200 & & 388 & 149 \\ \text { August } & 40 & & 39 & 47 \\ \text { September } & 42 & & 39 & 57 \\ \text { October } & 39 & 418 & 35 & 44 \\ \text { Oct-Nov SRS } & 200 & & 406 & 150 \\ \text { November } & 40 & & 43 & 49 \\ \text { December } & 37 & & 32 & 44\end{array}$

*Side channels not sampled in fixed site sampling

Sample Sizes-Seasonal means: dissolved oxygen.

$\begin{array}{lcccc}\text { Month/Episode } & \text { Main Channel } & \text { Side Channel* } & \text { Backwater Contiguous } & \text { Impounded } \\ \text { January } & 25 & & 26 & 26 \\ \text { Jan-Feb SRS } & 182 & 332 & 278 & 123 \\ \text { February } & 34 & & 30 & 33 \\ \text { March } & 39 & & 47 & 43 \\ \text { April } & 44 & 60 & 47 \\ \text { Apr-May SRS } & 200 & 420 & 431 & 150 \\ \text { May } & 39 & & 55 & 47 \\ \text { June } & 51 & & 62 & 53 \\ \text { July } & 43 & 411 & 50 & 46 \\ \text { July-Aug SRS } & 195 & & 386 & 149 \\ \text { August } & 40 & & 39 & 47 \\ \text { September } & 42 & & 39 & 57 \\ \text { October } & 39 & & 35 & 44 \\ \text { Oct-Nov SRS } & 200 & & 406 & 150 \\ \text { November } & 40 & 418 & 43 & 49 \\ \text { December } & 37 & & 32 & 44\end{array}$

*Side channels not sampled in fixed site sampling 
Sample sizes-Seasonal means. $\mathrm{pH}$.

\begin{tabular}{|c|c|c|c|c|}
\hline Month/Episode & Main Channel & Side Channel* & Backwater Contiguous & Impounded \\
\hline January & 24 & & 25 & 26 \\
\hline Jan-Feb SRS & 162 & 302 & 237 & 113 \\
\hline February & 34 & & 33 & 33 \\
\hline March & 39 & & 47 & 38 \\
\hline April & 42 & & 57 & 47 \\
\hline Apr-May SRS & 188 & 387 & 361 & 131 \\
\hline May & 38 & & 51 & 41 \\
\hline June & 49 & & 60 & 51 \\
\hline July & 43 & & 50 & 46 \\
\hline July-Aug SRS & 200 & 419 & 388 & 149 \\
\hline August & 40 & & 39 & 47 \\
\hline September & 42 & & 39 & 57 \\
\hline October & 39 & & 35 & 44 \\
\hline Oct-Nov SRS & 196 & 401 & 402 & 150 \\
\hline November & 39 & & 40 & 49 \\
\hline December & 36 & & 32 & 42 \\
\hline \multicolumn{5}{|c|}{ * Side channels not sampled in fixed site sampling } \\
\hline \multicolumn{5}{|c|}{ Sample Sizes: Seasonal means, conductivity. } \\
\hline Month/Episode & Main Channel & Side Channel* & Backwater Contiguous & Impounded \\
\hline January & 25 & & 25 & 24 \\
\hline Jan-Feb SRS & 182 & 332 & 279 & 123 \\
\hline February & 34 & & 33 & 33 \\
\hline March & 39 & & 48 & 43 \\
\hline April & 44 & & 60 & 47 \\
\hline Apr-May SRS & 200 & 420 & 431 & 150 \\
\hline May & 39 & & 55 & 47 \\
\hline June & 51 & & 62 & 53 \\
\hline July & 43 & & 50 & 46 \\
\hline July-Aug SRS & 197 & 411 & 386 & 149 \\
\hline August & 40 & & 39 & 47 \\
\hline September & 42 & & 39 & 57 \\
\hline October & 39 & & 35 & 44 \\
\hline Oct-Nov SRS & 200 & 418 & 405 & 150 \\
\hline November & 40 & & 43 & 49 \\
\hline December & 37 & & 32 & 44 \\
\hline
\end{tabular}

*Side channels not sampled in fixed site sampling 
Sample Sizes: Seasonal means, Secchi depth.

$\begin{array}{lrcrc}\text { Month/Episode } & \text { Main Channel } & \text { Side Channel* }^{*} & \text { Backwater Contiguous } & \text { Impounded } \\ \text { January } & 22 & & 24 & 24 \\ \text { Jan-Feb SRS } & 181 & 322 & 272 & 113 \\ \text { February } & 34 & & 34 & 33 \\ \text { March } & 38 & & 46 & 43 \\ \text { April } & 44 & & 60 & 47 \\ \text { Apr-May SRS } & 200 & 420 & 428 & 150 \\ \text { May } & 37 & & 55 & 47 \\ \text { June } & 49 & & 62 & 51 \\ \text { July } & 42 & 419 & 50 & 45 \\ \text { July-Aug SRS } & 198 & & 387 & 140 \\ \text { August } & 39 & & 38 & 47 \\ \text { September } & 42 & & 39 & 57 \\ \text { October } & 39 & 414 & 35 & 44 \\ \text { Oct-Nov SRS } & 197 & & 407 & 150 \\ \text { November } & 39 & & 43 & 49 \\ \text { December } & 36 & & 42 & 43\end{array}$

*Side channels not sampled in fixed site sampling

Sample Sizes: Seasonal means, turbidity.

$\begin{array}{lcccc}\text { Month/Episode } & \text { Main Channel } & \text { Side Channel* } & \text { Backwater Contiguous } & \text { Impounded } \\ \text { January } & 25 & & 26 & 26 \\ \text { Jan-Feb SRS } & 180 & 329 & 279 & 123 \\ \text { February } & 34 & & 34 & 33 \\ \text { March } & 38 & & 47 & 44 \\ \text { April } & 44 & & 61 & 47 \\ \text { Apr-May SRS } & 200 & 420 & 430 & 150 \\ \text { May } & 39 & & 55 & 47 \\ \text { June } & 51 & & 61 & 53 \\ \text { July } & 42 & & 48 & 46 \\ \text { July-Aug SRS } & 198 & 416 & 388 & 144 \\ \text { August } & 40 & & 39 & 47 \\ \text { September } & 43 & & 39 & 57 \\ \text { October } & 39 & & 34 & 44 \\ \text { Oct-Nov SRS } & 199 & 418 & 406 & 150 \\ \text { November } & 40 & & 44 & 49 \\ \text { December } & 35 & & 32 & 44\end{array}$

*Side channels not sampled in fixed site sampling 
Sample sizes: seasonal means, suspended solids.

$\begin{array}{lrcrr}\text { Month/Episode } & \text { Main Channel } & \text { Side Channel* } & \text { Backwater Contiguous } & \text { Impounded } \\ \text { January } & 21 & & 16 & 21 \\ \text { Jan-Feb SRS } & 160 & 289 & 245 & 108 \\ \text { February } & 27 & & 25 & 23 \\ \text { March } & 30 & & 31 & 31 \\ \text { April } & 43 & 54 & 41 \\ \text { Apr-May SRS } & 199 & 418 & 430 & 135 \\ \text { May } & 38 & & 51 & 44 \\ \text { June } & 51 & & 62 & 53 \\ \text { July } & 41 & 399 & 48 & 43 \\ \text { July-Aug SRS } & 189 & & 370 & 142 \\ \text { August } & 38 & 38 & 44 \\ \text { September } & 43 & & 38 & 57 \\ \text { October } & 36 & 32 & 40 \\ \text { Oct-Nov SRS } & 184 & 383 & 386 & 142 \\ \text { November } & 37 & & 41 & 45 \\ \text { December } & 35 & & & 40 \\ \text { * Side channels not sampled in fixed site sampling } & & & \end{array}$

Sample sizes: seasonal means, total nitrogen.

\begin{tabular}{lcccc} 
Month/Episode & Main Channel & Side Channel* $^{*}$ & Backwater Contiguous & Impounded \\
January & 21 & & 18 & 23 \\
Jan-Feb SRS & 87 & 150 & 147 & 57 \\
February & 31 & & 29 & 29 \\
March & 34 & & 36 & 37 \\
April & 42 & & 53 & 40 \\
Apr-May SRS & 96 & 192 & 204 & 68 \\
May & 37 & & 51 & 45 \\
June & 51 & & 62 & 53 \\
July & 43 & \multirow{2}{*}{196} & 50 & 45 \\
July-Aug SRS & 94 & & 181 & 68 \\
August & 40 & & 39 & 46 \\
September & 42 & & 36 & 53 \\
October & 39 & 197 & 35 & 44 \\
Oct-Nov SRS & 101 & & 197 & 74 \\
November & 39 & & 43 & 48 \\
December & 36 & & 31 & 42
\end{tabular}

*Side channels not sampled in fixed site sampling 
Sample sizes: seasonal means, nitrate-nitrite nitrogen.

\begin{tabular}{lrccc} 
Month/Episode & Main Channel & Side Channel* & Backwater Contiguous & Impounded \\
January & 21 & & 15 & 23 \\
Jan-Feb SRS & 86 & 146 & 81 & 55 \\
February & 28 & & 27 & 29 \\
March & 33 & & 33 & 37 \\
April & 41 & & 50 & 40 \\
Apr-May SRS & 96 & 193 & 177 & 68 \\
May & 37 & & 49 & 47 \\
June & 47 & & 56 & 53 \\
July & 40 & \multirow{2}{*}{195} & 41 & 45 \\
July-Aug SRS & 94 & & 107 & 67 \\
August & 37 & & 30 & 45 \\
September & 40 & & 29 & 52 \\
October & 37 & 198 & 30 & 43 \\
Oct-Nov SRS & 101 & & 123 & 73 \\
November & 35 & & 38 & 46 \\
December & 33 & & 30 & 44
\end{tabular}

*Side channels not sampled in fixed site sampling

Sample sizes: seasonal means, total phosphorous.

$\begin{array}{lcccc}\text { Month/Episode } & \text { Main Channel } & \text { Side Channel* }^{*} & \text { Backwater Contiguous } & \text { Impounded } \\ \text { January } & 21 & & 18 & 23 \\ \text { Jan-Feb SRS } & 88 & 151 & 147 & 58 \\ \text { February } & 31 & & 29 & 29 \\ \text { March } & 34 & & 36 & 37 \\ \text { April } & 43 & & 54 & 41 \\ \text { Apr-May SRS } & 96 & 193 & 205 & 68 \\ \text { May } & 37 & & 51 & 45 \\ \text { June } & 51 & & 62 & 53 \\ \text { July } & 43 & & 49 & 45 \\ \text { July-Aug SRS } & 95 & 196 & 184 & 68 \\ \text { August } & 40 & & 39 & 46 \\ \text { September } & 42 & & 36 & 53 \\ \text { October } & 39 & & 35 & 44 \\ \text { Oct-Nov SRS } & 90 & 175 & 182 & 66 \\ \text { November } & 39 & & 43 & 48 \\ \text { December } & 36 & & 31 & 42\end{array}$

*Side channels not sampled in fixed site sampling 
Sample sizes: seasonal means, soluble reactive phosphorous.

$\begin{array}{lcccc}\text { Month/Episode } & \text { Main Channel } & \text { Side Channe } *^{*} & \text { Backwater Contiguous } & \text { Impounded } \\ \text { January } & 17 & & 12 & 20 \\ \text { Jan-Feb SRS } & 81 & 130 & 103 & 46 \\ \text { February } & 25 & & 28 & 28 \\ \text { March } & 32 & & 31 & 37 \\ \text { April } & 36 & & 50 & 37 \\ \text { Apr-May SRS } & 88 & 171 & 165 & 53 \\ \text { May } & 37 & & 50 & 44 \\ \text { June } & 49 & & 60 & 48 \\ \text { July } & 41 & 193 & 46 & 38 \\ \text { July-Aug SRS } & 96 & & 182 & 49 \\ \text { August } & 38 & & 37 & 38 \\ \text { September } & 41 & & 35 & 54 \\ \text { October } & 37 & 174 & 33 & 43 \\ \text { Oct-Nov SRS } & 89 & & 157 & 61 \\ \text { November } & 37 & & 39 & 49 \\ \text { December } & 30 & & 26 & 42\end{array}$

* Side channels not sampled in fixed site sampling

Sample sizes: seasonal means, chlorophyll-a.

$\begin{array}{lrccr}\text { Month/Episode } & \text { Main Channel } & \text { Side Channel* } & \text { Backwater Contiguous } & \text { Impounded } \\ \text { January } & 14 & & 6 & 6 \\ \text { Jan-Feb SRS } & 177 & 326 & 279 & 123 \\ \text { February } & 19 & & 11 & 9 \\ \text { March } & 15 & & 16 & 14 \\ \text { April } & 25 & & 24 & 18 \\ \text { Apr-May SRS } & 200 & 418 & 439 & 149 \\ \text { May } & 20 & & 21 & 19 \\ \text { June } & 28 & & 27 & 19 \\ \text { July } & 23 & 421 & 24 & 19 \\ \text { July-Aug SRS } & 199 & & 384 & 168 \\ \text { August } & 22 & & 13 & 21 \\ \text { September } & 24 & & 16 & 21 \\ \text { October } & 22 & 398 & 15 & 18 \\ \text { Oct-Nov SRS } & 191 & & 390 & 143 \\ \text { November } & 22 & & 15 & 20 \\ \text { December } & 20 & & 12 & 17\end{array}$

*Side channels not sampled in fixed site sampling 


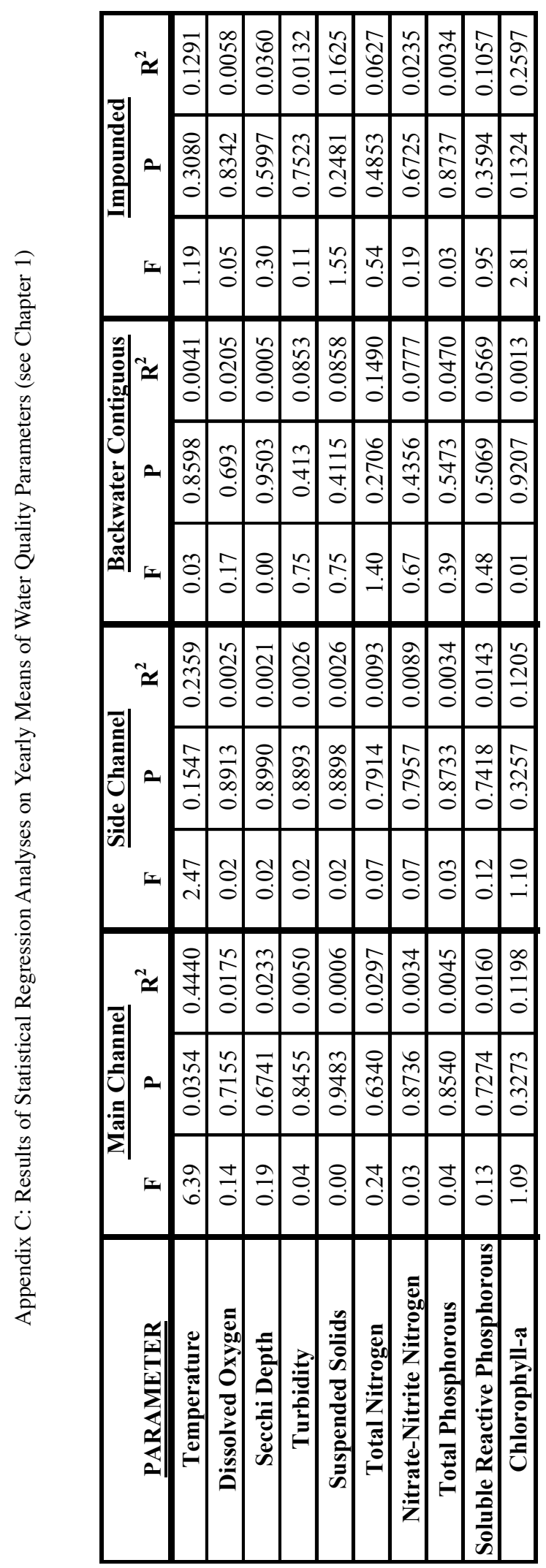




\section{Appendix D: Further Details on Statistical Analyses}

\section{Calculation of Means}

Both the fish and water quality components of LTRMP use a stratified random sampling design to allow for the calculation of poolwide means, properly weighted across aquatic areas (i.e., major habitat types, strata). Ickes et al. (2005) and Lubinski et al. (2001) provide further details on the stratified random design for both components, and we will summarize how the design works for the fish component in Pool 26. The entire aquatic area of Pool 26 is partitioned into $50-\mathrm{m}^{2}$ sampling grids, and these grids are categorized by the following strata (Table 1): main channel border unstructured (MCB-U), main channel border structured (MCB-S; i.e., wing dams), contiguous backwater shoreline (BWC-S), impounded shoreline (IMP-S), and side channel border (SCB). To generate means for a single strata, it is appropriate to calculate simple arithmetic means. To generate pool-wide means, it is necessary to use the appropriate mean and variance estimators for stratified random designs (Cochran 1977).

In SAS (SAS for Windows Version 8.02), proc surveymeans can be used to generate appropriate pool-wide means for a stratified random design. Throughout this bulletin, we calculated pool-wide means using proc surveymeans, weighting by the total number of sampling $50-\mathrm{m}^{2}$ grids in each strata (Table 1). We used the same total number of sampling grids within each strata for each year from 1994 to 2004. Below is a SAS program that will calculate annual pool-wide means of catchper-unit-effort for largemouth bass from day electrofishing data collected in Pool 26. This program assumes you have already downloaded the LTRMP day electrofishing data for Pool 26 from 1994 through 2004, and that you have created a SAS data set including the following variables: barcode, strata, date, pool, effort, speciescode, catch.

Table 1. The total number of 50- $\mathrm{m}^{2}$ sampling grids in each of the five strata defined for stratified random sampling of fishes in Pool 26.

\begin{tabular}{lr}
\hline Strata & Number of 50- $\mathrm{m}^{2}$ sampling grids \\
\hline MCB-U & 3199 \\
MCB-S & 7 \\
BWC-S & 764 \\
IMP-S & 172 \\
SCB & 5671 \\
\hline
\end{tabular}




\section{SAS Program}

data stratatotal; *this creates a data set of strata weights for each year;

input strata \$_total_;

do year=1994 to 2004 by 1 ; do period=1 to 3 by 1; output; end; end;

datalines;

MCB-U 3199

MCB-S 7

SCB

BWC-S 764

IMP-S 172

run;

Proc sort;

by year strata;

run;

data all; *this data step creates a year variable from date, and creates a variable "larbas" for proper enumeration of largemouth bass;

set pool26bass;

year $=$ year(date);

larbas $=0 ; \quad *$ this creates zero catches for each sample;

if $\operatorname{spec}=$ 'LMBS' then larbas = catch;

run;

proc sort;

by barcode;

run;

proc means noprint; *creates a data set with the total number of largemouth bass captured in each sample;

by barcode;

var larbas;

id pool year effort strata;

output out=steptwo sum=;

run;

data calccpue; *converts the raw counts to CPUE;

set steptwo;

larbas $=$ larbas $*$ effort $/ 15$;

run;

Proc sort data = calccpue;

by year strata;

run;

ods listing close; 
proc surveymeans data=calccpue total=stratatotal; $*$ creates proper strata weights accounting for different numbers of samples

stratum strata / list; each year;

var larbas;

by year;

ods output Statistics=Stats;

ods output Stratainfo=Stratainfo;

run;

ods listing;

data cleanrate;

set Stratainfo;

keep year strata rate;

run;

proc sort data=cleanrate;

by year strata;

run;

data itsallhere;

merge calccpue cleanrate;

by year strata;

sweight $=1 /(3 *$ rate $)$;

run;

ods listing close;

proc surveymeans data $=$ itsallhere total $=$ stratatotal $; *$ calculates pool-wide means;

stratum strata;

weight sweight;

var larbas;

by year;

ods output Statistics = mydata;

run;

ods listing;

proc print data $=$ mydata; 
run;

\section{Defining Age Groups Based on Length}

For monitoring programs that sample all sizes of fishes, it is useful to be able to identify young-of-the-year (YOY) fishes. Several standard texts provide length criteria for approximating a cut-off (i.e., maximum length) for YOY fishes (e.g., see references in Barko et al. 2005). For this bulletin, we chose to define cut-off lengths for designating fishes as YOY using the Von Bertalanffy growth equation (Busacker et a. 1990) as a starting point, and refining the cut-off through graphical analysis $\begin{aligned} & \text { of LTRMP length da } \\ & \text { growth equation is: }\end{aligned} L_{t}=L_{\infty}\left[1-e^{-K\left(t-t_{o}\right)}\right]$ where: $\mathrm{Lt}=$ length at age $\mathrm{t}$

$\mathrm{L} \infty=$ maximum (asymptotic) length

$\mathrm{K}=$ growth coefficient

$\mathrm{t}_{0}=$ the age at size $=0$

We used parameter estimates $(\mathrm{K}, \mathrm{L} \infty)$ reported on fishbase (www.fishbase.org) to estimate length at Age 1. We then refined a cut off length, above or below the Von Bertalanffy estimate, by graphing LTRMP data on the length of all individuals of a species captured in a year by day for all LTRMP sampling gear (e.g., Fig. $1)$. The YOY cohort is usually readily identifiable when LTRMP data are graphed this way. Adjusting the Von Bertalanffy estimate in this way is desirable for at least two reasons: 1) because growth and the size a given species of fish reaches at Age 1 should vary geographically and from system to system, and 2) the length distribution of fishes captured by LTRMP will have unavoidable biases associated with size-specific sampling biases of gear. For each species, we examined graphs for five or more years to determine a cut -off length which would best minimize inclusion of Age-1 fishes but include the majority of YOY fishes (Fig. 1). There will certainly be some misidentifications using this method but the vast majority of YOY fishes identified this way should be YOY fishes. We feel analyses of LTRMP data for YOY fishes identified through this technique can provide valuable information regarding abundance and growth of YOY fishes. For identification of Age-1 fishes, we included all fishes with lengths greater than or equal to the YOY cut-off, but less than the length at Age-2 estimated from the Von Bertalanffy growth

Table 2. Length criteria in millimeters of total length (TL) used for categorizing fishes as young-of-the-year (YOY) or Age-1. Note that YOY fishes were categorized as those less than the length criteria, not less than or equal to the length criteria.

\begin{tabular}{llrl}
\hline Common Name & \multicolumn{1}{c}{ Scientific Name } & YOY & Age 1 \\
\hline Bighead carp & Hypopthalmichthys nobilis & $<230$ & \\
Black crappie & Pomoxis nigromaculatus & $<80$ & $80 \leq \mathrm{TL}<150$ \\
Blue catfish & Ictalurus furcatus & $<140$ & \\
Bluegill & Lepomis macrochirus & $<60$ & $60 \leq \mathrm{TL}<105$ \\
Common carp & Cyprinus carpio & $<140$ & $140 \leq \mathrm{TL}<280$ \\
Channel catfish & Ictalurus punctatus & $<100$ & $100 \leq \mathrm{TL}<210$ \\
Freshwater drum & Aplodinotus grunniens & $<150$ & $150 \leq \mathrm{TL}<280$ \\
Gizzard shad & Dorosoma cepedianum & $<120$ & $120 \leq \mathrm{TL}<140$ \\
Grass carp & Ctenopharyngodon idella & $<210$ & \\
Largemouth bass & Micropterus salmoides & $<100$ & $100 \leq \mathrm{TL}<200$ \\
Sauger & Sander canadensis & $<150$ & $150 \leq \mathrm{TL}<230$ \\
Silver carp & Hypopthalmichthys molitrix & $<200$ & \\
Smallmouth buffalo & Ictiobus bubalus & $<150$ & $150 \leq \mathrm{TL}<280$ \\
White bass & Morone chrysops & $<150$ & $150 \leq \mathrm{TL}<220$ \\
White crappie & Pomoxis annularis & $<90$ & $90 \leq \mathrm{TL}<180$ \\
\hline
\end{tabular}



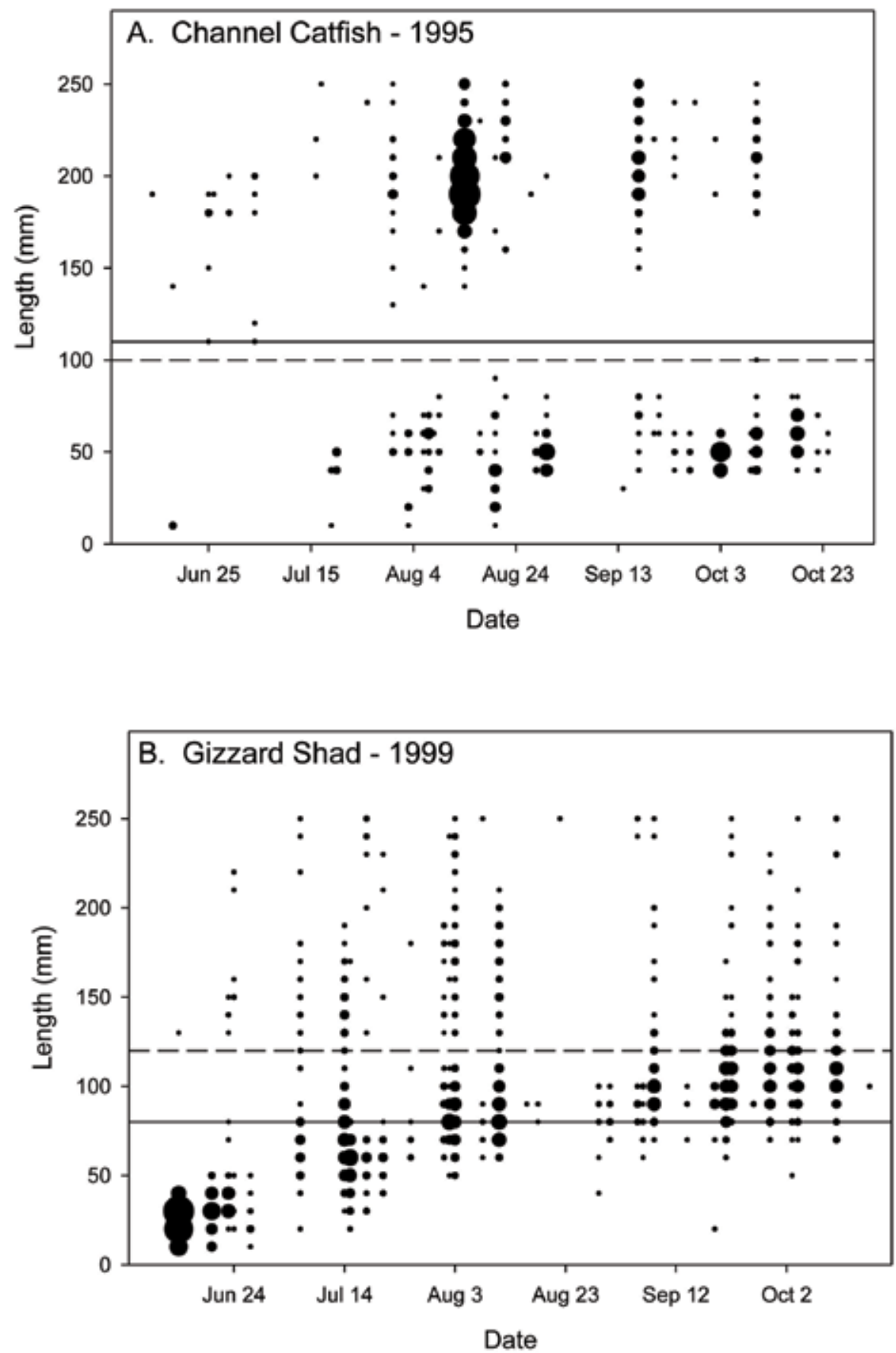

Figure 1. Two examples of cut-off lengths used to define YOY fishes. Length at date (for clarity, fish $>250 \mathrm{~mm}$ are not shown) for all channel catfish (A) and gizzard shad (B) captured during LTRMP monitoring (all gear) of Pool 26 in 1995 (A) and 1999 (B). The size of the bubbles reflects the number of individuals captured for a particular length and date. The solid line represents the length at Age 1 identified through that Von Bertalanffy growth equation, and the dashed line represents the YOY cut-off length chosen for each species. 
equation (Table 2).

\section{Literature Cited}

Barko, V.A., B.S. Ickes, D.P. Herzog, R.A. Hrabik, J.H. Chick, and M.A. Pegg. 2005.

Spatial, temporal, and environmental trends of fish assemblages within six reaches of the Upper Mississippi River system. U.S. Geological Survey, Upper Midwest Environmental Sciences Center, La Crosse, Wisconsin. Technical Report LTRMPP 2005-T002. 27 pp. (DTIC ADA-431398)

Busacker, G.P., I.R. Adelman, and E.M. Goolish. 1990. Growth. Pages 363-388 in C.B. Schreck and P.B. Moyle, eds. Methods for fish biology. American Fisheries Society, Bethesda, Maryland.

Cochran, W.G. 1977. Sampling techniques, 3rd edition. John Wiley and Sons, New York. Ickes, B.S., M.C. Bowler, A.D. Bartels, D.J. Kirby, S. DeLain, J.H. Chick, V.A. Barko, K.S. Irons, and M.A. Pegg. 2005. Multiyear synthesis of the fish component from 1993 to 2002 for the Long Term Resource Monitoring Program. U.S. Geological Survey, Upper Midwest Environmental Sciences Center, La Crosse, Wisconsin. LTRMPP 2005-T005. 60 pp. + CD-ROM (Appendixes A-E). (NTIS PB2005-107572)

Lubinski, K, R. Burkhardt, J. Sauer, D. Soballe, and Y. Yin. 2001. Initial analyses of change detection capabilities and data redundancies in the Long Term Resource Monitoring Program. U.S. Geological Survey, Upper Midwest Environmental Sciences Center, La Crosse, Wisconsin. LTRMPP 2001-T001. 23 pp. + Appendixes A-E. (NTIS PB2002100123) 

RESEARCH INSTITUTE

Illinois Natural History Survey

Forbes Natural History Building

1816 South Oak Street

Champaign, Illinois 61820

217-333-6880 